Extração de termos de manuais técnicos de produtos tecnológicos: uma aplicação em Sistemas de Adaptação Textual 



\title{
Extração de termos de manuais técnicos de produtos tecnológicos: uma aplicação em Sistemas de Adaptação Textual
}

\author{
Fernando Aurélio Martins Muniz
}

Orientadora: Profa. Dra. Sandra Maria Aluísio

Dissertação apresentada ao Instituto de Ciências Matemáticas e de Computação - ICMC-USP, como parte dos requisitos para obtenção do título de Mestre em Ciências Ciências de Computação e Matemática Computacional. VERSÃO REVISADA.

USP - São Carlos

Junho de 2011 
Ficha catalográfica elaborada pela Biblioteca Prof. Achille Bassi e Seção Técnica de Informática, ICMC/USP, com os dados fornecidos pelo(a) autor(a)

\begin{tabular}{|c|c|}
\hline M963e & $\begin{array}{l}\text { Muniz, Fernando Aurélio Martins } \\
\text { Extração de termos de manuais técnicos de produtos } \\
\text { tecnológicos: uma aplicação em Sistemas de Adaptação } \\
\text { Textual / Fernando Aurélio Martins Muniz; orientadora } \\
\text { Sandra Maria Aluísio -- São Carlos, } 2011 \text {. } \\
\quad 112 \text { p. }\end{array}$ \\
\hline & 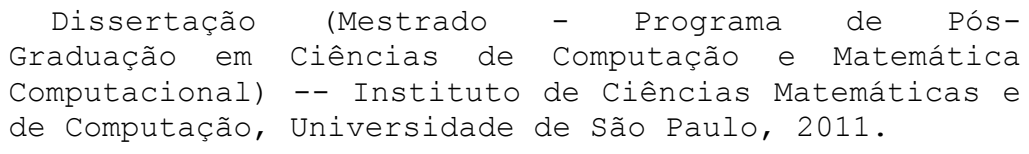 \\
\hline & $\begin{array}{l}\text { 1. LINGUíSTICA COMPUTACIONAL. 2. EXTRAÇÃO } \\
\text { AUTOMÁTICA DE TERMOS. 3. SIMPLIFICAÇÃO TEXTUAL. } 4 . \\
\text { ADAPTAÇÃO TEXTUAL. I. Aluísio, Sandra Maria, orient. } \\
\text { II. Título. }\end{array}$ \\
\hline
\end{tabular}




\section{Dedicatória}

Aos meus pais, João Acássio Muniz e Célia Ferreira Martins Muniz. 


\section{Agradecimentos}

Aos meus pais, por acreditarem em mim e sempre me apoiarem de forma incondicional em todos os momentos da minha vida.

O Deus, por permitir que eu concluísse mais essa etapa na minha vida.

Ao meu irmão Marcelo Caetano Martins Muniz, por todo suporte, auxílio e companheirismo. Ao meu irmão João Acássio Muniz Jr., por proporcionar momentos de descontração sempre que possível quando estávamos juntos.

À Sandra Maria Aluísio, por sua orientação e pela confiança em mim depositada.

À minha namorada Josiane, pelo apoio e carinho durante todos os momentos, principalmente nos mais difíceis.

Aos companheiros do laboratório NILC, por terem colaborado sempre que precisei.

A todos os amigos que conquistei na cidade de São Carlos e que de alguma forma me deram forças para seguir em frente.

Muito obrigado! 


\section{Sumário}

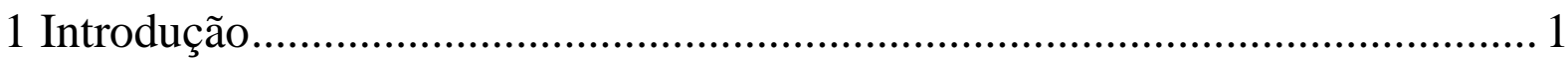

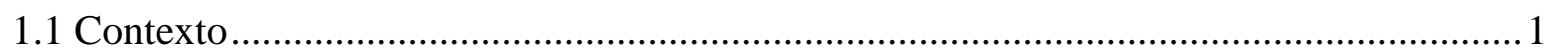

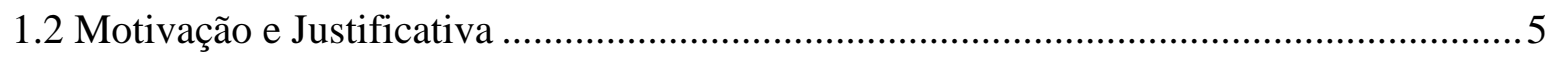

1.3 Hipótese e Objetivos do Projeto de Mestrado ..........................................................

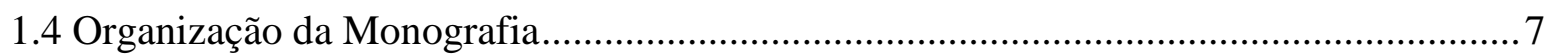

2 Trabalhos Relacionados: a Linguagem Controlada Usada em Manuais Técnicos, os Sistemas de Geração Automática de Manuais e os Sistemas de Perguntas e Respostas ................................................................................. 9

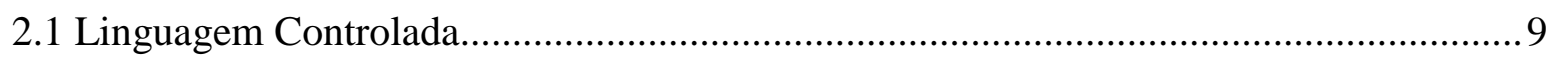

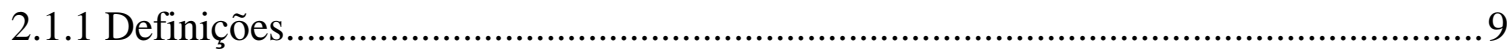

2.1.2 Os Componentes de uma Linguagem Controlada.............................................. 11

2.1.3 Plain English .......................................................................................... 12

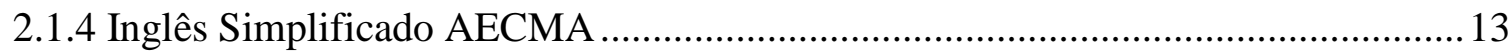

2.1.5 Linguagem Simplificada em Textos do Português do Brasil .................................. 14

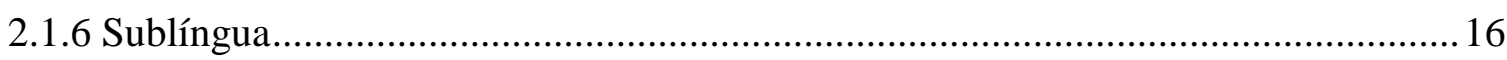

2.2 Tratamento de Textos Instrucionais em Trabalhos de PLN ......................................... 16

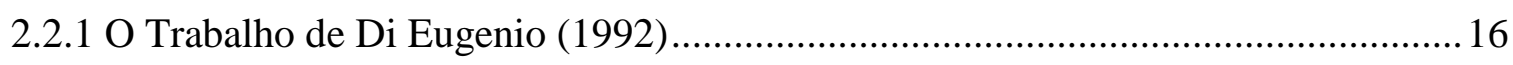

2.2.2 Geração Multilíngue de Manuais de Instrução .....................................................20

2.2.3 Estrutura de Textos Instrucionais e Sistemas de Perguntas \& Respostas ................ 30

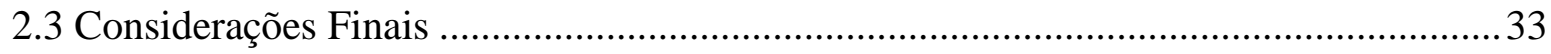


3 Métodos de Extração Automática de Termos ......................................................35

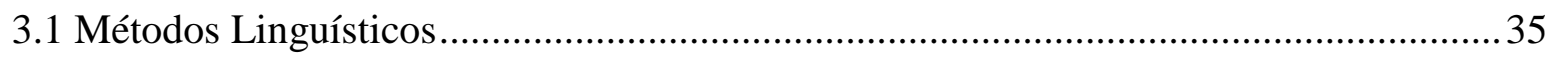

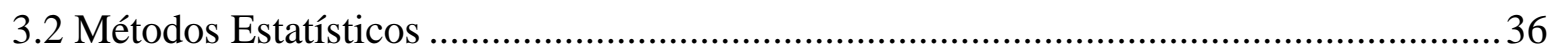

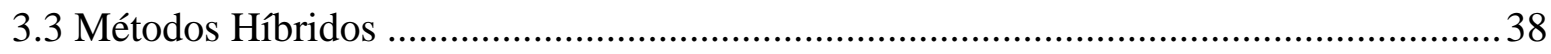

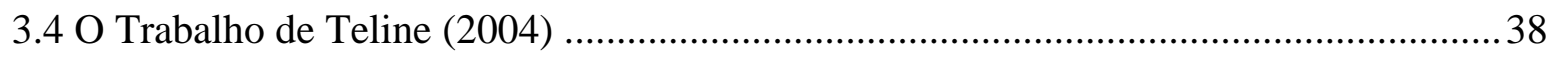

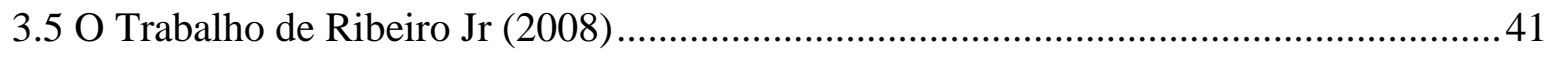

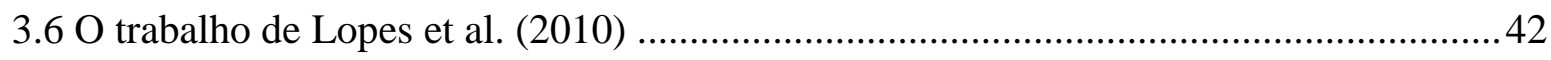

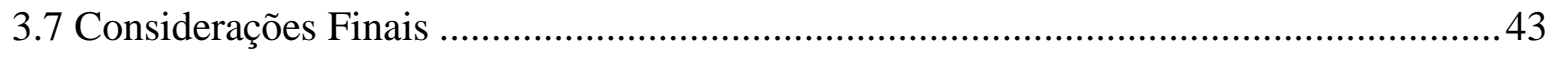

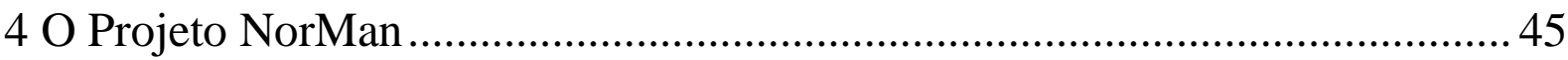

4.1 O Método de extração de termos dedicado a manuais técnicos - Norman Extractor ..... 45

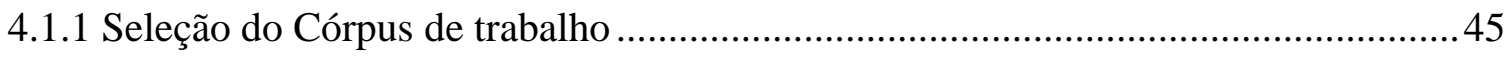

4.1.2 O Método de extração de termos sensível ao gênero de instruções .........................49

4.2 Aplicação do resultado da extração em Sistemas de Adaptação Textual ........................54

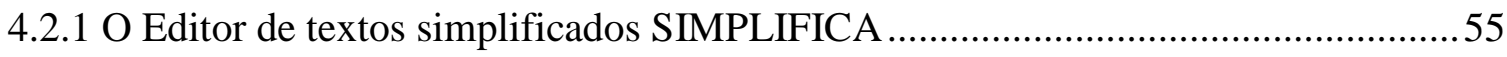

4.3 O Portal do Projeto Norman e o sistema Norman Extractor........................................ 60

5. Avaliação do Método de Extração de Termos para Manuais ........................ 61

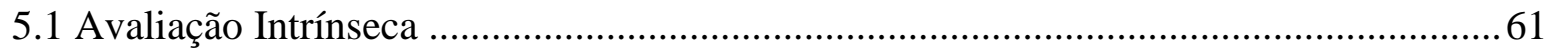

5.1.1 Comparação do Norman Extractor com métodos de Extração para Artigos

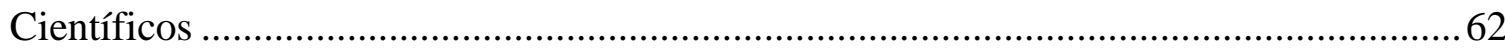

5.1.2 Avaliação do método Norman Extractor via estatística Kappa................................66

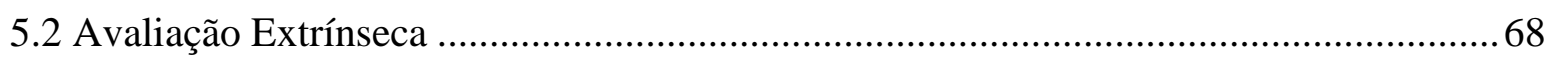

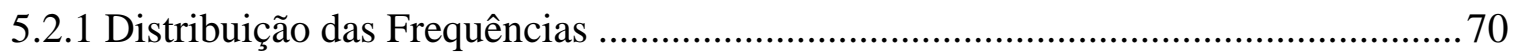

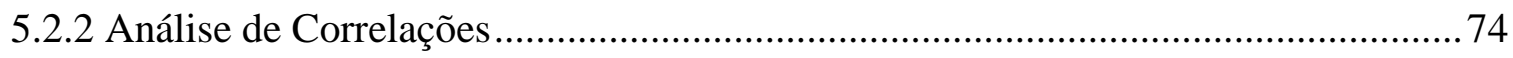


6. Conclusão

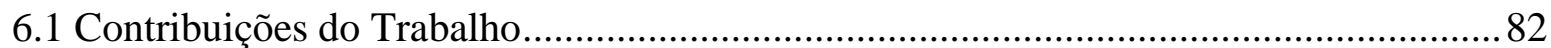

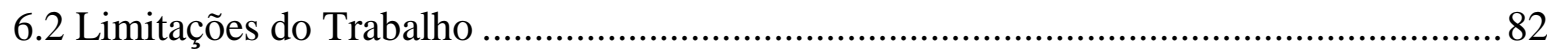

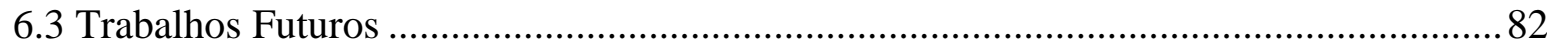

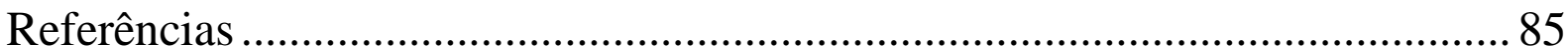

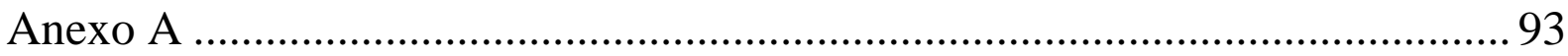

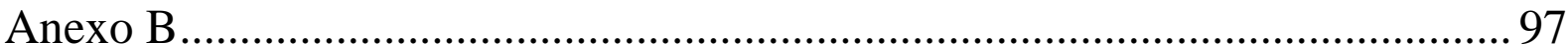

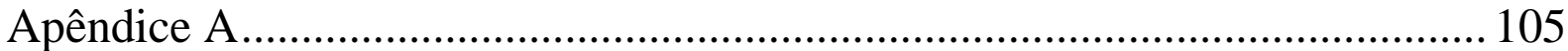

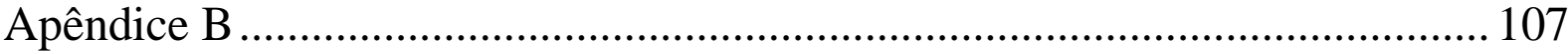

Apêndice C .......................................................................................... 111 


\section{Lista de Figuras}

Figura 1 - Diagrama de Blocos da Arquitetura de DRAFTER (Paris et al., 1995).

Figura 2 - Exemplos de posturas que um manual de produtos pode adotar (Paris \& Scott, 1994) 27

Figura 3 - Estrutura Global de Manuais de Produtos (Paris \& Scott, 1994) .28

Figura 4 - Precisão obtida pelas três abordagens e a semiautomática (Teline, 2004) ..... 39

Figura 5 - Cobertura obtida pelas três abordagens e a semiautomática (Teline, 2004). 40

Figura 6 - Medida F obtida pelas 3 abordagens e a semiautomática (Teline, 2004) 40

Figura 7 - Exemplo de trecho de um dos manuais processado pelo PALAVRAS ....................50

Figura 8 - Exemplos das formas gramaticais encontradas nos manuais.................................. 50

Figura 9 - NorMan Extractor reconhecendo uma relação habilita 51

Figura 10 - Padrões Morfossintáticos aplicados em um trecho do manual, com o valor do Cvalue à direita. 51

Figura 11 - Padrões morfossintáticos para extração de termos compostos 52

Figura 12 - Padrões morfossintáticos usados na extração de termos simples 52

Figura 13 - Lista de candidatos a termos ranqueados pelo C-Value geradas pelo sistema Norman Extractor 53

Figura 14 - Diagrama do método de extração NorMan.... 53

Figura 15 - Sistema Simplifica.... .56

Figura 16 - Palavras marcadas após o processo de simplificação léxica. 58

Figura 17 - Trecho de manual com termos técnicos marcados para receber informações adicionais ad Wikipédia.

Figura 18 - Trecho do manual de instruções usado na avaliação, com as palavras marcadas .68

Figura 19 - Exemplos de questões utilizadas na avaliação

Figura 20 - Média de conhecimento prévio dos termos da avaliação 71

Figura 21 - Média da utilidade da informação extra fornecida para cada termo .72

Figura 22 - Média de acerto das questões. 72

Figura 23 - Comparação de conhecimento prévio, utilidade e acertos entre as palavras complexas e os termos técnicos..... 


\section{Lista de Tabelas}

Tabela 1 - Frequência das formas gramaticais em português para a relação gera (Delin et al., 1994)

Tabela 2 - Frequência das formas gramaticais em português para a relação habilita (Delin et al., 1994)..... 29

Tabela 3 - Distribuição das seções dos manuais do córpus 48

Tabela 4 - Resultados da lista de unigramas para os métodos de Teline (2004) e o Norman Extractor

Tabela 5 - Resultados da lista de bigramas para os métodos de Teline (2004) e o Norman Extractor .65

Tabela 6 - Resultados da lista de trigramas para os métodos de Teline (2004) e o Norman Extractor 65

Tabela 7 - Valor da estatística Kappa para unigramas, usando 3 juízes e 150 termos candidatos 66

Tabela 8 - Classificação de valores Kappa 67

Tabela 9 - Valor da estatística Kappa para bigramas, usando 2 juízes e 150 termos candidatos

Tabela 10 - Valor da estatística Kappa para trigramas, usando 2 juízes e 150 termos candidatos

Tabela 11 - Perfis e resultados da avaliação dos 15 funcionários da Prefeitura da Campus da USP em São Carlos 70

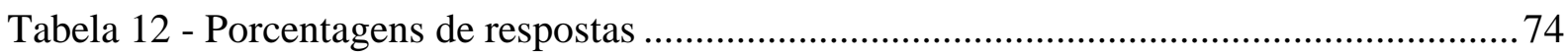

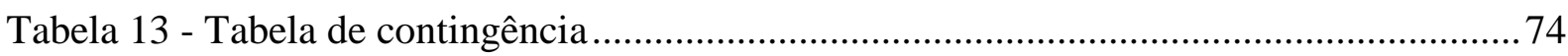

Tabela 14 - Tabela de distribuição do qui-quadrado .............................................................. 75

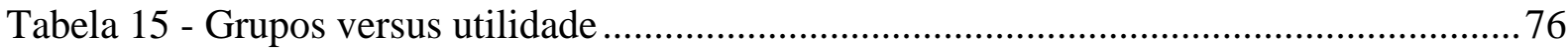

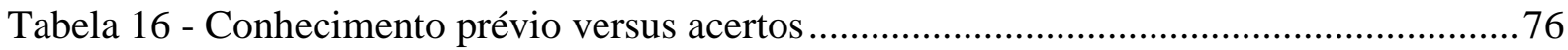

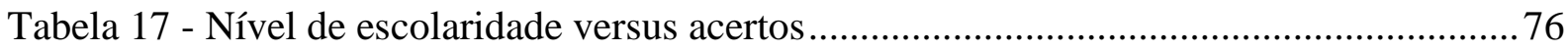

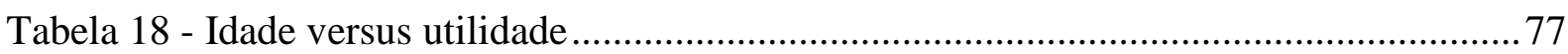

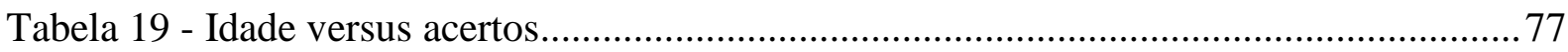




\section{Resumo}

No Brasil, cerca de $68 \%$ da população é classificada como leitores com baixos níveis de alfabetização, isto é, possuem o nível de alfabetização rudimentar (21\%) ou básico (47\%), segundo dados do INAF (2009). O projeto PorSimples utilizou as duas abordagens de Adaptação Textual, a Simplificação e a Elaboração, para ajudar leitores com baixo nível de alfabetização a compreender documentos disponíveis na Web em português do Brasil, principalmente textos jornalísticos. Esta pesquisa de mestrado também se dedicou às duas abordagens acima, mas o foco foi o gênero de textos instrucionais. Em tarefas que exigem o uso de documentação técnica, a qualidade da documentação é um ponto crítico, pois caso a documentação seja imprecisa, incompleta ou muito complexa, o custo da tarefa ou até mesmo o risco de acidentes aumenta muito. Manuais de instrução possuem duas relações procedimentais básicas: a relação gera - generation - (quando uma ação a gera automaticamente uma ação $\beta$ ), e a relação habilita - enablement - (quando a realização de uma ação $\alpha$ permite a realização da ação $\beta$, mas o agente precisa fazer algo a mais para garantir que $\beta$ irá ocorrer). O projeto aqui descrito, intitulado NorMan, estudou como as relações procedimentais gera e habilita são realizadas em manuais de instruções, dando base para a criação do sistema NorMan Extractor, que implementa um método de extração de termos dedicado ao gênero de textos instrucionais, especificamente aos manuais técnicos. Também foi proposta a adaptação do sistema de autoria de textos simplificados criado no projeto PorSimples - o SIMPLIFICA - para atender o gênero de textos instrucional. O SIMPLIFICA adaptado usa a lista de candidatos a termo, gerada pelo sistema NorMan Extractor, com duas funções: (a) para auxiliar na identificação de palavras que não devem ser simplificadas pelo método de simplificação léxica baseado em sinônimos, e (b) para gerar uma elaboração léxica para facilitar o entendimento do texto. 


\section{Abstract}

In Brazil, $68 \%$ of the population can be classified as low-literacy readers, i.e., people at the rudimentary (21\%) and basic (47\%) literacy levels, according to the National Indicator of Functional Literacy (INAF, 2009). The PorSimples project used the two approaches of Textual Adaptation, Simplification and Elaboration, to help readers with low-literacy levels to understand Brazilian Portuguese documents on the Web, mainly newspaper articles. In this research we also used the two approaches above, but the focus was the genre of instructional texts. In tasks requiring the use of technical documentation, the quality of documentation is a critical point, because if the documentation is inaccurate, incomplete or too complex, the cost of the task or even the risk of accidents is greatly increased. Instructions manuals have two basic procedural relationships: the relation generation (by performing one of the actions $(\alpha)$, the other $(\beta)$ will automatically occur), and the relation enablement (when $\alpha$ enables $\beta$, then the agent needs to do something more than $\alpha$ to guarantee that $\beta$ will be done). The project presented here, entitled NorMan, investigated the realization of the relationships between procedural actions in instruction manuals, providing the basis for creating an automatic term extraction method devoted to the genre of instructional texts, specifically technical manuals. We also proposed an adaptation of the authoring system of simplified texts created in the project PorSimples - the SIMPLIFICA - to deals with the genre of instrumental texts. The new SIMPLIFICA uses the list of term candidates, generated by the proposed method, with two functions: (a) to assist in the identification of words that should not be simplified by the lexical simplification method based on synonyms, and (b) to generate a lexical elaboration to facilitate the comprehension of the text. 


\section{Introdução}

\subsection{Contexto}

Esse projeto foi desenvolvido no âmbito do Núcleo Interinstitucional de Linguística Computacional (NILC ${ }^{1}$ ), criado em 1993, um grupo interdisciplinar de professores e pesquisadores que se dedica à pesquisa e ao desenvolvimento de recursos, ferramentas e sistemas de Processamento de Língua Natural (PLN), tais como o desenvolvimento de córpus e léxicos, etiquetadores morfossintáticos, sumarizadores automáticos, aplicações de tradução de máquina e ferramentas de suporte à escrita, entre outros. Alguns projetos do NILC foram de fundamental importância para este trabalho, como o projeto PorSimples ${ }^{2}$ e o ExPorTer ${ }^{3}$, descritos oportunamente.

Desde 2001, o índice INAF ${ }^{4}$ (Indicador de Alfabetismo Funcional) mede os níveis de alfabetismo funcional na população brasileira, tendo identificado quatro níveis de alfabetização na população (INAF, 2009), até o momento. São eles:

1 - Analfabetismo: Corresponde a situação daqueles que não conseguem realizar tarefas simples que envolvem a leitura de palavras e frases. Esse nível abrange 7\% da população brasileira;

2 - Alfabetismo nível rudimentar: Corresponde à capacidade de localizar uma informação explícita em textos curtos e familiares, como anúncios ou pequenas cartas. Este nível atinge $21 \%$ da população brasileira;

3 - Alfabetismo nível básico: Neste nível, a pessoa tem a habilidade de ler e compreender textos de tamanho médio e podem localizar informações e realizar inferências simples. Este nível abrange $47 \%$ da população brasileira;

4 - Alfabetismo nível pleno: Corresponde à habilidade de ler textos longos, encontrar vários tipos de informação, comparar textos diferentes e realizar inferências. Este nível corresponde a $25 \%$ da população brasileira.

\footnotetext{
${ }^{1}$ http://nilc.icmc.usp.br/

2 http://caravelas.icmc.usp.br/wiki/index.php/Principal

${ }^{3} \mathrm{http} / / /$ nilc.icmc.usp.br/nilc/projects/termextract.htm

${ }^{4}$ http://www.ipm.org.br/
} 
As duas características distintivas entre os três níveis de alfabetismo (ou alfabetização) são o tamanho e a complexidade do texto a ser lido e compreendido, o que nos remete à área de Adaptação Textual (AT).

Adaptação textual (AT) é uma atividade comum de professores para facilitar a compreensão de conteúdos e também usada no cenário do ensino de novas línguas (Burstein, 2009). Seus benefícios são vários, tais como, ajudar aprendizes de língua e crianças que estão aprendendo a ler diferentes gêneros textuais, facilitando sua compreensão. Também, ajudar audiências com necessidades especiais, tais como leitores com baixo nível de letramento, adultos em fase de alfabetização, pessoas engajadas em cursos de Educação à Distância, para os quais a compreensão é de grande importância, surdos que se comunicam com a língua de sinais e desejam aprender línguas como português ou inglês, entre outros, a ler e compreender textos (Aluisio \& Gasperin 2010).

Os estudos na área de AT tentam responder duas questões: O que é modificado? e Como é modificado? Para responder à primeira questão, as pesquisas investigam modificações nos diferentes níveis linguísticos: fonológico, léxico, sintático e discursivo. Já para a segunda, existem duas grandes abordagens (ou tipos) de adaptações: Simplificação Textual (ST) e Elaboração Textual (ET) (Young 1999; Urano 2000). A primeira pode ser definida como qualquer tarefa que reduza a complexidade de um texto (por exemplo, no nível léxico ou sintático), enquanto tenta preservar o significado e informação (Siddharthan, 2003; Mapleson, 2006; Max, 2006). A ET, por sua vez, tem o objetivo de esclarecer e explicar conceitos e informações e tornar as conexões explícitas em um texto, por exemplo, fornecendo sinônimos para palavras conhecidas por um grupo de falantes ou definições curtas para conceitos complexos. É importante dizer que a simplificação e a elaboração são fortemente relacionadas; enquanto a simplificação aumenta a inteligibilidade de um texto (torna ele mais fácil de ser lido), a elaboração melhora a compreensão do texto, isto é, facilita o entendimento de conceitos nos textos.

A ST é uma área de pesquisa emergente no campo de Processamento de Língua Natural (PLN). Algumas abordagens envolvem simplificação da estrutura léxica e sintática, por meio de substituição de palavras incomuns por palavras mais comuns e frequentes (simplificação léxica - SL) e também pela divisão e mudança da sintaxe da sentença. O exemplo a seguir faz uma simplificação sintática de uma oração em voz passiva transformando a sentença em voz ativa: 
Original: Essa escolha deve ser feita eventualmente por Lula.

Simplificado: Lula deve, eventualmente, fazer essa escolha.

Outro exemplo realiza a simplificação sintática por meio da divisão de uma oração coordenada sindética em várias sentenças, através da eliminação do marcador de coordenação, repetindo o núcleo do sujeito para cada período:

Original: A Mesa tem de aprovar o parecer e enviá-lo ao plenário.

Simplificado: A Mesa tem de aprovar o parecer. A Mesa tem de enviá-lo ao plenário.

Alguns trabalhos na área de Simplificação Textual propõem o descarte de partes do texto e a adição de material extra para explicar palavras complexas (Petersen et al., 2007). Esta última abordagem é melhor definida como Elaboração Léxica. Os seus métodos consistem no acréscimo de definições, sinônimos, antônimos ou hiperônimos das palavras consideradas complexas, ao invés de substituí-las (Urano, 2000). Por exemplo, para a sentença "Todos sabem que Ken é diligente e gentil com os outros." uma SL a transformaria em "Todos sabem que Ken é esforçado e gentil com os outros." enquanto que um exemplo de EL seria: "Todos sabem que Ken é diligente, ou esforçado, e gentil com os outros."

O projeto PorSimples (Simplificação Textual do Português para Inclusão e Acessibilidade Digital) (Aluísio et al., 2008a, 2008b; Caseli et al., 2009; Candido Jr. et al., 2009; Aluisio e Gasperin, 2010), abordou tanto a simplificação como a elaboração de textos, visando a construção de sistemas que promovem o acesso a textos em Português do Brasil para pessoas com níveis rudimentar e básico de alfabetização e também para aquelas com problemas cognitivos, como dislexia e afasia, por exemplo. Os objetivos iniciais do PorSimples foram a criação de dois tipos de tecnologias:

(i) um sistema de autoria, chamado SIMPLIFICA, para apoiar a produção de textos simplificados no qual textos originais recebem simplificação léxica e sintática com possível pós-edição pelos autores;

(ii) um sistema (chamado FACILITA) para permitir pessoas com baixo nível de letramento/alfabetização a lerem conteúdo da Web, que é composto de ferramentas de simplificação, sumarização e explicitação do conteúdo.

Entretanto, no último ano do projeto, finalizado em abril de 2010, as funções da ferramenta FACILITA foram repartidas, fato esse que gerou outras duas ferramentas, com o objetivo de melhor se adequarem a duas abordagens distintas de leitura existentes: (i) leitura 
rápida para se obter a informação principal de um texto (FACILITA) e (ii) leitura detalhada para melhoria do nível de letramento do leitor (EDUCATIONAL FACILITA).

O foco principal dos sistemas desenvolvidos no projeto PorSimples são os textos do gênero informativo, diferentemente deste projeto, que visou o estudo e a adaptação do sistema de autoria on-line SIMPLIFICA para a escrita de textos do gênero instrucional, particularmente manuais técnicos de produtos tecnológicos.

Textos instrucionais consistem de uma sequência de instruções, concebidas com certa precisão a fim de atingir um objetivo. O usuário deve seguir passo a passo as instruções a fim de alcançar os resultados esperados (por exemplo, montar um computador). Textos procedimentais explicam como atingir um determinado objetivo através de ações que estão ao menos parcial e temporalmente organizadas. (Aouladomar \& Saint-Dizier, 2005). Alguns autores, como Aouladomar \& Saint-Dizier (2005), usam os dois termos como sinônimos, mas o importante é reconhecer que sob o rótulo de textos instrucionais existem conjuntos ou famílias de textos que são agrupados de acordo com seu objetivo e estilo. De acordo com Aouladomar \& Saint-Dizier (2005), podemos citar os seguintes conjuntos:

- Textos regulamentares, que caracterizam comportamentos esperados.

- Textos procedimentais, definidos como um conjunto linear (ou quase) de instruções.

- Programáticos, que incluem receitas, composições musicais, dentre outros, e indicam um conhecimento que é passado de um especialista para usuários que devem seguir estritamente as instruções dadas.

- Textos prescritivos, que contêm informação sobre o modo de realizar uma atividade.

- Textos injuntivos que são os que visam convencer o ouvinte a obedecer a uma vontade do emissor (quem fala), a fazer ou a não fazer algo, seja ordenando ou pedindo gentilmente.

- Textos de ajuda cujo propósito é sugerir, recomendar soluções e opções, explicar e informar.

No projeto PorSimples, foi compilada uma lista de palavras denominadas simples, que são aquelas que estão presentes no seguinte conjunto de recursos/córpus: Dicionário Ilustrado do Português (Biderman, 2005), lista de palavras frequentes de textos de jornais dedicados a 
crianças, como a Seção Para Seu Filho Ler do jornal Zero Hora, e uma lista de palavras concretas disponíveis no trabalho de Janczura (2007).

Essas palavras auxiliam os sistemas do PorSimples a identificarem os possíveis casos de simplificação léxica presentes nos textos. No caso dos manuais de instruções, existem termos que devem ser preservados e, para isso, neste projeto de mestrado foi necessária a criação de uma ferramenta para extração automática de termos em manuais. Este tipo de extração é novidade, pois no melhor do nosso conhecimento, não há ferramentas de extração dedicada a textos de manuais.

Existem três tipos de abordagens para extração de termos. A primeira, chamada de linguística, faz uso apenas de conhecimento linguístico. A segunda utiliza apenas métodos estatísticos, e é denominada abordagem estatística. A última abordagem, que é a mais utilizada, combina conhecimentos linguísticos e estatísticos e é denominada abordagem híbrida. Essas abordagens apresentadas no projeto ExPorTer (Teline, 2004) serão explicadas com mais detalhes no Capítulo 4, que também apresentará a abordagem desenvolvida por Ribeiro Jr (2008), que utiliza conhecimento semântico para auxiliar a tarefa de extração de termos de Lopes et al. (2010), que usa pontos de cortes absolutos e relativos para indicar relevância na lista de termos.

\subsection{Motivação e Justificativa}

Tarefas operacionais, procedimentos de manutenção e diagnósticos de falhas em sistemas técnicos complexos requerem o uso de documentação técnica. A qualidade dessa documentação é um ponto crítico. Se a documentação está imprecisa, incompleta ou difícil de entender, o custo e o tempo da operação de reparo irá aumentar muito. Até mesmo prejuízo a equipamentos caros ou acidentes com vítimas humanas podem ocorrer devido ao mau entendimento da documentação técnica (Eijk, 1997).

O desenvolvimento contínuo de novas tecnologias e produtos, combinados com o fato de que grande parte da população tem um nível básico ou rudimentar de alfabetização torna clara a importância da boa escrita de manuais técnicos, bem como demonstra ser um assunto interessante a ser estudado.

Em (Paris et al., 1995) uma análise de requisitos para uma ferramenta de suporte à escrita de documentos técnicos multilíngues confirmou que uma ferramenta de auxílio à 
escrita é mais útil do que uma ferramenta de geração automática que mantém o escritor longe do texto produzido.

Paris \& Scott (1994) mostram que os manuais de instruções podem ter diferentes estilos, isto é, nem todas as instruções são registradas, usam uma sequência de imperativos, como seria mais natural de se esperar, e que diferentes partes do manual frequentemente usam diferentes estilos.

Aouladomar (2005a) faz uma análise da estrutura de manuais e de perguntas relacionadas a textos procedimentais (por exemplo: "Como?" e "Por quê?") e mostra que perguntas e fragmentos de textos procedimentais podem ser combinados a fim de produzirem respostas para máquinas de busca.

Delin (1994) apresenta as duas relações procedimentais básicas, gera e habilita, identificadas por Alvin Goldman (Goldman, 1970). A relação gera é uma relação que aparece entre duas ações e que passa o sentido de que após a realização da ação "A", a ação "B" ocorrerá automaticamente, ou seja, “A” gera "B". No português, expressões linguísticas da relação gera geralmente envolvem o conectivo "para", primeiramente seguido por um infinitivo e, em ocasiões raras, seguido por um sintagma nominal. O seguinte trecho de um manual de instruções, em português, de uma serra elétrica, exemplifica essa relação (Delin, 1994):

Para colocar a serra na posição de corte oblíquo, solte a porca borboleta e incline a sapata para o ângulo desejado. (Black\&Decker)

A relação habilita é o tipo de relação que ocorre quando a realização de uma ação "A" não resulta na realização automática da ação "B". Apesar de o conectivo "para" também ser usado para a relação habilita, ele não foi encontrado em (Delin, 1994). Ao contrário, neste estudo, as relações habilita foram encontradas por meio de sinais de ordem temporal nas ações envolvidas, em orações consecutivas ou ligadas pela conjunção "e".

Desligue a serra da tomada antes de fazer qualquer ajuste. (Black\&Decker) 


\subsection{Hipótese e Objetivos do Projeto de Mestrado}

A hipótese desta pesquisa é a de que a proposta de um método de extração de termos para manuais deve levar em conta as orações que realizam as relações gera e habilita como nicho privilegiado para extrair os termos técnicos. Como suporte para esta afirmação, temos vários trabalhos da área de geração de textos instrucionais que elencam as relações gera e habilita como sendo as principais em manuais (Di Eugenio, 1992; Delin et al., 1994; Paris \& Scott, 1994). Desta forma, o objetivo deste trabalho, intitulado projeto NorMan, foi estudar, em um córpus criado no escopo desta pesquisa, como as relações procedimentais entre ações gera e habilita são realizadas em instruções de manuais técnicos de produtos tecnológicos em português. Este estudo deu base para a criação de um método de extração automática de termos para o gênero de manuais de produtos tecnológicos, que foi implementado no sistema NorMan Extractor. Como prova de conceito, o uso desta extração automática de termos permitiu a criação de um dicionário de termos tecnológicos para serem usados no módulo de simplificação léxica do sistema SIMPLIFICA, desenvolvido no projeto PorSimples, que foi adaptado nesta pesquisa para trabalhar com textos do gênero instrucional.

\subsection{Organização da Monografia}

Esta monografia está organizada conforme o que se segue. No Capítulo 2, são apresentados trabalhos relacionados com a criação e uso de Linguagens Controladas, que são amplamente utilizadas na produção de manuais técnicos. Também, são apresentados trabalhos da área de PLN sobre modelagem computacional de instruções, sistemas de geração automática de manuais e sistemas de perguntas e respostas adaptados ao tratamento de textos instrucionais. No Capítulo 3, são apresentadas as várias abordagens de desenvolvimento de métodos de extração automática de termos. No Capítulo 4, é apresentado o desenvolvimento do projeto NorMan, o método de extração automática de termos dedicado a manuais técnicos (NorMan Extractor), bem como o córpus de trabalho, a adaptação da simplificação léxica do sistema SIMPLIFICA e o portal deste projeto. No Capítulo 5, é apresentada a avaliação intrínseca e extrínseca do método de extração e a análise dos resultados. No Capítulo 6, é apresentada a conclusão do trabalho, com suas contribuições, limitações e propostas para trabalhos futuros. 


\section{Trabalhos Relacionados: a Linguagem Controlada Usada em Manuais Técnicos, os Sistemas de Geração Automática de Manuais e os Sistemas de Perguntas e Respostas}

\subsection{Linguagem Controlada}

Os princípios da linguagem controlada foram originados pelo inglês básico de Ogden (1932), na década de 1930. O inglês básico foi proposto tanto como uma língua internacional quanto uma base para o aprendizado do inglês como segunda língua. Ela consiste de 850 palavras básicas (Veja Anexo A) e algumas inflexões e regras de derivação (Kaji, 1999).

A primeira linguagem controlada para documentação técnica, chamada Caterpillar Fundamental English (CFE), foi desenvolvida na década de 1960 para melhorar a compreensão de leitura dos usuários não nativos dos manuais da Caterpillar, que é uma fabricante de equipamento pesado. Além disso, linguagens controladas têm mantido uma forte associação com o objetivo de reduzir custos e tempos de tradução de manuais. A Caterpillar, por exemplo, desenvolveu nos anos 1990 uma linguagem mais controlada ainda que a CFE (chamada Caterpillar Technical English (CTE)) em conjunto com o Center for Machine translation (CMT) da Carnegie Mellon University ${ }^{5}$ para facilitar a tradução automática (Kaji, 1999).

Várias outras companhias internacionais como a Ericsson, IBM, Xerox e Scania seguiram os passos da Caterpillar, gerando várias linguagens controladas ou simplificadas.

Como resultado dos crescentes requisitos de qualidade e da globalização da economia, o uso de linguagens controladas tem sido aumentado nas documentações técnicas, e junto com isso cresce o interesse do uso de PLN para apoiar a criação de textos fontes seguindo as recomendações de uma linguagem controlada (Eijk, 1997).

\subsubsection{Definições}

Usada em documentação técnica, linguagem controlada é uma linguagem escrita de acordo com regras rigorosas e com um vocabulário limitado. O objetivo é eliminar a possibilidade de

\footnotetext{
${ }^{5}$ Veja detalhes em: Projeto KANT - http://www.lti.cs.cmu.edu/Research/Kant
} 
ambiguidade. Foi verificado que textos fontes escritos numa linguagem controlada são muito mais fáceis de serem processados em tradução de máquina (Edwards \& Kingscott, 1997).

Os fatores importantes em uma análise do processo de compreensão de um texto são, segundo Leffa (1996): o texto, o leitor e as circunstâncias em que se dá o encontro. Entre os fatores relativos ao texto, destacam-se a legibilidade (apresentação gráfica do texto) e a inteligibilidade (uso de palavras frequentes e estruturas sintáticas menos complexas). As linguagens controladas surgiram para amenizar o problema da baixa inteligibilidade de textos, ao reduzirem a complexidade da estrutura sintática do texto, ao realizarem a desambiguação léxica e ao tratarem de problemas de tradução, pois o controle semântico e sintático facilita a tradução de uma língua para outra. Podemos citar as seguintes vantagens no uso de linguagens controladas (Altwarg, 2006; Burg, 1996; Cole, 1997):

- Melhoria na inteligibilidade, pela redução da ambiguidade léxica e estrutural, e por prescrever regras estilísticas;

- Melhoria na manutenibilidade, que é consequência direta da melhoria na inteligibilidade;

- Processamento computacional facilitado, em função da ambiguidade reduzida e das regras estilísticas prescritas;

- Tradução automática facilitada.

Existem também algumas desvantagens no uso de linguagem controlada que devem ser conhecidas, segundo (Altwarg, 2006; Burg, 1996; Cole, 1997):

- Redução do poder de expressão, causada por restrições da linguagem;

- Redução na velocidade de escrita, pois é necessário "pensar" mais para decidir que palavras e construções sintáticas são permitidas para serem usadas. A correção das violações das regras da linguagem também custa tempo;

- Considerável investimento, necessário para o treinamento das pessoas envolvidas para escreverem na linguagem controlada corretamente.

As linguagens controladas são mais usadas em aplicações comerciais e industriais, como na autoria de manuais técnicos de uso e manutenção, que possuem uma grande quantidade de documentos complexos que são frequentemente atualizados nos quais a terminologia é específica de um domínio. O melhor exemplo conhecido de linguagem 
controlada é o AECMA Simplified English ${ }^{6}$, uma norma internacional aceita para escrever manuais técnicos na indústria aeroespacial. O padrão AECMA surgiu em 1979, e cresceu da experiência coletiva de vários grandes fabricantes nas últimas décadas, cujo objetivo é simplificar a documentação técnica, tanto para leitura na língua original, quanto para facilitar a tradução automática e para exportação para outros mercados (Mitkov, 2003). Além disso, encontramos o uso de linguagem controlada em domínios nos quais a documentação é tradicionalmente muito complexa ou mal escrita, como nos documentos do governo, do setor de finanças e do jurídico.

\subsubsection{Os Componentes de uma Linguagem Controlada}

Uma linguagem controlada pode ser definida como uma série de restrições de vocabulário, gramática e estilo. Uma linguagem controlada prescreve esses elementos de uma maneira limitada e formal. A restrição de vocabulário é de fundamental importância para qualquer linguagem controlada, tendo como principal objetivo a redução da ambiguidade (Kaji, 1999). Além da restrição de vocabulário, um estudo terminológico deve ser realizado dentro do domínio específico. Através desse estudo, serão identificados candidatos a termos e suas variantes, que serão usados na criação de uma base de termos. Essa base é utilizada para evitar que informações importantes sejam perdidas durante a simplificação de uma frase. Toda linguagem controlada possui regras gramaticais específicas. Essas regras são responsáveis por definir quais tipos de construções de frase são permitidas. Geralmente essas regras visam facilitar os textos propondo frases simples e curtas. Alguns exemplos de regras gramaticais podem ser observados a seguir (Kaji, 1999):

- Usar frases curtas. Esta regra é simples, porém muito eficaz, pois frases curtas contêm menos ambiguidades;

- Eliminar palavras redundantes. Também reduz a ambiguidade e ajuda na tradução automática;

- Evitar o uso de voz passiva;

- Não usar sequências muito grandes de substantivos.

As gramáticas devem ser adaptadas para cada linguagem controlada conforme suas necessidades. Formato e layout também fazem parte da linguagem controlada. Por exemplo, a utilização de uma lista pode eliminar uma estrutura coordenada complexa, e resulta em pequenas frases, muito mais fáceis de serem interpretadas. A padronização de convenções

\footnotetext{
${ }^{6}$ AECMA é o acrônimo francês para Associação Europeia de Fabricantes de Equipamentos Aeroespaciais
} 
estilísticas também deve ser aplicada no formato de datas e moedas, tabelas, e variantes ortográficas (Kaji, 1999).

\subsubsection{Plain English}

O Plain English é um movimento na Inglaterra e Estados Unidos que se iniciou no fim dos anos 1970 como uma reação à falta de clareza na linguagem usada nos documentos do governo e comércio. Ele usa recomendações (o Plain Language ${ }^{7}$ ) que, em princípio pode ser aplicado a qualquer língua natural.

O Plain Language pode ajudar a escrever um texto simples e curto, claro, efetivo e fácil de entender para o público alvo. Um documento que siga o Plain Language usa palavras economicamente e em um nível que a audiência possa entender, criando um texto sensível ao leitor como reforça Leffa (1996):

Algumas recomendações de como escrever e organizar as informações em Plain Language ${ }^{8}$ são:

a) Escreva utilizando pronomes pessoais para falar diretamente aos leitores;

b) Seja direto; elimine qualquer ambiguidade;

c) Use a lógica simples e comum criando conexões entre ideias óbvias;

d) Use títulos ou subtítulos que informem ou resumam o texto;

e) Retire toda a informação que não é essencial para o propósito do texto, evitando assim longas descrições nominais;

f) Priorize a informação e coloque o que for mais importante no início;

g) Use gráficos, planilhas, e imagens para reforçar pontos e fatos complicados;

h) Use índices/sumário para documentos grandes ou crie uma introdução curta com o conteúdo de cada item.

Outras recomendações para reescrever e revisar textos são:

i) Mantenha o sujeito e o verbo próximos do início da sentença;

\footnotetext{
${ }^{7}$ http://www.plainlanguage.gov/

${ }^{8} \mathrm{http}: / /$ www.plainlanguagenetwork.org/
} 
ii) Explique somente uma ideia por sentença;

iii) Faça frases entre 25 a 35 palavras em média (dados para o inglês);

iv) Use verbos em vez de substantivos para exemplificar sua ação;

v) Use a voz ativa: tendo certeza que o sujeito é bem definido assim como sua ação;

vi) Use palavras e construa sentenças positivas; evite frases com aspectos negativos;

vii) Faça uma sintaxe (construção gramatical) simples;

viii) Evite a formalidade quando desnecessário; Simplifique suas palavras, escolha a linguagem cotidiana;

ix) Evite jargões, palavras estrangeiras e termos jurídicos;

$\mathrm{x}$ Use palavras técnicas com cuidado: defina ou providencie exemplos descritivos;

xi) Minimize abreviações;

xii) Coloque a ideia principal antes das exceções e condições;

xiii) Use termos e conceitos importantes de maneira consistente.

Entretanto, mesmo as recomendações da Plain Language não especificam detalhadamente o que seria uma sintaxe simples nem o que seria a linguagem cotidiana, embora o manual com as recomendações apresente vários exemplos de simplificação para a língua inglesa.

\subsubsection{Inglês Simplificado AECMA}

O inglês simplificado AECMA é utilizado pela maioria das grandes fabricantes de equipamento aeroespacial, e por muitas empresas aéreas. O guia de inglês simplificado especifica três fontes de palavras:

1. Cerca de 950 palavras básicas aprovadas, todas com definições não técnicas bem definidas; entre elas incluem todas as preposições importantes, artigos e conjunções, bem como substantivos, verbos, adjetivos e advérbios;

2. Um número ilimitado de nomes técnicos, divididos em vinte categorias, que podem ser escolhidas pela organização, mas usadas somente como adjetivos ou substantivos, de acordo com certas orientações;

3. Verbos técnicos para designar seis categorias de processos de fabricação especificados pelo usuário, sujeito a regras rígidas de utilização.

Este padrão de inglês simplificado tem cerca de cinquenta e cinco regras que regem o uso de palavras e a construção de frases. Algumas delas são muito precisas: 
Você deve quebrar grupos de substantivos de quatro ou mais palavras reescrevendoos, usando hifenização ou uma combinação dos dois.

Entre as regras precisas, existem várias sobre pontuação. Algumas outras são um pouco vagas, como:

\section{Mantenha um tópico por sentença.}

ou então expressam metas de escritas desejáveis:

Tente variar o tamanho de sentenças e construções para manter o texto interessante.

A maioria das regras vagas ou orientações de metas podem ser vistas como princípios que se aplicam à boa prática de escrita de forma geral (Mitkov, 2003).

\subsubsection{Linguagem Simplificada em Textos do Português do Brasil}

Há uma tendência atual do governo brasileiro pela criação de guias ou cartilhas ${ }^{9}$ que utilizam uma linguagem simples e acessível a pessoas de qualquer idade e com um menor grau de instrução. Também, a RESOLUÇÃO No 7, DE 29 DE JULHO DE $2002^{10}$ estabelece regras e diretrizes para os sites da Administração Pública Federal que ditam que as páginas devem ser de fácil legibilidade; apresentar os conteúdos com clareza, simplicidade, objetividade, organicidade, atualidade, e veracidade; usar linguagem simples e direta, especialmente nas páginas iniciais; além de outros critérios.

No meio jurídico, a campanha Simplificação da Linguagem Jurídica, lançada pela Associação dos Magistrados Brasileiros (AMB) em 2005 foi criada para que magistrados, advogados, promotores e outros operadores do Direito utilizem linguagem mais simples para facilitar o entendimento da população em geral. Nesta campanha foi lançado um livro contendo um glossário com as expressões técnicas mais usuais nos meios forenses e as respectivas traduções, na tentativa de combater o juridiquês. Geralmente estas cartilhas de orientação legal (COL) tornam as leis mais acessíveis ao desconstruir a linguagem

\footnotetext{
9 Veja, por exemplo, a cartilha Lei Maria da Penha em: http://www.agenciaalagoas.al.gov.br/noticiasgoverno/governo-lanca-cartilha-sobre-a-lei-maria-da-penha (Acessado em 6/2/2008) ou a cartilha lançada pelo Ministério do Trabalho e Emprego com informações úteis para brasileiros e brasileiras que vivem no exterior: http://download.uol.com.br/ultnot/cartilha.pdf.

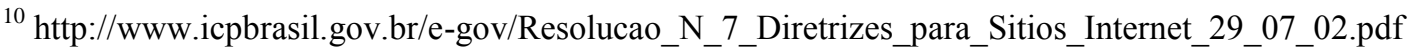


jurídica. A versão em forma de cartilha ilustrada do Novo Código Civil Brasileiro que entrou em vigor em 11/1/2003 foi lançada em 2003 (Carvalho Netto, 2003).

Outras cartilhas lançadas pelo governo com informações de interesse amplo como saúde, trânsito, etc. também são escritas em linguagem simples. Uma em específico foi lançada pelo Ministério do Trabalho e Emprego com informações úteis para brasileiros que vivem no exterior $^{11}$.

O governo brasileiro também editou leis que tornam as bulas de medicamentos mais fáceis de serem lidas, separando as informações para o público geral da informação para médicos e farmacêuticos e lançando o site de busca Bulário da ANVISA ${ }^{12}$.

$\mathrm{Na}$ mídia jornalística, há um interesse grande pela linguagem simplificada, aproveitando jornalistas experientes e bem articulados para a criação de seções como "De palavra em palavra", do jornal Estado de São Paulo, "Para seu Filho Ler" do Jornal Zero Hora entre outras.

A ciência também foi desmistificada para crianças com revistas como "Ciência Hoje das Crianças"13 do Instituto Ciência Hoje (ICH), uma organização social de interesse público sem fins lucrativos vinculada à Sociedade Brasileira para o Progresso da Ciência (SBPC). A revista Ciência Hoje das Crianças mostra ao público infantil que a ciência faz parte da vida de cada um e pode ser muito divertida. A revista estimula a curiosidade e a compreensão dos fenômenos do dia a dia, com a ajuda de ilustrações e experiências que podem ser realizadas pelas próprias crianças. É instrumento fundamental em sala de aula como fonte de pesquisa aos professores e de grande importância para os alunos na elaboração de deveres e projetos escolares. A publicação é adotada pelo MEC e distribuída para 107 mil escolas, como material de apoio paradidático.

Uma das vantagens dos materiais simplificados é que preparam o leitor para a leitura eventual dos textos autênticos. Por isso, segundo Ramos (2006) os textos instrucionais sempre devem dispor da referência bibliográfica ao final das unidades para que os leitores as consultem quando for de seu interesse e necessidade.

\footnotetext{
${ }^{11} \mathrm{http} / / /$ download.uol.com.br/ultnot/cartilha.pdf

${ }^{12} \mathrm{http}$ ///bulario.bvs.br/

${ }^{13} \mathrm{http}$ ://ich.unito.com.br/
} 


\subsubsection{Sublíngua}

Uma sublíngua é uma língua usada em domínios ou assuntos específicos, tais como biologia e engenharia aeroespacial. Exemplos de sublínguas são a linguagem de relatórios meteorológicos, manuais de manutenção de aviões, artigos científicos sobre fármacos e anúncios de venda de imóveis (Grishman, 2001).

Por exemplo, a palavra 'chip' no domínio da computação significa um pedaço de material semicondutor, enquanto 'chip' em um bar britânico significa um pedaço de batata frita. Cada um destes domínios tem um vocabulário para suas necessidades. A principal diferença entre uma linguagem controlada e uma sublíngua é que na linguagem controlada os termos, a sintaxe e a semântica são propositalmente limitados, geralmente com objetivos particulares em mente, e na sublíngua essas limitações não são especificadas e evoluem naturalmente (Altwarg, 2006).

\subsection{Tratamento de Textos Instrucionais em Trabalhos de PLN}

Nesta seção, apresentamos trabalhos de análise de córpus de manuais de instrução em várias línguas para: a criação de modelos computacionais de instrução (Seção 2.2.1); a criação de uma ferramenta, baseada na tecnologia de geração multilíngue, que dá suporte à produção de manuais de usuário de produtos de software (Seção 2.2.2); a criação de sistemas de perguntas e respostas baseados na estrutura global de textos instrucionais/procedimentais (Seção 2.2.3).

Tanto o trabalho de Di Eugenio (1992), apresentado na Seção 2.2.1, como o do grupo de pesquisadores que desenvolveram o DRAFTER (Delin et al., 1994), apresentado na Seção 2.2.2, apresentaram um estudo das relações procedimentais gera (generation) e habilita (enablement). Estas relações são importantes neste projeto de mestrado, pois elas são fundamentais para a escrita adequada de manuais e sua realização varia de língua para língua, indicando realizações preferenciais que, ao serem levadas em consideração na escrita de manuais alcançarão uma eficácia maior para o uso, manutenção e cuidados dos produtos.

\subsubsection{O Trabalho de Di Eugenio (1992)}

No trabalho de Barbara Di Eugenio (1992) é feita uma análise da cláusula de propósito ou finalidade no contexto do entendimento de instruções. Essa análise mostra que os objetivos afetam a interpretação ou execução das ações, e dão apoio ao uso do modelo de relações gera (generation) e habilita (enablement) entre as ações. 
A análise das cláusulas de finalidade é relevante para o problema de entendimento de instruções em língua natural porque elas:

- estabelecem explicitamente objetivos e sua interpretação mostra que o objetivo que o ouvinte adota guia-o durante a realização das tarefas.

- aparecem para expressar as relações entre ações gera ou habilita, apoiando a proposta de que essas duas relações são necessárias para o modelo de ações.

Segundo Di Eugenio (1992), uma pessoa A usa uma cláusula de finalidade para explicar um objetivo $\mathrm{X}$ a uma pessoa $\mathrm{B}$ através da execução de uma tarefa Y. Porém, um ponto importante que tem sido ignorado é que o objetivo $X$ também limita a interpretação da tarefa Y. Por exemplo, considere o exemplo abaixo, tomado de Di Eugenio (1992), com traduções para o português entre parênteses:

a) Place a plank between two ladders (Coloque uma prancha entre duas escadas)

b) Place a plank between two ladders to create a simple scaffold (Coloque uma prancha entre duas escadas para criar um andaime simples)

Nos dois casos (a) e (b) a ação a ser executada é "Coloque uma prancha entre duas escadas". Porém, essa informação não é específica, e existem várias maneiras de "colocar a prancha". O objetivo "criar um simples andaime" restringe a escolha da posição de colocação da prancha. A sentença no infinitivo "to create a simple scaffold"/"para criar um andaime simples" é uma cláusula de propósito que expressa o propósito de um agente na realização de uma dada ação.

Na maioria dos casos, um objetivo $\mathrm{X}$ descreve uma mudança no mundo. No entanto, em alguns casos:

1) a mudança não é no mundo, mas sim no conhecimento de quem recebe a instrução. Ao executar uma tarefa $\mathrm{Y}$, o conhecimento de quem a está executando pode ser mudado em respeito a certa proposição ou ao valor de certa entidade. Por exemplo:

You may want to hang a coordinating border around the room at the top of the walls. To determine the amount of border, measure the width (in feet) of all walls to be covered and divide by three. Since borders are sold by the yard, this will give you the number of yards needed (Di Eugenio, 1992). 
(Você pode querer colocar uma moldura no topo da parede ao redor da sala. Para determinar a quantidade de moldura, meça a largura (em pés) de todas as paredes a serem cobertas e divida por três. Como as molduras são vendidas em jardas, isto lhe dará o número de jardas necessárias.)

Vários desses exemplos envolvem verbos como "check", "make sure" (checar, ter certeza, entre outros) seguido pelo complemento "that" (que) descrevendo um estado e. O uso de tais verbos tem um efeito pragmático que faz com que o executor da tarefa não somente cheque se e acontece, pois se e não acontecer, ele fará algo para funcionar. Por exemplo:

To attach the wires to the new switch, use the paper clip to move the spring type clip aside and slip the wire into place. Tug gently on each wire to make sure it's secure (Di Eugenio, 1992).

(Para fixar os fios no novo interruptor, use um clip de papel para mover o grampo de mola para o lado e colocar o fio no lugar. Puxe suavemente cada fio para ter certeza de que está seguro.)

2) A cláusula de finalidade pode informar ao executor que o mundo não deve mudar, que dado evento deve ser evitado. Por exemplo:

Tape raw edges of fabric to prevent threads from raveling as you work (Di Eugenio, 1992).

(Costure as bordas de tecido cru para evitar que o fio desfie enquanto você trabalha.)

Do ponto de vista do processamento do discurso, interpretar uma cláusula de finalidade pode afetar o modelo de discurso, em particular por introduzir novos referentes. Isto acontece quando o efeito de $\mathrm{Y}$ é criar um novo objeto, e $\mathrm{X}$ o identifica. Verbos frequentemente usados neste contexto são criar, fazer, formar, etc. Por exemplo:

Join the short ends of the hat band to form a circle (Di Eugenio, 1992).

(Una as extremidades curtas da banda do chapéu para formar um círculo.) 


\subsubsection{As Relações Gera e Habilita}

A relação entre duas ações (Ação Y contribui para o objetivo $\mathrm{X}$ ), na maioria das vezes expressa uma relação gera, e nas restantes, habilita.

Gera é a relação entre ações ligada pela preposição "by" (por/via) em inglês - "turning on the light by flipping the switch" (acender a luz via pressão no interruptor). Formalmente, pode-se dizer que uma ação X condicionalmente gera outra ação Y se e somente se:

- X e Y são simultâneos;

- $\quad X$ não é parte da execução de $Y$;

- Quando X acontece, uma série de condições C tornam-se válidas, assim a junção da ocorrência de X e C implicam na ocorrência de Y. No caso da relação gera entre flipping the switch e turning on the light, o conjunto $\mathrm{C}$ de condições seriam: fiação, interruptor e lâmpada estarem funcionando.

Gera é uma relação pervasiva entre descrições de ações naturais. No córpus do trabalho de Barbara Di Eugenio, a cláusula encabeçada por "by" (por) é usada com menos frequência do que as cláusulas de finalidade para expressar a relação gera: $95 \%$ de 101 cláusulas de finalidade expressaram relação gera, contra 27 cláusulas "por" no mesmo córpus. Isto significa que a relação gera em textos instrumentais é expressa principalmente por cláusulas de finalidade, na língua inglesa. Estes mesmos resultados são confirmados pelo trabalho de Delin et al. (1994), mostrado na Seção 2.2.2.

A relação habilita acontece entre duas ações X e Y só e somente se uma ocorrência de $\mathrm{X}$ traz certas condições que são necessárias (mas não necessariamente suficientes) para o desempenho subsequente de Y. Apenas cerca de 5\% dos exemplos do trabalho de Barbara Di Eugenio demonstram a relação habilita:

Unscrew the protective plate to expose the box. (Desaperte os parafusos da placa de proteção para expor a caixa.)

Desapertar os parafusos da placa de proteção habilita a remoção da placa que gera a exposição da caixa.

As relações gera e habilita são necessárias para modelar ações. Uma das justificativas para isto é que elas nos permitem chegar a conclusões sobre a execução de ações. 
Se uma ação $\mathbf{X}$ gera $\mathbf{Y}$, duas ações foram descritas, mas apenas $\mathbf{X}$, o gerador, precisa ser realizada. Em contraste à relação gera, se $\mathbf{X}$ habilita $\mathbf{Y}$, após executar X, Y ainda precisa ser executada: $\mathrm{X}$ deve temporariamente preceder $\mathrm{Y}$, no sentido de que $\mathrm{X}$ deve começar, mas não necessariamente terminar, antes de Y. No exemplo a seguir, hold (segurar) deve continuar por toda duração de fill (encher):

Hold the cup under the spigot to fill it with coffee. (Segure a xícara embaixo da torneira para enchê-la com café.)

Do mesmo modo que a relação gera afeta a execução do gerador, a relação habilita afeta a execução da ação habilita.

\subsubsection{Geração Multilíngue de Manuais de Instrução}

O Instituto de Pesquisa em Tecnologia da Informação (ITRI ${ }^{14}$ ) existiu como um departamento da Universidade de Brighton até 2005, entretanto, a pesquisa em Processamento de Língua Natural continua nesta universidade com o grupo Natural Language Technology Group $\left(\mathrm{NLTG}^{15}\right)$. Dentre as várias pesquisas desenvolvidas tanto no ITRI como no NLTG, neste projeto nos interessa as que envolvem estudos de córpus de textos instrucionais e os projetos relacionados a esse gênero de textos. Dois projetos são importantes nesta pesquisa: DRAFTER (DRafting Assistant For TEchnical wRiters) e AGILE (Automatic Generation of Instructions in Languages of Eastern Europe).

DRAFTER (Paris \& Scott, 1994; Delin et al., 1994; Paris et al., 1995) foi um projeto de quatro anos de duração que utilizou a tecnologia da geração multilíngue para dar suporte na produção de manuais de usuário de produtos de software em francês e em inglês. AGILE (Hartley et al., 2001) utilizou a tecnologia para geração de manuais de software em múltiplas línguas sem a necessidade de tradução, desenvolvida no projeto DRAFTER, para adicionar três novas línguas ao sistema de geração: búlgaro, russo e tcheco.

Diferente dos sistemas de geração automática de manuais de instrução, que deixam os autores fora do processo, focando na produção automática das instruções, o DRAFTER é uma ferramenta de apoio destinada a ser integrada ao ambiente de trabalho dos autores, visando o auxílio da produção e a automatização de algumas tarefas mais tediosas.

\footnotetext{
${ }^{14} \mathrm{http}: / / \mathrm{www}$. itri.brighton.ac.uk/aboutindex.html

${ }^{15}$ http://www.nltg.brighton.ac.uk/nltg/
} 
O primeiro passo para desenvolver o DRAFTER foi a realização de uma análise de requisitos dos usuários, identificando o ambiente amplo no qual a ferramenta proposta seria utilizada. Nessa análise de requisito, foram feitas entrevistas com autores técnicos, tratando de vários tópicos, desde as limitações de tempo e orçamento para essa área de trabalho, como também as partes do trabalho que eram consideradas interessantes, a dificuldade, entre outros. Os entrevistados explicaram a sucessão e a divisão do tempo na tarefa de criação de documentação. Além disso, a forma como os documentos eram desenvolvidos, as fontes de informações, e as tarefas e recursos utilizados foram identificados.

Os desenvolvedores do sistema relatam que uma das descobertas durante a análise de requisitos foi a de que os elaboradores de manuais gastam pouco tempo escrevendo textos novos. Grande parte do trabalho deles é atualizar os documentos existentes. Além disso, foram definidas cinco tarefas principais durante a análise das entrevistas. Elas são: aquisição de conhecimento, planejamento do documento, composição, validação e manutenção.

A tarefa de aquisição de conhecimento é muito difícil e ocupa tanto tempo quanto a própria escrita dos documentos técnicos. Os autores de manuais têm que trabalhar junto com os engenheiros e designers para obter informações sobre a estrutura e os procedimentos do produto, consultam o código fonte dos programas para ter acesso aos comentários e também experimentam protótipos do produto. No primeiro momento que os autores entram em contato com o produto, eles criam um modelo mental do mesmo, da perspectiva do usuário. Um registro formal desse modelo seria útil na documentação de subsequentes mudanças do produto pelo mesmo autor ou por colegas. Isto poderia ser usado quando um mesmo procedimento necessita ser explicado novamente em um contexto diferente. Apesar de importante, esse modelo não é criado explicitamente.

No planejamento do documento, os autores dos manuais devem estabelecer a estrutura geral e o objetivo do documento. A estrutura típica do um manual de instruções é ter um pequeno capítulo para cada tarefa, dividido em operações com cinco ou seis linhas.

Na composição, geralmente são feitos vários rascunhos para um documento. Os autores de manuais devem ser comunicadores eficientes, evitando jargões e transmitindo a informação com termos claros e concisos. Com treinamento e experiência, os autores se familiarizam com as normas padrões de redação técnica. A maioria das companhias também possui guias de estilo, que podem ser formais ou informais; podem, por exemplo, recomendar ou prescrever o uso de construções e terminologias específicas. Um guia de estilo 
rigorosamente formalizado impõe uma linguagem controlada, que pode ser difícil e demorada para se dominar.

A validação é feita por mecanismos de controle de qualidade que vão desde a leitura informal por colegas até a revisão formal feita por comitês. Algumas organizações passam os documentos finais por verificadores automáticos de gramática e terminologia.

A manutenção dos documentos é feita sempre quando um produto sofre alguma alteração. Uma grande parte do tempo dos autores é destinada a essa tarefa.

Após a análise das entrevistas e do entendimento da tarefa, foram definidas as funções desejáveis para uma ferramenta de suporte à escrita. São elas:

- Suporte para reuso de conhecimento através do auxílio da criação de um modelo de conhecimento adquirido pelos autores - Essa função seria útil para formalizar e organizar de maneira consistente o conhecimento adquirido, permitindo assim seu reuso e compartilhamento com colegas de trabalho.

- Produção de formulações alternativas quando possível - Os autores desejam a possibilidade de ter opções na hora de expressar um conjunto de instruções, pois existem vários caminhos para isso, e eles querem escolher a mais apropriada.

- Disponibilização dos primeiros rascunhos (daí o nome da ferramenta DRAFTER) produzidos simultaneamente em várias línguas - Quanto mais rápido os rascunhos forem disponibilizados, mais rápido serão descobertos quais conhecimentos estão faltando pra determinada língua, além de agilizar todo o processo.

- Propagação de alterações por todo o documento e línguas - Ao efetuar uma alteração no texto, as demais partes do documento que contêm a mesma informação também devem ser atualizadas.

- Suporte para terminologia consistente e precisa - termos técnicos devem ser empregados consistentemente dentro e entre documentos, mesmo se forem produzidos por autores diferentes.

- Manter a satisfação criativa da escrita técnica - uma ferramenta de suporte a escrita deve automatizar aspectos que os escritores acham tediosos, como por exemplo, revisão e alguns aspectos rudimentares da composição (terminologia e 
sintaxe), deixando o autor livre para trabalhar melhor na estruturação do conteúdo e transmissão das ideias.

Baseado na análise de requisitos que foi descrita até agora, foi planejado e implementado o DRAFTER. A arquitetura da ferramenta é mostrada na Figura 1.

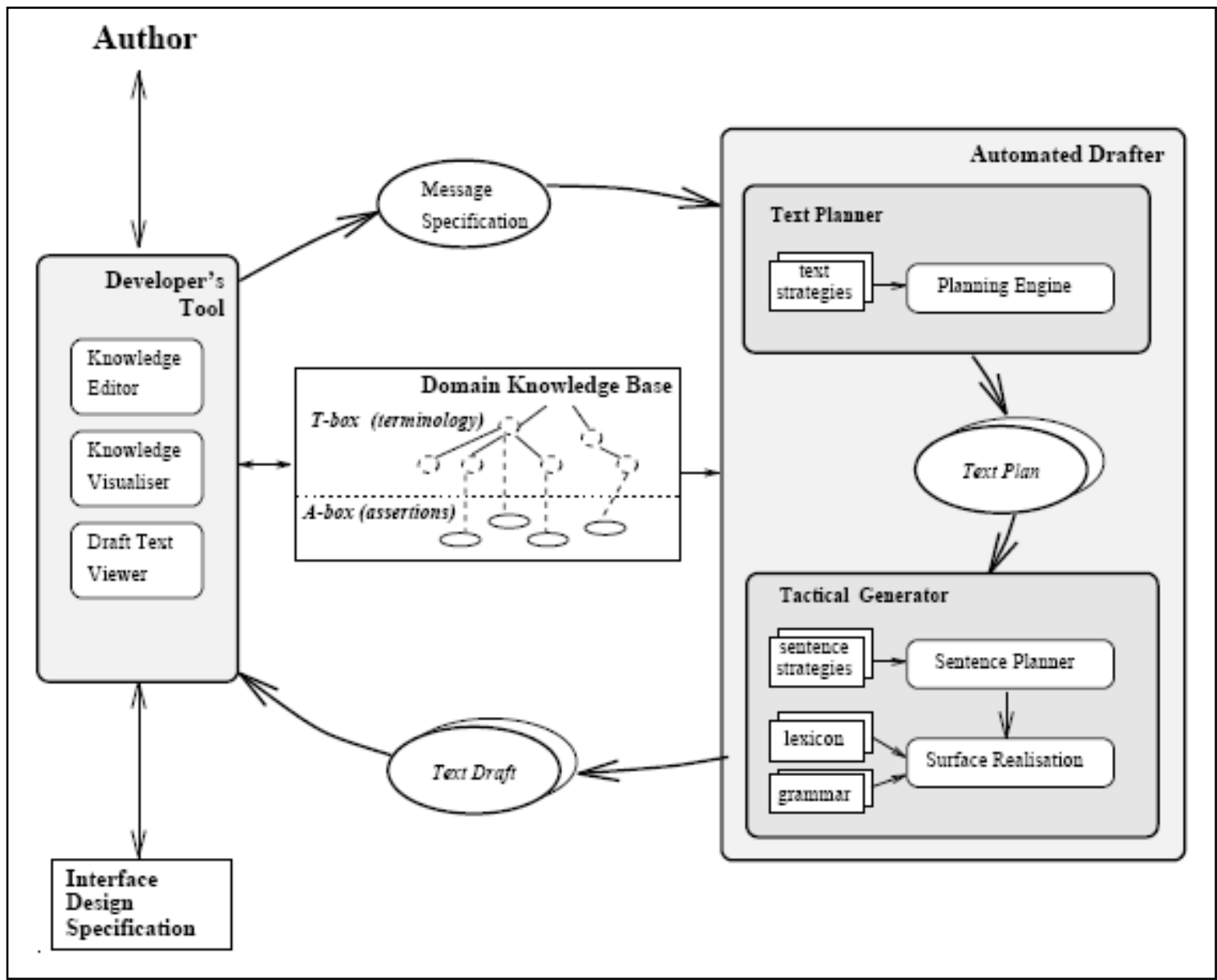

Figura 1 - Diagrama de Blocos da Arquitetura de DRAFTER (Paris et al., 1995)

O DRAFTER contém três módulos de processamento, que formam duas ferramentas de suportes principais:

- Uma interface para o escritor técnico. Permite ao autor especificar formalmente os procedimentos necessários para o usuário atingir seu objetivo. Ajuda também os escritores a controlar o processo de elaboração.

- A ferramenta de elaboração. Compreende dois componentes principais: o planejador estratégico e o gerador tático. O planejador estratégico determina o conteúdo e a estrutura do texto, e o gerador tático executará a realização das sentenças. O resultado será rascunhos das instruções em Inglês e Francês definidos pelo autor através da interface. 
Dando base aos componentes de processamento, existe um modelo do domínio, que é o repositório principal de informações sobre o domínio.

O Modelo do Domínio é uma coleção de entidades representando a informação comumente usada no domínio de software. Essas entidades incluem ações, estados, objetos e uma série de relações entre elas. Este conhecimento é derivado de um estudo de um córpus multilíngue de manuais de software, e é tratado como independente de língua, que é um requisito básico para geração multilíngue. Os autores usam os conceitos e relações do modelo de domínio para especificar os procedimentos apropriados para o sistema de software em particular que está sendo documentado. Este estudo de córpus é de fundamental importância para este mestrado e será descrito na Seção 2.2.2.1.

O DRAFTER fornece uma interface para criar e manter um registro formal do conhecimento que o autor aprendeu durante a tarefa de aquisição de conhecimento. Ela permite aos usuários especificar o conhecimento conceitual requerido para a tarefa a ser documentada, informação importante do ponto de vista do usuário. Ela explora o modelo de domínio para fornecer guia e estrutura. A interface engloba as seguintes funções:

- Construção e manutenção da base de conhecimento de afirmações que contém a descrição das funções que o usuário pode realizar com o software que está sendo documentado.

- Visualização dos aspectos da base de conhecimento.

- Visualização e edição dos rascunhos gerados automaticamente.

Todas essas funções são chamadas através de menus, ícones e outros objetos sensíveis ao mouse. A base de conhecimento de afirmações pode ser atualizada com a inclusão de novas informações. Essas alterações são feitas através de um editor de conhecimento. Através desse editor, o autor escolhe um nó apropriado no modelo de domínio no qual a nova informação será subordinada. Para isso, são usados menus para escolher o conceito a ser atualizado. Após a escolha do conceito, o sistema gera um formulário dinamicamente para que o autor entre com as informações. O sistema também possibilita a anotação de imagens com informação semântica.

O DRAFTER possui também um visualizador da base de conhecimento, que possibilita os autores consultar relacionamentos entre ações, métodos e sub-ações, através de uma forma gráfica. Além disso, o visualizador é integrado com as funções de construção e edição da base de conhecimento. 
Na visualização e edição dos rascunhos que foram gerados automaticamente, o texto é sensível ao mouse, permitindo ao autor consultar a base de conhecimento a partir da parte do texto que foi selecionado. Também é possível fazer alterações no texto que foi gerado automaticamente, através de um editor que também é disponibilizado.

O DRAFTER usa um sistema de planejamento de texto que monta uma árvore de discurso através de um objetivo comunicativo que foi informado pelo autor. A partir desse objetivo, o sistema busca em sua biblioteca de estratégias de discursos um plano capaz de atingir tal objetivo. Nessa árvore, o nó raiz representa o objetivo inicial que foi traçado pelo plano, e as folhas representam os passos a serem tomados. Essa árvore também inclui relações de coerência indicando como as várias partes dos textos são retoricamente relacionadas. Algumas limitações impostas pelos padrões da escrita ou pelo estilo da empresa podem ser unidas à estratégia de discurso, e pela associação de várias estratégias para o mesmo objetivo, é possível construir rascunhos alternativos, conforme desejado pelo autor.

A cobertura do gerador tático no inglês foi estendida para gerar os tipos de sentenças encontrados em manuais de instruções, e seu ambiente flexível foi usado para desenvolver uma gramática em francês.

\subsubsection{A Análise de Córpus no Projeto DRAFTER}

Nesta seção, descrevemos o trabalho de Paris \& Scott (1994) que apresenta um estudo sobre a variação estilística dos manuais de instrução. A pesquisa mostra que os manuais podem ter diferentes estilos, como por exemplo, o fato de nem todas as instruções serem registradas por meio de uma sequência de imperativos. Além disso, diferentes partes dos manuais usam diferentes estruturas de discurso e formas de realização. A análise de córpus deu suporte às decisões de geração multilíngue no projeto DRAFTER, descrito na Seção 2.2.2 Geração Multilíngue de Manuais de Instrução. Também, relatamos as frequências das formas gramaticais para expressar as relações gera e habilita, encontradas no córpus de instruções em português do estudo de Delin et al. (1994), por ser o português a língua de interesse deste trabalho de mestrado.

\subsection{Variação Estilística dos Manuais de Instrução}

Instruções são usadas para transmitir direções para se cumprir uma tarefa. Entre essas direções, estão incluídas ações que devem ser realizadas sobre instalações, manutenção e 
também avisos e alertas sobre a segurança da execução das tarefas. $\mathrm{O}$ modo mais direto de fazer com que o leitor execute uma tarefa é o uso de sequências de imperativos. Em Paris \& Scott (1994) foi verificada, na análise do córpus, que existe uma variação na transmissão das instruções, mostrando que em alguns casos são usadas declarações simples. Muitos podem considerar que declarações simples estão fora do escopo de instruções, mas o estudo também mostra que essas declarações são frequentemente instruções implícitas, como mostrado a seguir nos exemplos de Paris \& Scott (1994):

Imperativo: Coloque o filtro na jarra a vácuo para impedir a fuga de aroma e temperatura;

Declarações Simples: $O$ café pode ser filtrado diretamente na jarra. O suporte do filtro se encaixa perfeitamente na abertura da jarra, prevenindo a fuga do aroma do café.

Essas variações nos manuais de instruções estão ligadas à postura tomada pelo autor em relação ao leitor. Geralmente, diferentes posturas são adotadas na descrição de produtos e também em avisos e advertências. Essas posturas são geralmente uma decisão institucional do fabricante do produto, e são chamadas de "estilo da casa". Elas são usadas para projetar uma imagem da empresa para os leitores.

Na análise do córpus de Paris \& Scott (1994) com 30 manuais de produtos em inglês e francês que tinham entre 1 a 20 páginas tentou-se identificar as diferentes atitudes que os textos expressavam e as realizações. $\mathrm{Na}$ análise, foram identificados quatro tipos diferentes de postura que um manual pode adotar, com exemplos em francês e inglês mostrados na Figura 2, que são apresentados abaixo:

- Fornecimento de Informação: O texto concentra-se na informação factual a ser transmitida. Essa postura pretende aumentar o conhecimento do leitor sobre o produto/tarefa em questão. Para transmitir informação, os escritores mostram forte preferência pelo uso de declarações ativas simples.

- Elogio: O texto enfatiza os aspectos positivos do produto e parabeniza o leitor pela boa escolha na aquisição. Neste caso também são usadas declarações simples ativas, mas muito qualificadores são usados, geralmente são adjetivos positivos e superlativos. Eles são usados para mostrar a superioridade dos atributos do produto, o conforto, a qualidade do material, entre outros. 
(1) Information Provisio - from Dietrich self-cleaning enamel oven:

L'émail auto-nettoyant est de couleur brun foncé moucheté de blanc pour certaines piéces.

Loose English Translation: The self-cleaning enamel is dark brown, speckled with white on some parts.

(2) Information Provision - from HP LaserJet 4 Printer Installation Guide:

The optional 500-sheet paper tray assembly comes equiped with a tray housing and either a legal, letter, A4, and executive authorized HP dealer. The part number of the letter, A4 and executive multi-size paper tray is C2084B...

(3) Eulogy - from Sennheisser Headphones:

To wish to convince you of de superior quality of the dynamic open air headphone HD 40 would be something of a paradox as you are by now already in possession of this product. However, the arguments for the HD 40 are in fact very convincing:

- High quality reproduction.

- Extremely comfortable thanks to very low weight.

- Problem-free connection by means of universal connector.

- Very flat storage space thanks to turntable driver elements.

(4) Directive - from Krupp Expresso Coffee Machine:

Do not use or put down the appliance on any hot surface (such as a stove hot-plate) or in the vicinity of an open gas flame

(5) Directive - from Camping Stove: Camping Gaz International:

Utilisez toujours votre réchaud dans un endroit suffisamment aéré, sans l'envelopper dans un objet quelconque et pas trop prés de matières inflammables.

Loose English Translation: Always use your stove in a well ventilated place, without wrapping it in any object and no too close to flammable substances.

(6) Explanation - from Dietrich Oven:

To avoid heavy spittings on the sole plate, it is advisable to cover it with an aluminium foil.

(7) Explanation - from EMSA Thermos:

Attention: Pour éviter d'abimer le récipient en verre, ne remuez pas les boissons avec des cuillères métalliques.

Loose English Translation: Waring: To avoid damage to the glass jug, do not stir drinks with metallic spoons.

Figura 2 - Exemplos de posturas que um manual de produtos pode adotar (Paris \& Scott, 1994)

- Diretivas sobre como realizar uma tarefa: O leitor deve realizar uma tarefa exatamente como prescrita. A lógica por trás das prescrições não é considerada necessária. A função principal do manual de instruções é fazer com que o leitor execute ou evite ações específicas. O jeito mais simples de fazer isso é através do fornecimento de direções que o usuário deve tomar para fazer ou não alguma ação. A preocupação é que o leitor siga as instruções, e não que ele saiba o porquê da ação ser ou não executada. $\mathrm{O}$ texto leva a autoridade do autor sobre o leitor e o deixa sem escolha. São usados atos da fala de diretivas fortes como ordens e proibições. Explicações sobre essas diretivas raramente são dadas. A forma como essas diretivas são passadas para o leitor pode variar conforme o quanto o autor deseja ser pessoal/impessoal. Essas diretivas podem ser passadas através do uso de imperativos, quando o autor está bem "próximo" (referência direta) do leitor. Quando o autor não está tão próximo assim do leitor, o uso de "deve" na forma modal, acompanhado de um advérbio pode ser usado. Quando o autor está muito distante do leitor (a ordem não está referida diretamente ao leitor), as diretivas são dadas na forma passiva, ou através de verbos que requerem que o objeto se torne o sujeito sintático, junto com um advérbio para enfatizar. Em todos os casos, 
diretivas fortes podem ser transmitidas usando termos como "nunca" ou "sob nenhuma circunstância" como parte da sentença ou mesmo como uma sentença separada.

- Explicações sobre a melhor maneira de completar uma tarefa: O leitor recebe ajuda sobre como alcançar uma tarefa, e uma explicação do porquê deveria ser feito da maneira prescrita. Isto oferece uma oportunidade para o leitor de construir um modelo mental da tarefa ou do produto.

Através da análise do córpus, também foi definida a estrutura global dos manuais de instruções e quais as posturas adotadas em cada parte. O resultado da análise traz uma estrutura formada por seis partes principais, apresentada na Figura 3.

\footnotetext{
Informações gerais

Esta parte do manual contém agradecimentos pela compra do produto, uma descrição do produto com suas vantagens e uma lista de partes e também apresenta as condições de garantias (ou a falta delas). Nesta parte do manual, as posturas utilizadas são a de Fornecimento de informação e elogios.

Informações sobre segurança

Esta parte inclui avisos, conselhos gerais de segurança e passos cruciais que devem ser realizados, sejam eles para realizar a tarefa ou para obter melhores resultados. A postura tomada nesta parte pode ser o uso de diretivas ou de explicações.

Etapa de preparação ou instalação

Contém informações sobre como instalar o aparelho, ou sobre quais passos devem ser realizados antes do primeiro uso. O uso de diretivas e explicações é apropriado nesta seção.

Uso

Contém os passos ou ações que devem ser realizadas pelo leitor para usar o produto e atingir os objetivos de diferentes tarefas. O uso de diretivas e explicações é apropriado nesta seção.

Limpeza, Cuidado e Manutenção

Nesta seção o autor apresenta para o leitor como ele deve limpar e cuidar do produto. O uso de diretivas $e$ explicações é apropriado nesta seção.

Resolução de problemas

O objetivo desta parte do manual é ajudar o leitor a identificar a fonte do problema e fornecer informação sobre o que poderia acontecer de errado se um passo não for propriamente realizado. Ações a serem tomadas, junto com condições sobre as quais são apropriadas e soluções para os problemas, são fornecidas. A postura utilizada nessa seção é, geralmente, a diretiva.
}

Figura 3 - Estrutura Global de Manuais de Produtos (Paris \& Scott, 1994)

Alguns manuais contêm todas as seis partes da Figura 3, claramente indicadas. Entretanto, há manuais que, devido a problemas de espaço, principalmente, intercalam as 
partes. Um exemplo de intercalação de partes encontrada na análise de Paris \& Scott (1994) foi a apresentação de cuidados logo após uma tarefa ser expressa no manual. É importante notar que uma estrutura global, também chamada de estrutura esquemática, apresenta suas partes/componentes numa ordem esperada e, portanto, tal ordem das partes não pode aparecer aleatoriamente.

\subsection{Realização das Expressões Gera e Habilita em Português}

O trabalho de Delin et al. (1994) trata de textos originais nas línguas inglesa, francesa e portuguesa. Os resultados do estudo serviram de base para o projeto DRAFTER, pois informam quais são os mapeamentos mais comuns das relações gera e habilita para uma língua e se há ambiguidade entre as formas da língua para essas relações.

O córpus do português do Brasil foi formado por oito manuais de instrução, que possuem de 2 a 7 páginas. Os manuais são de produtos e são dirigidos para o público não especialista, que é o mesmo público que nos dedicamos neste projeto de mestrado. A avaliação de frequência se deu em 33 relações gera e 32 habilita. A maioria das relações gera envolvem o uso do conectivo "para" seguido de um infinitivo, como pode ser observado na Tabela 1.

Tabela 1 - Frequência das formas gramaticais em português para a relação gera (Delin et al., 1994).

\begin{tabular}{lcc} 
Forma gramatical & Contagem & Porcentagem \\
\hline Para + Infinitivo & 23 & $70 \%$ \\
Se + Subjuntivo & 3 & $9 \%$ \\
Para + Frases & 2 & $6 \%$ \\
Sequência & 1 & $3 \%$ \\
2 outras formas & 4 & $12 \%$ \\
\hline
\end{tabular}

Total: 33

Para relações habilita, o uso de sequências (Uma sequência de imperativos, tanto em frases consecutivas, ou dentro de frases e ligadas pela conjunção "e") é predominante, como mostrado na Tabela 2.

Tabela 2 - Frequência das formas gramaticais em português para a relação habilita (Delin et al., 1994).

\begin{tabular}{|c|c|c|}
\hline Forma gramatical & Contagem & Porcentagem \\
\hline Sequência & 25 & $78 \%$ \\
\hline Condição "depois" & 4 & $12 \%$ \\
\hline Condição "antes" & 3 & $9 \%$ \\
\hline
\end{tabular}




\subsubsection{Estrutura de Textos Instrucionais e Sistemas de Perguntas \&}

\section{Respostas}

No trabalho de Farida Aouladomar (Aouladomar, 2005a; 2005b; Aouladomar \& Saint-Dizier, 2005) foi feita uma análise da estrutura de perguntas procedimentais "Como?" e "Por quê?". Também foi feita uma pesquisa sobre a estrutura de textos procedimentais e as relações retóricas relevantes para responder as perguntas.

O trabalho é baseado na língua francesa e utiliza estudos baseados em córpus de sistemas de perguntas e respostas procedimentais de vários domínios, entre eles estão saúde, educação, turismo, comportamento social, ciência da computação e manutenção.

As perguntas procedimentais geralmente são introduzidas pelo pronome interrogativo “Como”. No entanto, existem vários casos em que esse pronome não está relacionado com perguntas procedimentais, como por exemplo:

- Situações nominais: Como isto se chama?

- Situações causais: Como isto aconteceu?

- Situações booleanas (Verdadeiro ou Falso): Você vai de carro ou ônibus?

- Usado como forma instrucional: Como cuscuz é comido em Marrocos?

- Situação de escolha: Como posso pagar o ingresso?

A única situação nesta análise em quem o pronome "Como" é usado em perguntas procedimentais é a situação instrucional:

\section{Como posso trocar o pneu do meu carro?}

Existem outras formas de iniciar uma pergunta procedimental:

- Na forma de "O que fazer para...": O que fazer para conseguir um visto para os Estados Unidos?

- Perguntas usando ("É possível” ou "Posso") + Sintagma verbal: É possível criar diretórios usando php?

Existem quatro categorias conceituais para perguntas procedimentais que foram encontradas em $90 \%$ dos casos do córpus de estudo. Para terem uma análise que é simples e fácil de adaptar para outras línguas, foram consideradas as categorias básicas de verbos, como 
as utilizadas na WordNet (Fellbaum, 1998) que foram adaptadas para o francês em (SaintDizier, 1998). As categorias são apresentadas a seguir:

- Ação: Caracterizada pelo uso de verbos de mudança, criação e destruição e manutenção: construir, revisar, montar, desmontar, reparar, mudar. Aparecem em textos procedimentais de receitas, guias "Faça você mesmo", manuais de manutenção e construção.

- Comunicação: Caracterizada pelos verbos de interação social e verbos psicológicos: Contatar, negociar, convencer, gerenciar. Estes aparecem em horóscopos, guias de gerenciamento e educação.

- Aquisição de conhecimento: Caracterizada principalmente por verbos de cognição e verbos que expressam formas de transferência de conhecimento: Aprender, resolver, melhorar. Estes tipos de textos são encontrados em enciclopédias e textos didáticos.

- Itinerário: Caracterizada por verbos de movimento: ir, alcançar, acessar. Aparecem em guias de viagem e de conduta.

A representação das perguntas procedimentais, utilizada em experimentos com perguntas procedimentais curtas, possui o formato:

\section{Pergunta (procedimento (tipo), foco, restrições).}

Tipo é uma dos quatro categorias que foram apresentados anteriormente, foco é geralmente o sintagma verbal: o predicado e seus argumentos, que caracterizam o objetivo e as restrições são compostas por adjuntos do predicado. Como exemplo, a pergunta:

Como reservar um voo na web?

É representado da seguinte maneira:

Pergunta (procedimento (ação), [reservar (verbo, morfológico), voo (substantivo, transporte)], [na (preposição, meio)], [web (substantivo, comunicação)])

A estrutura de textos procedimentais foi elaborada na forma de uma gramática. Nesta gramática, parênteses representam opcional, + significa iteração, a vírgula é usada apenas com um separador, / significa "ou" e o operador < indica a precedência preferida. Estes símbolos correspondem a etiquetas em XML, e permitem a anotação dos textos instrucionais.

O nó topo é denominado objetivo: 
Objetivo -> título, (sumário), (advertência), (pré-requisitos), (figura)+ < sequências de instrução.

Sumário -> título+. Descreve a organização global do procedimento. Útil quando o procedimento é complexo.

Advertência -> texto, (figura)+, (pré-requisitos). Representam precauções globais e prevenções associadas com ações ou objetivos.

Pré-requisitos -> lista de objetivos, sequência de instruções. Descreve todo tipo de equipamento necessário para executar determinada tarefa.

Figuras servem para demonstrar esquemas de montagens e diagramas de vários tipos. São usadas para tornar as instruções mais claras.

Sequências de instruções são estruturadas da seguinte forma:

Sequências de instruções -> seqint < conectores discursivos < sequências de instruções / seqint.

Seqint é um dos quatro tipos abaixo:

Seqint -> (objetivo), sequência imperativa linear / (objetivo), sequência opcional / (objetivo), sequência alternativa / (objetivo), sequência imperativa co-temporal.

Cada tipo de sequência de instrução é definido a seguir:

Sequência imperativa linear $\rightarrow$ instrução < (marca temporal), sequência imperativa linear / instrução.

Sequência opcional -> expressão condicional, sequência imperativa linear.

Sequência alternativa - > (expressão condicional), sequência imperativa linear, (marca de oposição alternativa) < seqint / (expressão condicional, seqint)+

Sequência imperativa co-temporal -> sequência imperativa linear < marca cotemporal < sequência imperativa co-temporal / instrução.

Finalmente, a instrução é o último nível e possui recursão no objetivo:

Instrução -> (expressão iterativa), ação, (objetivo)+, (referência)+, (maneira)+, (motivação), (limite), (figura)+, (advertência) / objetivo.

A estrutura retórica desempenha vários papéis nesta abordagem. Ela contribui para reforçar a produção de respostas bem formadas, permite a integração entre textos procedimentais com objetivos similares, apesar de ser uma tarefa difícil, e também é usada para responder perguntas com uma alta exatidão por identificar claramente instrumentos, 
riscos e equipamentos necessários. Foram identificadas 17 relações retóricas na análise do córpus, que serão apresentadas a seguir:

- Sequência: é uma relação multi-núcleo onde os núcleos são ligados por uma relação de sucessão.

- Resultado: especifica que uma ação não pode começar antes que o resultado desejado de uma ação anterior seja alcançado.

- Propósito: ocorre entre o objetivo e as ações destinadas a alcançar tal objetivo.

- Avaliação: é uma pequena diferença entre o propósito e a relação de resultado porque é possível avaliar quando a ação foi feita corretamente ou não.

- Limite: Liga uma ação com um satélite que representa uma interrupção.

- Alternativa: liga duas ações alternativas.

- Meios: É a ligação entre uma ação e os instrumentos necessários para executar tal ação.

- Referência: Encontra-se entre uma ação e um seguimento que fornece a localização de um procedimento no texto ou em textos relacionados através de um hyperlink.

- Pré-requisitos: ocorre entre um objetivo ou ação e uma lista de instrumentos sem os quais a ação ou objetivo não é realizado.

- Opção: é considerada quando uma ação depende da realização de uma situação condicional.

- Prevenção: Relação normalmente encontrada entre uma ação e uma advertência.

- Condição: aparece quando a ação resulta da ocorrência de uma situação condicional.

- Co-ocorrência: ocorre quando o núcleo é ligado por uma relação co-temporal.

- Concorrência: ocorre entre duas ações co-temporais rivais.

- Motivação: ocorre quando a informação enviada pelo satélite faz com que o leitor aumente a vontade de executar a ação.

\subsection{Considerações Finais}

O estudo das linguagens controladas e dos sistemas de geração automática de manuais evidenciou a importância da inteligibilidade dos textos instrucionais. Além disso, esse estudo trouxe informações acerca da estrutura e variações estilísticas dos manuais de instruções, tornando clara a organização estrutural de um manual de instrução. 
As relações gera e habilita se mostraram como essenciais no escopo de um manual de instrução. Essas relações representam as instruções propriamente ditas em um manual de instrução e, portanto, se tornam o alvo ideal para extração de termos. 


\section{Métodos de Extração Automática de Termos}

Devido ao grande volume de informação técnica disponível nos últimos anos, juntamente com a expansão da internet, a tarefa manual de extração de terminologia tornou se inviável.

Um sistema de extração automática de candidatos a termo (SEACAT) é formado por um conjunto de programas para o reconhecimento de unidades terminológicas de córpus (Estopà Bagot, 1999). Os candidatos a termos devem ser, posteriormente, validados por humanos. O objetivo dos SEACAT é a automatização da fase de seleção de todas as unidades terminológicas de um texto especializado.

Os SEACAT são classificados conforme a metodologia que utilizam para reconhecer as unidades terminológicas. São três as metodologias utilizadas (Teline, 2004):

- Metodologia baseada em conhecimento linguístico;

- Metodologia baseada em conhecimento estatístico;

- Metodologia híbrida, baseada em conhecimento linguístico e estatístico.

Essas metodologias serão detalhadas a seguir.

\subsection{Métodos Linguísticos}

Os métodos baseados em conhecimento linguístico utilizam diferentes recursos que fornecem diferentes informações linguísticas, que são usadas para a extração dos termos:

- Lexicográficas: dicionários de termos e lista de palavras auxiliares ("stopwords")

- Morfológicas: padrões de estrutura interna da palavra

- Morfossintática: categorias morfossintáticas e funções sintáticas

- Semânticas: classificações semânticas

- Pragmáticas: representações tipográficas e informações de disposição do termo no texto.

De acordo com Estopà Bagot (1999), a grande quantidade de ruído gerada (entre 55\% e 75\%) é um dos grandes problemas da abordagem linguística. Além disso, ela é dependente da língua para qual foi desenvolvida, e também pode ser dependente de uma única variante. Dessa forma, a aplicação de um método linguístico, desenvolvido para uma determinada língua, deve ser reavaliado e adaptado para outra língua. 
O trabalho de Heid et al. (1996) propõe um algoritmo com duas fases. A primeira fase consiste no pré-processamento linguístico e anotação automática dos textos. Na segunda fase são feitas as consultas ao córpus e a extração de informações relevantes.

O trabalho de Klavans e Muresan (2000; 2001a; 2001b), propõe um sistema baseado em regras que explora artigos orientados ao consumidor a fim de extrair definições e os termos que eles definem. Esta pesquisa pertencente ao Projeto de Biblioteca Digital na Universidade de Columbia. Uma meta desse projeto é apresentar definições precisas e legíveis de termos técnicos, que podem ser encontrados em artigos que apresentam complexidade intermediária, através do uso de uma linguagem que seja compreensível aos usuários. $\mathrm{O}$ algoritmo consiste na combinação de técnicas superficiais de processamento de língua natural com análise gramatical, com o intuito de explorar textos eficientemente. É baseado em dois módulos:

1) Módulo de processamento de texto superficial que realiza análise de padrões com o uso de uma gramática de estado finito guiada por expressões linguísticas, e um conjunto limitado de marcadores de texto, representado, por exemplo, por indicadores estruturais.

Esse módulo é baseado num POS tagger e na gramática de estado finito para identificar termos médicos e extrair definições. Na identificação de frases nominais simples foram utilizados um etiquetador e o analisador sintático parcial (chunker) de sintagmas nominais.

2) Módulo de análise gramatical que utiliza uma rica gramática lexicalista orientada à dependência para analisar fenômenos linguísticos mais complexos, como aposição e anáfora.

\subsection{Métodos Estatísticos}

Os métodos baseados em conhecimento estatístico geralmente utilizam a frequência de palavras para detectar candidatos a termos. Outro detalhe do método estatístico é a sua dependência no tamanho do córpus. Se o córpus é pequeno, poucos termos são encontrados do total existente, e mesmo quando o córpus é grande, alguns são excluídos, pois têm baixa frequência.

Além disso, sistemas estatísticos geram bastante ruído, que são candidatos a termos que não possuem valor terminológico, ou seja, são palavras pertencentes à língua geral. 
Outra característica que diferencia o método estatístico do método linguístico é a independência de língua.

Métodos puramente estatísticos para a extração automática de termos são pouco utilizados, pois a maioria dos métodos implementados são os híbridos. As principais medidas utilizadas no método estatístico de extração automática de termos são os seguintes:

- Frequência de ocorrência (Daille, 1996; Manning; Schütze, 1999): É a medida mais simples para se encontrar termos em córpus. Se duas palavras aparecem frequentemente juntas, existe a possibilidade das palavras representarem uma função especial. No entanto, existe o risco de palavras funcionais, como artigos e preposições, serem selecionadas como candidatos a termos. Este método é independente de domínio e recursos externos, mas ele é fraco para recuperar termos com baixa frequência.

- Informação mútua (Pantel \& Lin, 2001): É uma medida de informação que uma variável contém sobre outra, sendo ela a redução da incerteza de uma variável randômica devido ao conhecimento da outra. Os cálculos são feitos usando a probabilidade das palavras ocorrerem num córpus de tamanho N. Esta medida foi usada inicialmente para extração de colocações $^{16}$. Quando palavras ou termos são adjacentes, a informação mútua é maior. Da mesma forma que a frequência de ocorrência, esta medida não é eficiente para extrair termos com baixa frequência.

- Coeficiente log-likelihood (Pantel \& Lin, 2001): Esta medida foi utilizada para amenizar o problema de recuperação de termos de baixa frequência da medida mútua. A diferença dela para a informação mútua, é que ela também considera termos raramente adjacentes como fortes candidatos a termos.

- Coeficiente Dice (Manning; Schütze, 1999): É uma medida similar à informação mútua, que faz um cálculo para saber o nível de relação entre duas palavras. A diferença desta medida para a informação mútua, é que esta não depende do tamanho da amostra.

- C-value (Frantzy \& Ananiadou, 1997): Esta medida é utilizada para extração de termos compostos. Ela é baseada na frequência de cadeias no córpus, porém ela

\footnotetext{
${ }^{16}$ Duas ou mais palavras que aparecem juntas frequentemente.
} 
utiliza um cálculo para evitar que subcadeias de cadeias já extraídas sejam consideradas candidatas a termos.

\subsection{Métodos Híbridos}

Os sistemas híbridos combinam conhecimentos linguísticos com conhecimentos estatísticos, e conseguem os melhores resultados. A ordem em que os conhecimentos são aplicados influencia os resultados. Sistemas em que o método estatístico é aplicado após o linguístico são os que geram melhores resultados, pois o conhecimento estatístico funciona como um complemento para o linguístico.

\subsection{O Trabalho de Teline (2004)}

Teline (2004) fez uma avaliação de métodos das três abordagens de extração automática de termos, descritos nas seções prévias. Foi utilizado um córpus contendo 164 artigos da área de Revestimentos Cerâmicos. O córpus analisado possuía 448.352 palavras. A lista de referência de termos possuía 381 termos (264 unigramas, 74 bigramas e 43 trigramas).

$\mathrm{Na}$ abordagem estatística foram usadas as medidas de frequência para unigramas, Frequência, Informação Mútua, Log-Likelihood e Coeficiente Dice para bigramas e para trigramas foram usadas Frequência, Informação Mútua, Log-Likelihood. Em seguida foi feita uma análise manual da lista de unigramas e bigramas candidatos a termos. Esta intervenção foi feita com o intuito de eliminar palavras e siglas da língua geral, marcas publicitárias, nomes próprios e símbolos especiais. Neste caso, o método estatístico com intervenção humana é considerado um método semiautomático.

$\mathrm{Na}$ abordagem linguística foi feito um pré-processamento no córpus para permitir a realização de consultas sobre o mesmo. O primeiro tipo de consulta realizada no córpus é a busca por expressões e indicadores estruturais, que são expressões linguísticas que geralmente vêm acompanhadas de definições, descrições e outros tipos de orações que concentram termos. Em seguida é feita uma busca de padrões morfossintáticos (Ex. Substantivo + adjetivo). Além disso, nesta abordagem é feito o uso de uma stoplist, que é uma lista contendo palavras da língua geral.

$\mathrm{Na}$ abordagem híbrida, foi feito o processamento do córpus e buscas por expressões e indicadores estruturais, em seguida foram aplicados métodos estatísticos (cálculo de 
frequência para unigramas, bigramas e trigramas e informação mútua para bigramas). Após essas etapas, foi feita uma intersecção com a lista de padrões morfossintáticos.

Para avaliar o desempenho dessas abordagens, foram utilizadas métricas clássicas da área de processamento de sinais, como a Precisão e Cobertura. Precisão é a razão das respostas corretas recuperadas pelo sistema e todas as respostas recuperadas, e Cobertura é a razão de respostas corretas e todas as respostas corretas possíveis.

Dentre os métodos implementados, o que retornou a melhor precisão foi o método semiautomático (estatístico + intervenção humana), seguido pela abordagem híbrida, estatística e por último, a linguística. Os resultados da precisão podem ser observados na Figura 4.

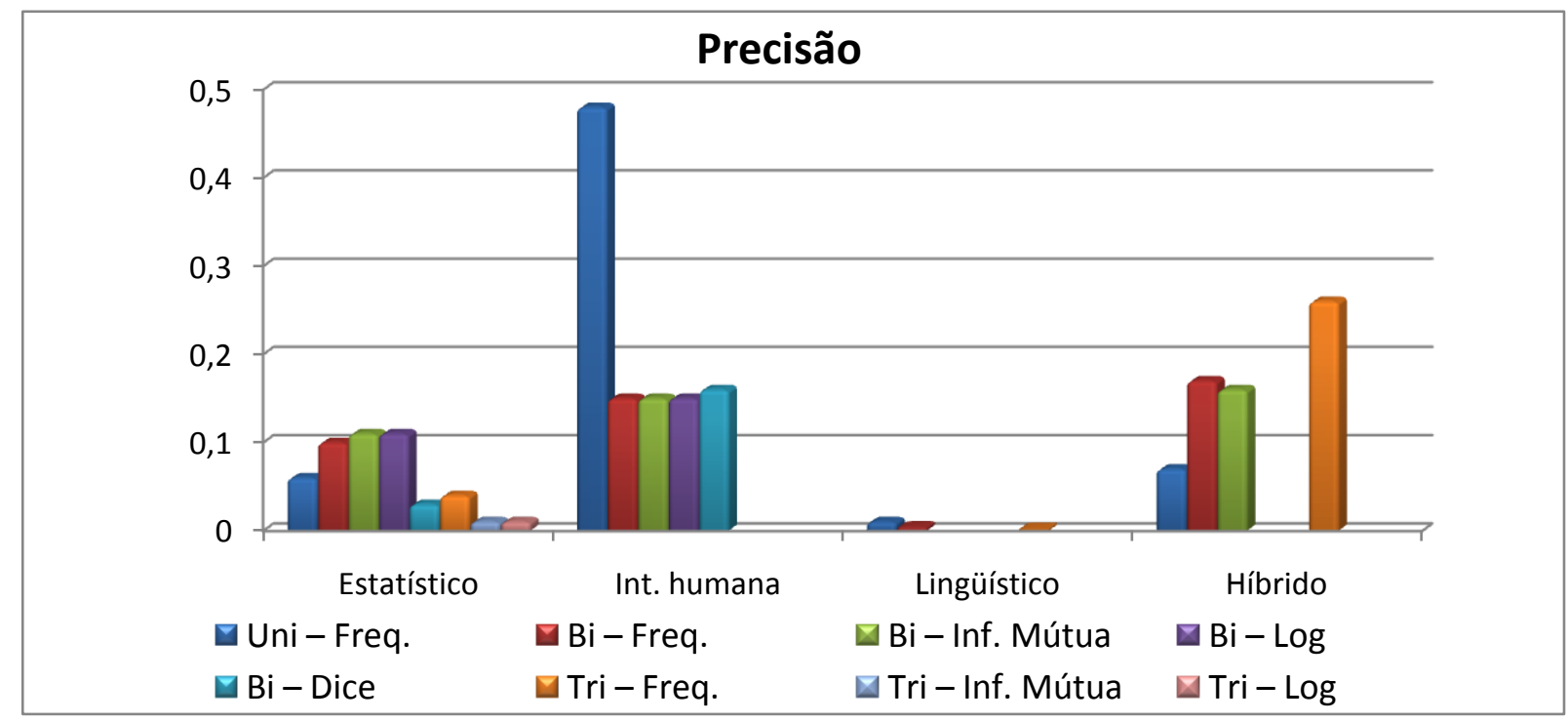

Figura 4 - Precisão obtida pelas três abordagens e a semiautomática (Teline, 2004)

Para cobertura, a abordagem linguística retornou os melhores resultados, seguidos pela semiautomática, estatística e híbrida. Os resultados de cobertura obtidos podem ser observados na Figura 5.

Para calcular o desempenho da tarefa, é usada a medida F, que é uma medida que permite colocar ênfase na precisão e na cobertura, sendo B um parâmetro que representa a importância relativa da precisão e cobertura. $\mathrm{Se} B=1$, ambos representam a mesma importância. Se B > 1, a precisão é mais relevante, caso B < 1, a cobertura é mais relevante:

$$
F=\frac{\left(B^{2}+1\right) * \text { precisão } * \text { revocação }}{B^{2} *(\text { precisão }+ \text { revocação })}
$$




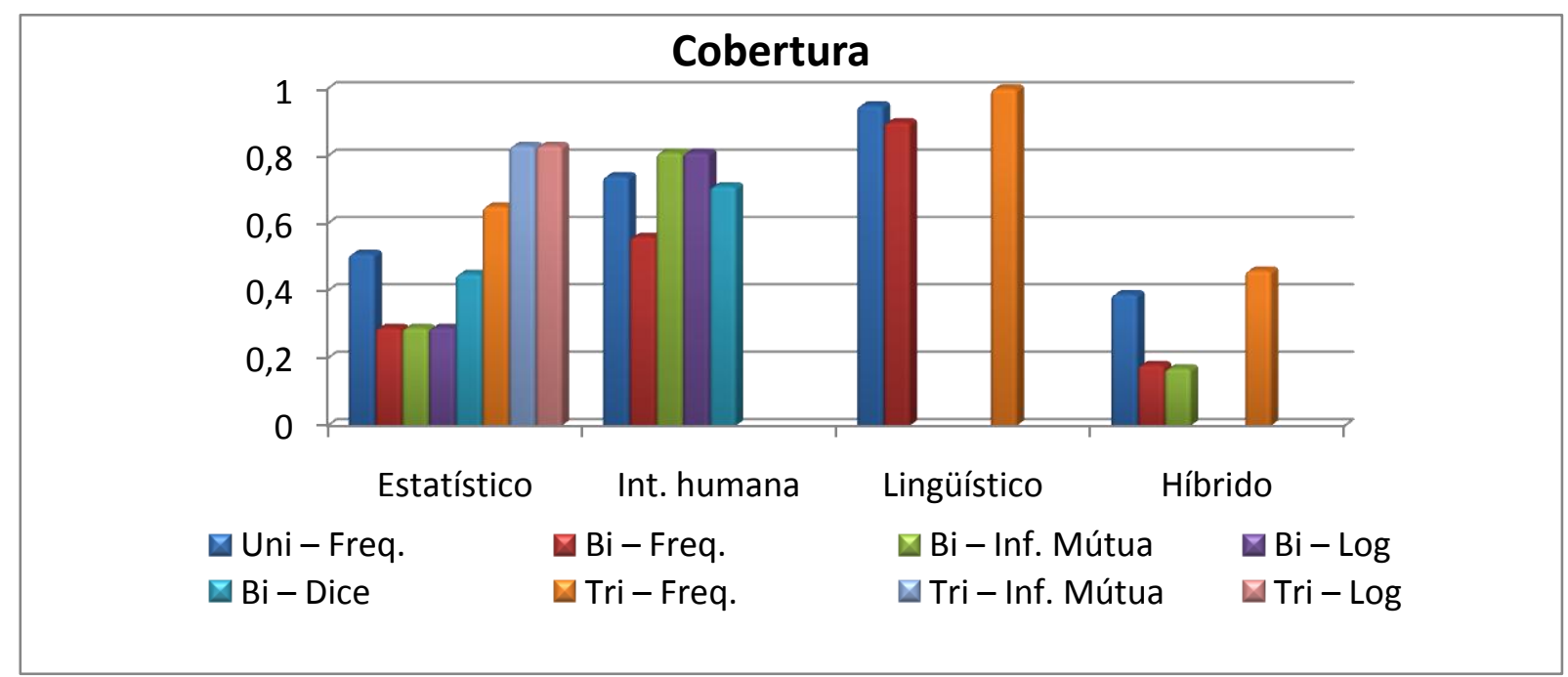

Figura 5 - Cobertura obtida pelas três abordagens e a semiautomática (Teline, 2004)

Novamente, o método semiautomático retornou os melhores resultados para a medida F, seguido da abordagem híbrida, estatística e linguística, respectivamente. Os valores obtidos podem ser observados na figura 6.

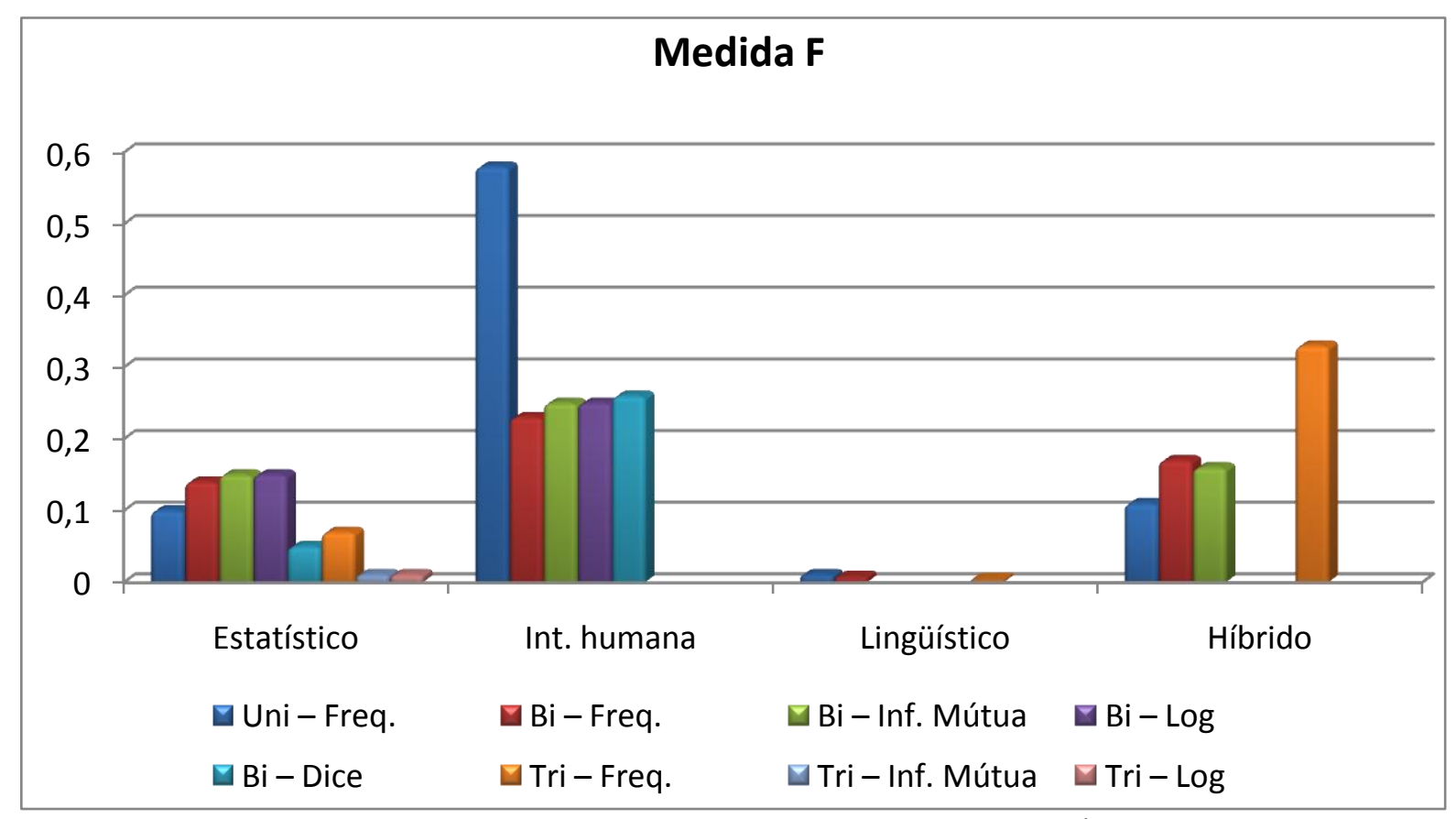

Figura 6 - Medida F obtida pelas 3 abordagens e a semiautomática (Teline, 2004)

A partir da análise dos resultados, concluiu-se que o método estatístico depende fortemente de uma intervenção humana para gerar resultados satisfatórios, e que o fato da medida F não ser tão alta (abaixo da média de 60\%, que é o normal para tarefa) se justifica pelo fato de que o córpus foi compilado a partir de uma única fonte. 


\subsection{O Trabalho de Ribeiro Jr (2008)}

No trabalho sobre construção de ontologias de Ribeiro Jr (2008) foi necessário fazer uso da extração automática de termos. Neste caso, foi utilizada uma abordagem híbrida. Os conhecimentos linguísticos utilizados foram a análise da classe gramatical, de sintagmas nominais e o uso de padrões morfossintáticos.

Em seguida, foram aplicados cálculos de relevância de frequência, $t f-i d f$ (Medida que considera relevantes os termos que possuem alta frequência de ocorrência em número limitado de documentos) e NC-Value, que estão descritos em (Ribeiro Jr, 2008).

Para avaliar o método, foi utilizado um córpus da área de Ecologia (Zavaglia et al., 2007) constituído por textos extraídos de partes dos livros "A Economia da Natureza" e "Ecologia", além de revistas presentes no projeto LácioWeb ${ }^{17}$. O córpus conta com um total de 260.921 palavras.

$\mathrm{Na}$ extração de unigramas, houve um empate de desempenho entre o uso das classes gramaticais e o núcleo do sintagma nominal combinado com o cálculo NC-Value usando $t f-i d f$ como parâmetro de frequência obtiveram os melhores índices de precisão (14,7\%), cobertura $(49,96 \%)$ e medida F $(22,39 \%)$.

Para extração de bigramas, o melhor método foi o uso de padrões morfossintáticos com o cálculo de relevância de frequência, obtendo índice de precisão de 5,7\%, cobertura de $41,91 \%$ e medida $\mathrm{F}$ de $10,04 \%$.

$\mathrm{Na}$ extração de trigramas, a melhor estratégia foi o uso de padrões morfossintáticos com o cálculo de relevância $t f$-idf, obtendo índice de precisão de 2,9\%, cobertura de $46,77 \%$ e medida $\mathrm{F}$ de $5,46 \%$.

Outra abordagem feita por (Ribeiro Jr, 2008) foi a adição do uso de conhecimento semântico extraído através do parser PALAVRAS (Bick, 2000) no método de extração híbrido. Nesta abordagem, é necessária a intervenção humana para escolher quais grupos semânticos serão utilizados na extração de termos, o que pode influenciar no resultado dependendo do nível de conhecimento do domínio da pessoa que fizer essas escolhas. Nos experimentos feitos por (Ribeiro Jr, 2008), o uso de conhecimento semântico trouxe um aumento médio de 17,33\% na precisão de extração de unigramas, aumento de 20,67\% na precisão de extração de bigramas e um aumento de 6,66\% na precisão de extração de trigramas. O sistema de extração foi incorporado no OntoLP, um plugin que serve de auxílio à engenharia de ontologias com base em córpus anotado da língua portuguesa.

${ }^{17}$ http://www.nilc.icmc.usp.br/lacioweb/ 


\subsection{O trabalho de Lopes et al. (2010)}

O trabalho de Lopes et al. (2010) apresentou uma avaliação da extração de termos compostos para um córpus do domínio de pediatria, constituído por 283 textos e 785448 palavras do Jornal de Pediatria ${ }^{18}$. A extração de termos foi feita usando três métodos diferentes e seu desempenho foi avaliado através do cálculo da precisão, cobertura e medida $\mathrm{F}$, com base numa lista de referência de termos compostos feita à mão.

A extração automática de termos foi realizada em três etapas: anotação linguística do córpus; extração de termos usando a ferramenta OntoLP (citada na Seção 3.5) e a seleção de termos pelo ponto de corte. A etapa de anotação linguística foi feita pelo parser PALAVRAS, que teve como entrada textos no formato ASCII (txt) e retornou arquivos XML contendo todas as palavras e suas características morfológicas. Na etapa de extração de termos, os arquivos XML foram usados como entrada na ferramenta OntoLP. Para extrair termos simples, foi usado o método de extração através da classe gramatical. Na extração de termos compostos, três métodos foram usados. O primeiro foi o método $n$-grama (NG), que extrai uma sequencia de $n$ palavras do texto e usa medidas estatísticas para avaliar a probabilidade de que cada sequência tem de ser classificada como termo. Este é um método puramente estatístico. O segundo método foi o de padrões morfossintáticos (MP), que identifica termos através da combinação de palavras que seguem um determinado padrão gramatical, como por exemplo, "substantivo-preposição-substantivo". O último método utiliza sintagmas nominais anotados pelo parser PALAVRAS para tentar identificar termos que podem estar presentes em seu núcleo.

A última etapa da avaliação consistiu na ordenação da lista de candidatos a termos pela relevância e pela diminuição da quantidade de candidatos irrelevantes através de um ponto de corte. Neste caso, a relevância dos candidatos a termos foi calculada através da frequência. No experimento realizado, foram usados pontos de corte absolutos, (por exemplo, termos com frequência menor que $10^{-5}(1 \mathrm{E}-5)$ foram descartados) e pontos de corte relativos (por exemplo, os primeiros $20 \%$ termos da lista ordenada).

A análise dos resultados do experimento com ponto de corte absoluto mostrou que a melhor medida F para bigramas foi para o método de padrões morfossintático, com valor de 0.5684 em 6E-6, contra 0.5478 em 6E-6 para o método de $n$-gramas e 0.4437 em 4E-6 para o

\footnotetext{
${ }^{18}$ http://www.jped.com.br/
} 
método de sintagmas nominais. Para trigramas, a melhor medida $F$ foi 0.5211 em $6 \mathrm{E}-6$ no método de $n$-gramas, contra 0.4612 em $6 \mathrm{E}-6$ no método de padrões morfossintáticos e 0.3671 em 4E-6 para sintagmas nominais.

$\mathrm{Na}$ análise dos resultados do experimento com ponto de corte relativo, a melhor medida $\mathrm{F}$ para bigramas foi obtida pelo método de padrões morfossintáticos com valor de 0.5547 em $10 \%$, contra 0.5233 em $10 \%$ no método de $n$-gramas e 0.4393 em $10 \%$ para sintagmas nominais. Para trigramas, a melhor medida $\mathrm{F}$ foi de 0.4831 em $5 \%$ no método de $n$ gramas, contra 0.4539 em 5\% no método de padrões morfossintáticos e 0.3510 em $10 \%$ para o método de sintagma nominal.

\subsection{Considerações Finais}

O estudo dos métodos de extração automática de termos e dos trabalhos neste capítulo serviu como base para a criação do método de extração automática de termos de manuais de instruções do projeto NorMan, que é baseado no método híbrido, utilizando padrões morfossintáticos, a identificação das relações gera e habilita e o cálculo do C-Value, utilizado para ranquear os candidatos a termos. 


\section{O Projeto NorMan}

Este capítulo é dividido em três grandes seções, uma dedicada ao método de extração de termos proposto para o gênero de manuais técnicos, chamado aqui de Norman Extractor, (Seção 4.1), outra que apresenta o cenário de aplicação do método (Seção 4.2), pois este trabalho se desenvolveu no escopo do projeto PorSimples, apresentado na Introdução, e a última dedicada à apresentação do Portal do projeto no qual o método Norman Extractor foi disponibilizado (Seção 4.3). Da mesma forma que o PorSimples, este mestrado tem como um de seus objetivos auxiliar no processo de produção de textos simplificados para analfabetos funcionais.

Apresentamos o córpus de estudo para a criação e avaliação do método de extração híbrido dedicado a manuais técnicos na Seção 4.1.1 e o método de extração em si, com suas várias etapas, recursos linguísticos e métrica escolhida para o ranqueamento de candidatos a termos na Seção 4.1.2. Embora Delin et al. (1994) tenha realizado um estudo de córpus em português sobre as relações gera e habilita, neste mestrado aumentamos o escopo de análise, com um córpus de 50 manuais. $\mathrm{Na}$ Seção 4.2.1, apresentamos o Editor de Textos SIMPLIFICA e seus três módulos: a Simplificação Léxica (módulo de interesse para esta dissertação de mestrado), a Simplificação Sintática e a Avaliação da Complexidade de Textos. O módulo de Simplificação Léxica (Seção 4.2.1.1) foi adaptado para receber uma nova lista de termos técnicos, extraídos pelo NorMan Extractor, de um dado produto tecnológico quando este for dedicado a tratar textos de manuais. O uso desta nova lista é duplo, pois pode auxiliar na identificação de termos que: (a) não devem ser simplificadas pelo método de simplificação léxica baseado em sinônimos, e (b) que podem receber uma elaboração léxica para facilitar o seu entendimento (Seção 4.2.1.2).

\subsection{O Método de extração de termos dedicado a manuais técnicos - Norman Extractor}

\subsubsection{Seleção do Córpus de trabalho}

Para a execução deste projeto, foi necessária a criação de um córpus de manuais de instruções. O primeiro passo foi determinar quais seriam os tipos de produtos que teriam os manuais avaliados. Baseado no objetivo geral do projeto, que é o estudo da simplificação de manuais de instruções, foram selecionados cinco categorias de produtos eletrodomésticos facilmente encontrados no comércio e na residência das pessoas. Para impedir que características 
individuais de produtos interferissem na análise, decidimos por uma amostragem ampla em que cada categoria de eletrodomésticos teria 10 exemplares de manuais de marcas distintas, resultando em um córpus de 50 manuais. As categorias de eletrodomésticos escolhidas foram as seguintes:

- Centrífuga de alimentos;

- Ferro de passar roupa;

- Fogão;

- Secador de cabelo;

- Televisor.

Após a determinação das categorias e da quantidade de manuais que deveriam ser recolhidos, foi feita uma busca na internet, em lojas virtuais, que comercializavam os eletrodomésticos das categorias selecionadas. Estes web sites geralmente fornecem uma cópia do manual no formato eletrônico PDF. Foram visitados vários web sites diferentes para recolhermos o total de 10 manuais por categoria.

O próximo passo foi a conversão dos manuais do formato PDF para o formato de texto puro (TXT), que é o formato mais simples, livre de formatação e que é amplamente utilizado em tarefas de processamento de texto.

Após a conversão dos 50 documentos, foi feita uma análise nos manuais para determinar quais eram as seções comumente encontradas em todos eles. Tomando como base a estrutura global dos manuais de instruções, com seis partes, apresentada na Seção 2.2.2.1.1, as oito seções encontradas foram as seguintes:

- Agradecimentos: Nesta seção, o leitor é parabenizado pela aquisição do produto. Além disso, existe normalmente um aviso para que o leitor leia atentamente e guarde o manual para eventuais consultas.

- Componentes: Nesta seção, o manual apresenta para o leitor quais são as peças e componentes presentes no produto. Geralmente esta seção também vem acompanhada de imagens ilustrativas.

- Garantia: Nesta seção, são apresentados os termos de garantia e uso dos eletrodomésticos. 
- Precauções: Esta seção explica ao leitor quais os cuidados que devem ser tomados ao utilizar o aparelho a fim de evitar acidentes, danos no aparelho e até mesmo garantir o bom funcionamento do mesmo.

- Instalação: Aqui, o manual apresenta ao leitor quais os passos devem ser tomados para a instalação e montagem do aparelho antes do uso.

- Instruções: A seção de instruções detalha o uso correto do aparelho após a instalação ou montagem.

- Manutenção: A seção de manutenção explica os procedimentos após o uso, como, por exemplo, a lavagem, limpeza e como armazenar o produto em local adequado.

- Problemas: Aqui são apresentados os possíveis problemas que podem ocorrer durante o uso do aparelho e são sugeridas soluções para os mesmos.

Após a divisão dos manuais em seções, foram realizadas análises estatísticas simples como a contagem de palavras simples e complexas. Para a contagem de palavras simples foi utilizada a lista de palavras simples do projeto PorSimples para que fosse conhecida qual é a porcentagem de palavras simples presente no córpus. Esta lista é composta de palavras que são supostamente, comuns e conhecidas para jovens, extraídas do Dicionário Ilustrado do Português (Biderman, 2005), uma lista de palavras frequentes de textos de jornais dedicados a crianças, como a Seção Para Seu Filho Ler do jornal Zero Hora e uma lista de palavras concretas disponíveis no trabalho de Janczura (2007). Os dados da contagem são apresentados na Tabela 3.

As seções que apresentaram maior número de palavras foram a seção de instalação, que corresponde a 17,15\% do córpus e a seção de instruções, que corresponde a 43,89\% do córpus. Além disso, essas duas seções são as que possuem o maior número de palavras difíceis. Levando-se em consideração essas duas características, foi decidido que ambas seriam boas candidatas à tarefa de extração de termos para a criação de um dicionário de palavras técnicas a ser usado na simplificação e/ou elaboração léxica de manuais técnicos. $\mathrm{O}$ córpus e estatísticas de cada manual e de cada componente estão disponíveis no Portal do projeto NorMan ${ }^{19}$ para visualização.

\footnotetext{
${ }^{19}$ http://www.nilc.icmc.usp.br/norman/index.php
} 
Tabela 3 - Distribuição das seções dos manuais do córpus

\begin{tabular}{|c|c|c|c|c|}
\hline Seção & $\begin{array}{c}\text { Palavras } \\
\text { fáceis }\end{array}$ & Palavras difíceis & Total & $\%$ \\
\hline Agradecimentos & $\begin{array}{c}2476 \\
87,58 \%\end{array}$ & $\begin{array}{c}351 \\
12,42 \%\end{array}$ & 2827 & $1,55 \%$ \\
\hline Componentes & $\begin{array}{l}2865 \\
78 \%\end{array}$ & $\begin{array}{l}808 \\
22 \%\end{array}$ & 3673 & $2,01 \%$ \\
\hline Garantia & $\begin{array}{c}14695 \\
86,75 \%\end{array}$ & $\begin{array}{c}2243 \\
13,25 \%\end{array}$ & 16938 & $9,30 \%$ \\
\hline Precauções & $\begin{array}{c}24400 \\
90,60 \%\end{array}$ & $\begin{array}{c}2530 \\
9,40 \%\end{array}$ & 26930 & $14,78 \%$ \\
\hline Instalação & $\begin{array}{c}26211 \\
83,91 \%\end{array}$ & $\begin{array}{c}5025 \\
\mathbf{1 6 , 0 9 \%}\end{array}$ & 31236 & $17,15 \%$ \\
\hline Instruções & $\begin{array}{c}66682 \\
83,42 \%\end{array}$ & $\begin{array}{c}13246 \\
\mathbf{1 6 , 5 8 \%}\end{array}$ & 79928 & $43,89 \%$ \\
\hline Manutenção & $\begin{array}{c}9712 \\
87,64 \%\end{array}$ & $\begin{array}{c}1369 \\
12,36 \%\end{array}$ & 11081 & $6,08 \%$ \\
\hline Problemas & $\begin{array}{c}8391 \\
88,44 \%\end{array}$ & $\begin{array}{c}1096 \\
11,56 \%\end{array}$ & 9487 & $5,20 \%$ \\
\hline TOTAL & $\begin{array}{r}155432 \\
85,35 \%\end{array}$ & $\begin{array}{c}26668 \\
14,65 \%\end{array}$ & 182100 & $100 \%$ \\
\hline
\end{tabular}




\subsubsection{O Método de extração de termos sensível ao gênero de instruções}

Durante a tarefa de simplificação léxica de manuais técnicos, é preciso tomar um cuidado especial em relação aos termos técnicos presentes no texto. Manuais técnicos contêm termos que não podem ser excluídos ou trocados por possíveis sinônimos da língua geral. De fato, caso um termo técnico seja erroneamente suprimido do texto ou trocado por um mais simples durante o processo de simplificação léxica, o sentido final da sentença poderá ficar seriamente comprometido, prejudicando o entendimento do leitor, como por exemplo, no termo "fonte de energia" não pode ser substituída por "nascente" ou "chafariz". Para evitarmos esse tipo de situação, é proposto um novo método de extração de termos, sensível ao gênero de instruções, descrito nesta subseção.

O método de extração de termos desenvolvido para o gênero de instruções é baseado nas relações generation (gera) e enablement (habilita), que são comumente encontradas em manuais, como descrito na Seção 2.2. Essas relações são de suma importância, pois elas demonstram explicitamente o que o leitor deve fazer para alcançar seu objetivo com segurança e livre de erros. Sabendo que as relações gera e habilita contêm as instruções propriamente ditas, conclui-se que as sentenças que contêm tais relações têm maior chance de conter candidatos a termos.

Para desenvolver a ferramenta de extração de termos, baseada no método descrito a seguir, foi escolhida a linguagem de programação Java, que é multi-plataforma. O método de extração de termos sensível ao gênero de instruções é dividido em cinco etapas, apresentadas a seguir.

ETAPA 1: A primeira etapa do método de extração é o pré-processamento dos textos ${ }^{20}$ pelo parser PALAVRAS (Bick, 2000) para a extração do conhecimento morfossintático dos textos. O conhecimento extraído do parser é utilizado para a identificação das relações gera e habilita (veja Figura 7).

\footnotetext{
${ }^{20}$ Neste trabalho, utilizamos as seções de instalação e instrução, pois a frequência das relações neste é maior.
} 


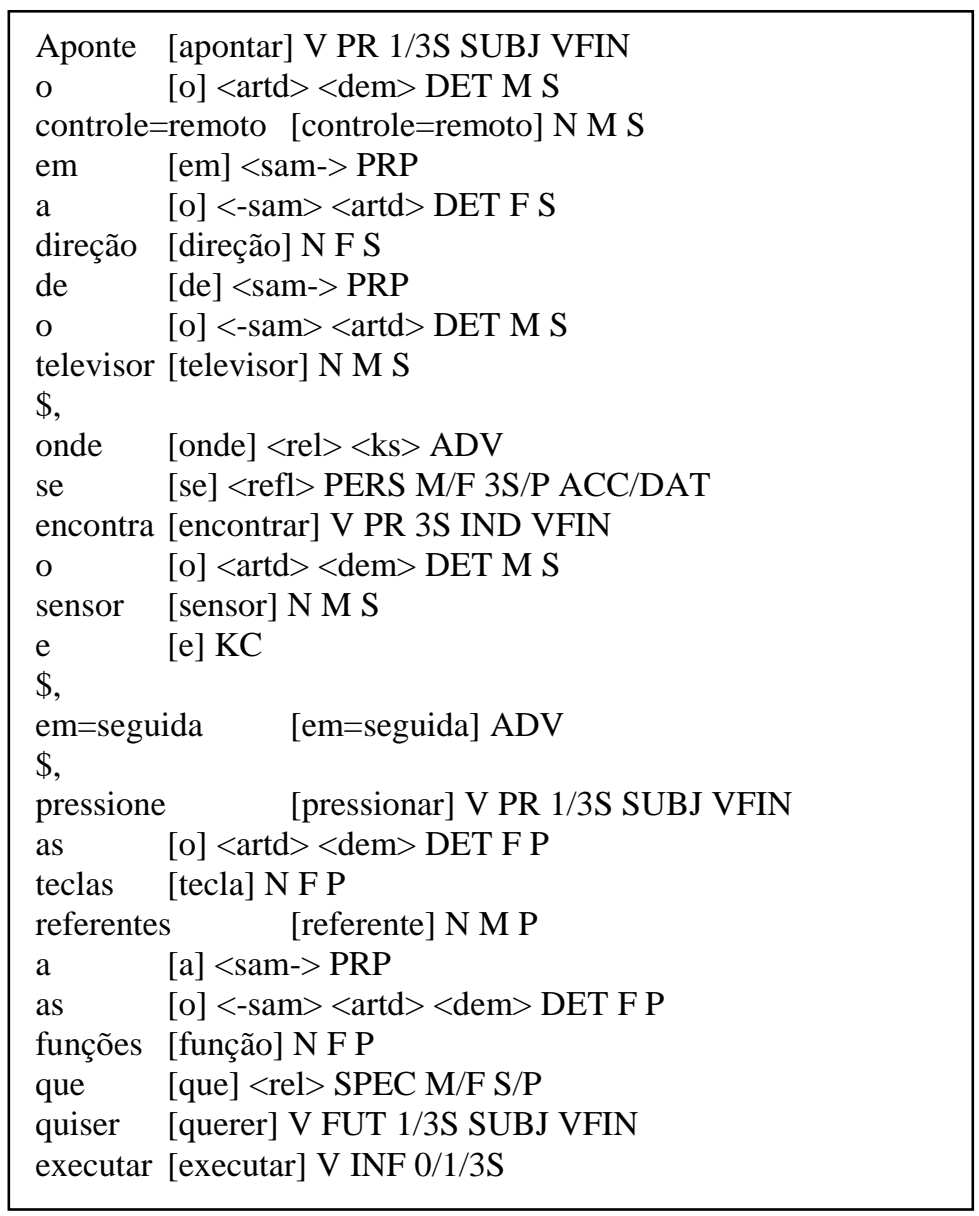

Figura 7 - Exemplo de trecho de um dos manuais processado pelo PALAVRAS

ETAPA 2: O arquivo resultante do pré-processamento pelo parser PALAVRAS é então usado como entrada pela etapa de extração na qual este arquivo é percorrido e são reconhecidas as sentenças de acordo com a marcação feita pelo parser PALAVRAS. Assim que uma sentença é reconhecida (Figura 9), a mesma é submetida a uma busca por umas das formas gramaticais descritas por Moura (2008) e Delin et. al. (1994). As formas gramaticais (Figura 8) usadas para a relação gera são as seguintes: "Para + Infinitivo", "Se + Subjuntivo" e "Para + Frases". Para a relação habilita, foram usadas as seguintes formas gramaticais: "Sequência", "condição Antes" e "condição Depois".

\section{Relações Gera \\ Para+Infinitivo: Selecione DVD para operar um DVD ou Reprodutor Home Theater \\ Se+Subjuntivo: Se quiser saber quanto tempo ainda resta para que o televisor desligue pressione uma $=$ vez a tecla SLEEP \\ Para+Sintagma: Para recepção dos sinais codificados comute a chave A/B para a posição $B$ e sintonize os canais através da unidade decodificadora \\ Relações Habilita \\ Sequência: Selecione uma das opções e pressione Enter para confirmar \\ Antes: É necessário ajustar a senha antes de bloquear os canais \\ Depois: Depois de remover os parafusos levante a TV removendo- a de o pedestal.}

Figura 8 - Exemplos das formas gramaticais encontradas nos manuais 
Aponte o controle=remoto em a direção de o televisor onde se encontra o sensor e em=seguida pressione as teclas referentes a as funções que quiser executar

VIMP DET N PRP DET N PRP DET N ADV PERS V DET N KC ADV VIMP DET N N PRP DET N SPEC VIMP VINF

** Relação Habilita detectada: Imperativo- Aponte ... + 1 sequência(s) de E

Figura 9 - NorMan Extractor reconhecendo uma relação habilita

ETAPA 3: Após a identificação da relação gera ou habilita, a sentença então é filtrada por uma lista de padrões morfossintáticos, gerando a lista final de candidatos a termos (Figura $10)$.

Aponte o controle $=$ remoto em a direção de o televisor onde se encontra o sensor e em=seguida pressione as teclas referentes a as funções que quiser executar

VIMP DET N PRP DET N PRP DET N ADV PERS V DET N KC ADV VIMP DET N N PRP DET N SPEC VIMP VINF

** Relação Habilita detectada: Imperativo- Aponte ... + 1 sequência(s) de E

Termo candidato: $\mathrm{n}$ - controle remoto - 229.99835057729794

Termo candidato: $\mathrm{n}$ - direção - 5.999850052481632

Termo candidato: $\mathrm{n}$ - televisor - 195.99790073474284

Termo candidato: $\mathrm{n}$ - sensor - 22.999400209926527

Termo candidato: $\mathrm{n}$ - teclas - 158.99775078722448

Termo candidato: $\mathrm{n}$ - referentes - 3.999700104963263

Termo candidato: $\mathrm{n}$ - funções - 76.99700104963263

Termo candidato: $\mathrm{v}$ - encontra - 3.0

Termo candidato: vimp - aponte - 7.0

Termo candidato: vimp - pressione - 788.9964012595592

Termo candidato: vimp - quiser - 21.0

Termo candidato: vinf - executar - 6.0

Figura 10 - Padrões Morfossintáticos aplicados em um trecho do manual, com o valor do C-value à direita

Os padrões morfossintáticos para extração de termos compostos são os mesmos usados por Baségio (Baségio, 2006 apud Ribeiro Jr, 2008), apresentados na Figura 11. Para o método de extração implementado neste projeto, o maior tamanho de termo composto aceito é três, isto é, são gerados uni, bi e trigramas.

Existem outros padrões morfossintáticos utilizados em extração automática de termos compostos, como os descritos por Zavaglia et al. (2007), porém neste trabalho apenas os padrões que se referem a bigramas e trigramas apresentados na figura 11 foram usados. Esses outros padrões podem ser implementados e avaliados em trabalhos futuros. Para termos simples, são utilizados os mesmos padrões de Teline (2004), que podem ser observados na Figura 12. 


\begin{tabular}{|c|}
\hline Substantivo Adjetivo Preposição Adjetivo Substantivo Adjetivo \\
\hline Substantivo Adjetivo Preposição Adjetivo Substantivo \\
\hline Substantivo Preposição Adjetivo Substantivo Adjetivo \\
\hline Substantivo Preposição Adjetivo Substantivo \\
\hline Substantivo Adjetivo Preposição Substantivo Adjetivo \\
\hline Substantivo Adjetivo Preposição Substantivo \\
\hline Substantivo Preposição Substantivo Adjetivo \\
\hline Substantivo Preposição Substantivo \\
\hline Substantivo Adjetivo
\end{tabular}

Figura 11 - Padrões morfossintáticos para extração de termos compostos

\begin{tabular}{|c|}
\hline Substantivo \\
\hline Adjetivo \\
\hline Verbo \\
\hline
\end{tabular}

Figura 12 - Padrões morfossintáticos usados na extração de termos simples

ETAPA 4: Nesta etapa, foram removidos da lista final de candidatos a termos todos aqueles n-gramas que estão presentes na STOPLIST (Veja Anexo B) que foi compilada para o projeto e-Termos ${ }^{21}$ com algumas adaptações para atender o gênero de manuais de instruções.

ETAPA 5: Nesta última etapa, a lista de candidatos a termos é ranqueada pelo C-value. O Cvalue é uma medida estatística usada para extração de termos multi-palavras. Para calcular o C-value, são usadas as seguintes características dos candidatos a termo: Frequência de ocorrência no córpus, frequência como parte de outro candidato a termo mais longo, o número total destes candidatos a termos mais longos. De posse dessa medida, o sistema faz o ranqueamento dos candidatos a termos. A figura 13 demonstra uma tela do sistema de extração NorMan com a lista final de unigramas ranqueados pelo C-Value.

O diagrama de todas as etapas pode ser observado na Figura 14.

Uma demonstração do funcionamento do método e da ferramenta que o implementa foi apresentada na Sessão de DEMOS do PROPOR 2010 (Muniz \& Aluisio, 2010) e está disponível na página do projeto $^{22}$.

\footnotetext{
${ }^{21} \mathrm{http}: / / \mathrm{www}$. etermos.cnptia.embrapa.br/

${ }^{22} \mathrm{http}: / /$ www.nilc.icmc.usp.br/norman/extractor/demo.php
} 


\begin{tabular}{|c|c|c|c|c|c|c|}
\hline \multicolumn{6}{|c|}{ NorMan Extractor - Extração de Termos } & \begin{tabular}{|l|l|l|}
$口$ & 回 & $\mathrm{X}$ \\
\end{tabular} \\
\hline \multicolumn{7}{|c|}{ File C-Value Help } \\
\hline Arquivo & \multicolumn{5}{|c|}{ I:|DropBoxMy DropboxWMESTRADOVAnalise_qualitativalsaida_unica_tv_processado.txt } & $\nabla$ Arquivo pré-processado \\
\hline Iniciar & & & & & Export CSV & Exportar TXT \\
\hline Texto & Processamento & Candidatos & Unigramas & Bigramas & $\mathrm{N}$-Gramas & \\
\hline \multicolumn{3}{|c|}{ Candidato } & & & C-Value & \\
\hline \multicolumn{3}{|c|}{ pressione } & & & 788.9964012595592 & 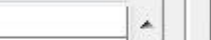 \\
\hline \multicolumn{3}{|c|}{ tv } & & & 640.9883040935673 & $\Xi$ \\
\hline \multicolumn{3}{|l|}{ teda } & & & 452.9937022042285 & \\
\hline \multicolumn{3}{|l|}{ menu } & & & 435.9880041985305 & \\
\hline \multicolumn{3}{|c|}{ selecionar } & & & 383.99940020992653 & \\
\hline \multicolumn{3}{|c|}{ imagem } & & & 372.9868046183836 & \\
\hline \multicolumn{3}{|c|}{ canal } & & & 357.99175288648973 & \\
\hline \multicolumn{3}{|l|}{ tela } & & & 353.99085320137954 & \\
\hline \multicolumn{3}{|c|}{ entrada } & & & 330.98455540560803 & \\
\hline \multicolumn{3}{|c|}{ canais } & & & 291.98785425101215 & \\
\hline \multicolumn{3}{|c|}{ função } & & & 270.9937022042285 & \\
\hline \multicolumn{3}{|c|}{ selecione } & & & 264.99070325386117 & \\
\hline \multicolumn{3}{|l|}{ cabo } & & & 252.99115309641624 & \\
\hline \multicolumn{3}{|l|}{ pode } & & & 249.0 & \\
\hline \multicolumn{3}{|l|}{ modo } & & & 217.98500524816313 & \\
\hline \multicolumn{3}{|c|}{ áudio } & & & 215.98500524816313 & \\
\hline \multicolumn{3}{|c|}{ ajuste } & & & 205.98290598290598 & \\
\hline \multicolumn{3}{|c|}{ televisor } & & & 195.99790073474284 & \\
\hline \multicolumn{3}{|c|}{ vídeo } & & & 187.98890388364072 & \\
\hline \multicolumn{3}{|l|}{ som } & & & 176.99070325386114 & \\
\hline sinal & & & & & 170.99115309641624 & \\
\hline tedas & & & & & 158.99775078722448 & \\
\hline item & & & & & 149.99820062977957 & \\
\hline $\mathrm{pc}$ & & & & & 139.997150997151 & - \\
\hline
\end{tabular}

Figura 13 - Lista de candidatos a termos ranqueados pelo C-Value geradas pelo sistema Norman Extractor

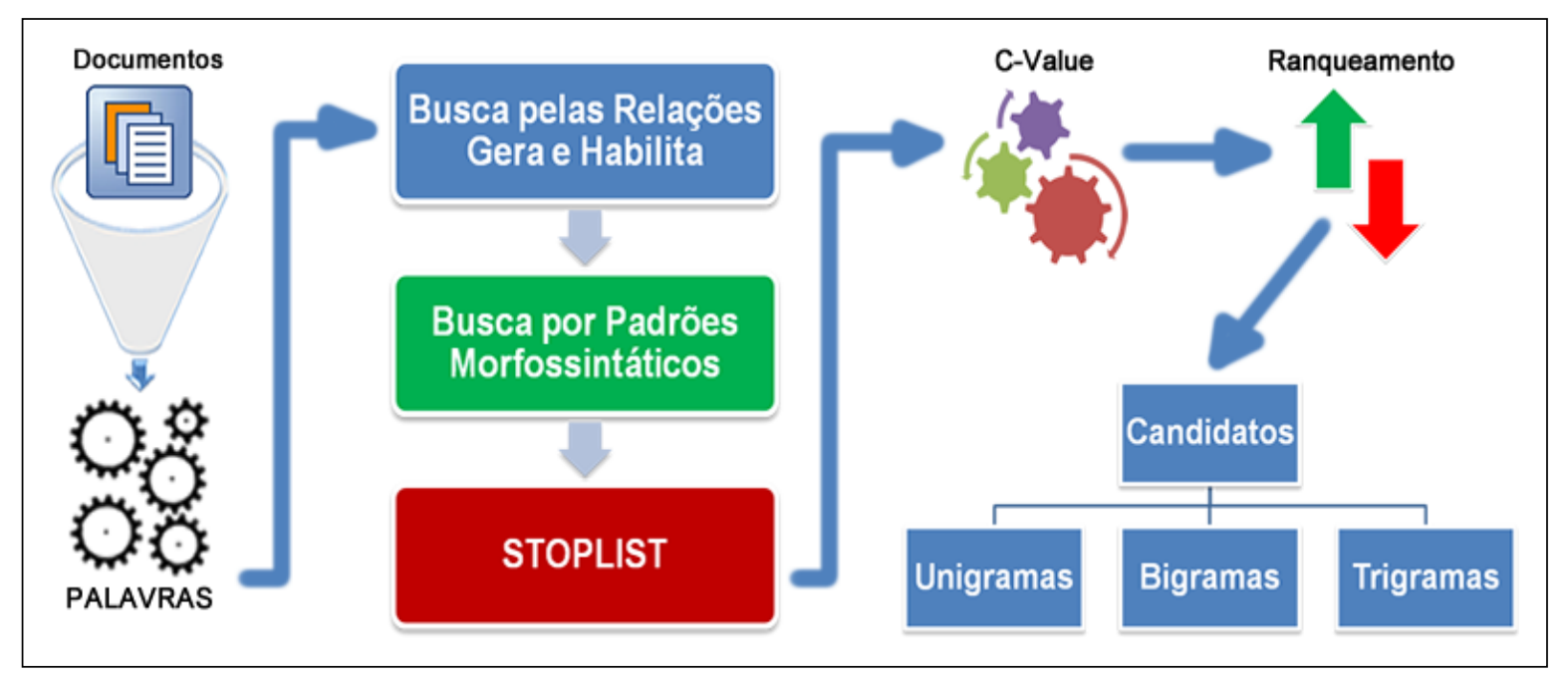

Figura 14 - Diagrama do método de extração NorMan 


\subsection{Aplicação do resultado da extração em Sistemas de Adaptação Textual}

O projeto PorSimples dedicou-se à tarefa de Adaptação Textual (AT), para ajudar leitores com baixo nível de alfabetização a compreender documentos disponíveis na Web em português do Brasil. Existem duas abordagens diferentes para a AT: a Simplificação Textual e a Elaboração Textual (Young, 1999). A primeira pode ser definida como qualquer tarefa que reduza a complexidade léxica ou sintática de um texto enquanto tenta preservar seu significado; tem grande impacto na inteligibilidade de um texto (facilidade de ser lido) e pode ser dividida em: Simplificação Léxica, Simplificação Sintática e Sumarização Automática, principalmente.

A Elaboração Textual propõe se a explicar conceitos e tornar explícitas as conexões entre as ideias do texto, e tem impacto na compreensibilidade de um texto (facilidade de ser compreendido). Estas duas abordagens foram exploradas no PorSimples (Aluísio \& Gasperin, 2010a, Aluísio \& Gasperin, 2010b). Particularmente para a Elaboração Textual foram propostos vários métodos de PLN: a) uso de sinônimos mais simples para palavras complexas no texto, b) explicitação de entidades mencionadas com inclusão de definições curtas da Wikipédia e imagens, c) explicitação da relação entre um verbo e seus argumentos que respondem a perguntas comumente utilizadas para a interpretação de um texto (Quem?, O quê?, Como?, Onde?, Por quê?).

A simplificação léxica de textos utilizada no Editor de Simplificação SIMPLIFICA ${ }^{23}$ basicamente identifica palavras complexas nos textos e fornece sugestões de substituição por uma lista de sinônimos mais frequentes para a palavra considerada complexa. Não há uma etapa de desambiguização de significado, tarefa que deve ser realizada pelo autor do texto.

Para o gênero de manuais de instrução, essa estratégia não pode ser aplicada, pois caso um termo técnico seja substituído por outra palavra, o entendimento da instrução pode ficar prejudicado, aumentando a chance da execução da instrução ser de forma errada, ocasionando acidentes e/ou prejuízos. Como exemplo podemos citar o termo "controle remoto". Caso o adjetivo "remoto" seja substituído pelo sinônimo "antigo", o termo perderia o sentido.

Para utilizar o Editor SIMPLIFICA com textos de manuais é, portanto, necessário saber quais são os termos técnicos de cada manual de instrução para que os mesmos sejam marcados para não sofrerem modificações. Como nem sempre se tem disponível uma lista de

\footnotetext{
${ }^{23}$ http://www.nilc.icmc.usp.br/porsimples/simplifica/
} 
termos técnicos para fazer essa verificação, faz-se necessário então o uso de ferramentas que gerem estas listas de forma automática. A seguir será explicado o funcionamento básico do editor de textos simplificados SIMPLIFICA e então serão detalhados o funcionamento da simplificação léxica e a adaptação do Editor para ser usado com manuais técnicos, fazendo uso da lista de termos extraída pelo NorMan Extractor.

\subsubsection{O Editor de textos simplificados SIMPLIFICA}

O SIMPLIFICA (Figura 15) é um sistema de autoria para apoiar a produção de textos simplificados no qual textos originais recebem simplificação automática com possível pósedição pelos autores. Pode ser utilizado por usuários que produzem conteúdos para sites da Web, por exemplo (Scarton, Gasperin \& Aluisio, 2010). Foi customizado para simplificar cada fenômeno sintático descrito em (Specia, Aluisio \& Pardo, 2008) e mais o tratamento de adjuntos adverbiais longos, para atender as necessidades de alfabetizados de nível rudimentar e básico (Gasperin, Maziero \& Aluísio, 2010). Possui também o módulo de Simplificação Léxica citado na seção anterior, e um avaliador automático da complexidade de textos (Aluisio et al., 2010), baseado nas classes de alfabetização do INAF (2009), isto é, classifica um texto de acordo com três classes: adequado a alfabetizados em nível pleno, básico e rudimentar e pode indicar a necessidade de mais simplificação léxica ou sintática, fornecendo a possibilidade de simplificar via um processo cíclico que pode ser avaliado a cada momento que o usuário autor desejar.

O módulo de simplificação sintática executa a simplificação sintática através de um Simplificador Sintático Simbólico (SS), direcionado a pessoas que possuem capacidade de localizar informações explícitas em textos curtos, definidos como analfabetos funcionais do nível rudimentar pelo INAF (2009). O SS é baseado em um conjunto de operações de simplificações pré-definidas. Além do SS, foi desenvolvido, embora não ainda incorporado, um Simplificador Sintático Estatístico (SE), direcionado a pessoas alfabetizadas de nível básico, que possuem capacidade de encontrar informações e fazer inferências em textos um pouco mais longos. O SE faz uso de aprendizado de máquina a partir de exemplos de simplificações naturais geradas por humanos para indicar quais orações são complexas; estas orações devem ser simplificadas pelo SS. Ao usar a abordagem de não simplificar todas as orações de um texto, consegue gerar textos com simplificações mais naturais. 
O módulo de simplificação léxica do SIMPLIFICA é responsável pela simplificação na qual sugestões de substituição de palavras complexas por sinônimos são oferecidas ao usuário do sistema. Este método de simplificação é descrito na seção abaixo, pois foi alvo de adaptações neste mestrado.

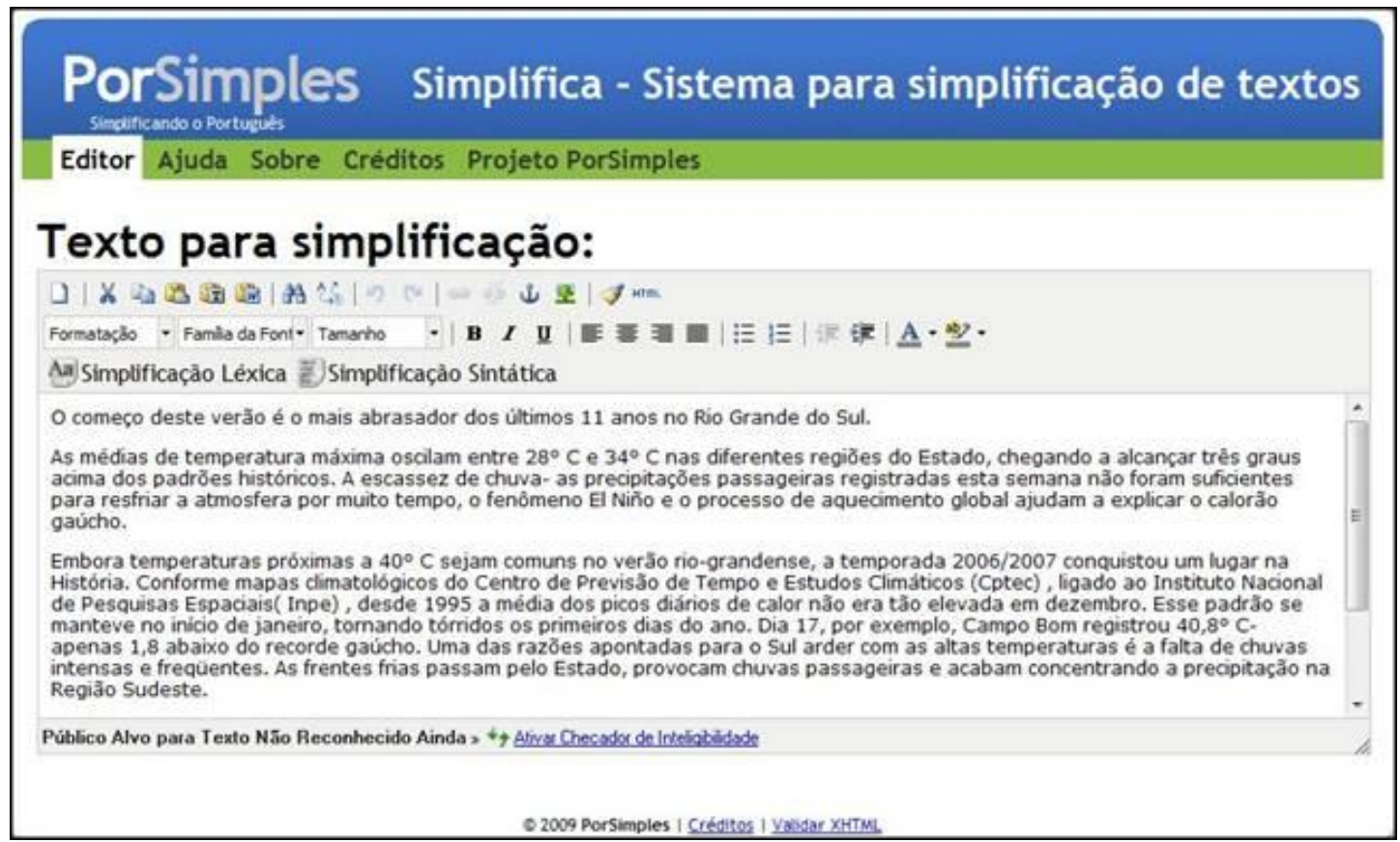

Figura 15 - Sistema Simplifica

\subsubsection{A simplificação léxica no SIMPLIFICA}

A primeira etapa da simplificação léxica é a marcação das palavras consideradas complexas. Para isso, são usados três dicionários que foram desenvolvidos para o Projeto PorSimples. Um dicionário é composto por palavras comuns para crianças, outro composto por palavras frequentes e outro composto por palavras concretas. O sistema percorre o texto e verifica cada palavra. Se a palavra não está no dicionário de palavras simples e também não é um nome próprio, então ela é considerada uma palavra complexa.

Para fazer a busca da palavra no dicionário de palavras simples, a mesma precisa estar lematizada e para isso foi utilizado o dicionário Unitex- $\mathrm{PB}^{24}$ para descobrir o lema de cada palavra.

A busca por um lema em um dicionário pode se tornar um problema quando processamos palavras ambíguas, como por exemplo, a palavra "canto", que pode ter como significado "o ponto ou área em que linhas e superfícies se encontram e formam um ângulo",

${ }^{24}$ http://www.nilc.icmc.usp.br/nilc/projects/unitexpb/web/dicionarios.html 
ou então pode ser o verbo "cantar" conjugado na primeira pessoa do singular do presente do Indicativo.

Para tratar essas ambiguidades eventualmente encontradas nos textos, o sistema utiliza o etiquetador gramatical MXPOST POS tagger (Ratnaparkhi, 1996) treinado com o conjunto de etiquetas NILC $\operatorname{tagset}^{25}$, que tem como objetivo etiquetar o texto identificando a categoria gramatical de cada palavra automaticamente.

Após a etiquetação das palavras, todas aquelas que não são substantivos, preposições ou numerais são selecionadas e então a busca no dicionário de palavras simples é feita utilizando a informação da categoria gramatical de cada palavra. Como se trata de uma operação automática, ela não é totalmente precisa e algumas palavras podem não constar no dicionário. Além disso, se o sistema não foi capaz de categorizar gramaticalmente a palavra, a busca no dicionário é feita utilizando apenas o lema e mesmo que a palavra não seja encontrada, ela é marcada como complexa.

Em seguida, todas as palavras que foram marcadas são linkadas com sinônimos mais simples. Para isso, dois recursos são utilizados: o tesauro TeP $2.0^{26}$ (uma coleção de palavras do português agrupadas em conjuntos que mantêm uma relação de sinonímia entre si) e o PAPEL $^{27}$ (um recurso léxico que consiste num conjunto de relações entre termos). Esse procedimento é executado quando o usuário clica na palavra marcada, disparando uma consulta por sinônimos no dicionário de palavras simples. A Figura 16 ilustra o texto com as palavras marcadas após o processo de simplificação léxica.

\footnotetext{
${ }^{25} \mathrm{http}: / /$ www.nilc.icmc.usp.br/nilc/TagSet/ManualEtiquetagem.htm

${ }^{26} \mathrm{http}: / /$ www.nilc.icmc.usp.br/tep2/

27 http://www.linguateca.pt/PAPEL/
} 


\begin{tabular}{|c|c|}
\hline Finalizar revisฮ̃o & \\
\hline \multirow{3}{*}{\multicolumn{2}{|c|}{$\begin{array}{l}\text { Fundamental no funcionamento do quadrado mágico do técnico Carlos Alberto Parreira , Kaká , o maior destaque d } \\
\text { amistoso contra a seleçào de Lucerna, clamou aos companheiros de ataque : } \\
\text { - Pelo menos um dos nossos atacantes vaí ter que voltar para ajudar na marcaçào - declarou o jogador do Milan, q } \\
\text { mostrou receio de ser coadjuvante de um time que tem Ronaldo e Ronaldinho como estrelas mais cintilantes . } \\
\text { - Vaidade atrapalha. Sei da minha responsabilidade no Milan e na Seleçào e também do momento vivido por meus } \\
\text { companheiros, principalmente o Ronaldinho - disse Kaká. }\end{array}$}} \\
\hline & \\
\hline & \\
\hline \multicolumn{2}{|c|}{ O técnico Parreira valorizou o empenho demonstrado pelo jogador no amistoso de ontem . } \\
\hline \multicolumn{2}{|l|}{ - O Kaká se espalhou muito bem pelo campo - elogiou o treinador. } \\
\hline \multicolumn{2}{|c|}{$\begin{array}{l}\text { Outro que recebeu elogios foi o centroavante Ronaldo. } 0 \text { técnico exaltou que o atacante mais uma vez mostrou } \\
\text { oportunismo. Aproveitou as chances criadas durante o tempo em que esteve em campo e marcou dois gols, o terceiro e } \\
\text { o quarto da goleada da Seleção. Aos poucos, recupera a forma, depois de mais de um mês e meio fora do futebol por } \\
\text { causa de contusão muscular na coxa direita : }\end{array}$} \\
\hline \multicolumn{2}{|c|}{$\begin{array}{l}\text { - A função do Ronaldo é fazer gols. Ele é isso. Fez contra o Fluminense (equipe sub - } 20 \text { em jogo - treino, no domingo ) e } \\
\text { fez hoje (ontem ). Só precisa melhorar sua forma física, porque ficou muito tempo parado. }\end{array}$} \\
\hline Finalizar revisäo & \\
\hline
\end{tabular}

Figura 16 - Palavras marcadas após o processo de simplificação léxica

\subsubsection{Adaptação da simplificação léxica para manuais técnicos}

Sabendo-se que em manuais de instrução os termos técnicos não podem sofrer substituição, pois a substituição de determinado termo pode alterar a interpretação de determinada instrução no manual e em razão disso, causar acidentes ou prejuízos, foi implementada algumas adaptações no método de simplificação léxica para atender o gênero de manuais de instruções.

O sistema FACILITA Educativo ${ }^{28}$, que também foi desenvolvido no projeto PorSimples, faz o uso da Wikipédia para trazer informações adicionais sobre Entidades Nomeadas que podem ser encontradas no texto. Essas informações facilitam a compreensão do texto e a aquisição de vocabulário pelo usuário. No FACILITA Educativo, o reconhecimento de entidades nomeadas foi feito através de uma adaptação do sistema Rembrandt (Cardoso, 2008), que é um dos melhores sistemas avaliados do HAREM II ${ }^{29}$ com a medida F de aproximadamente 57\%. Rembrandt utiliza classes e subcategorias para classificar entidades nomeadas. Na adaptação do Rembrandt, algumas dessas classes consideradas muito complexas foram removidas e outras foram renomeadas para atender aos usuários com baixo nível de alfabetização. Após uma Entidade Nomeada ser reconhecida, o FACILITA Educativo efetua uma busca na Wikipédia e retorna trechos das primeiras sentenças da Wikipédia. A hipótese de que as primeiras sentenças dos artigos da Wikipédia

\footnotetext{
${ }^{28} \mathrm{http} / / / \mathrm{www}$.watinha.com/educational-facilita/

${ }^{29} \mathrm{http}: / / \mathrm{www}$. linguateca.pt/HAREM/
} 
definem Entidades Nomeadas é suportada por uma avaliação estatística com um índice de confiabilidade de 95\%. Sabendo dos resultados positivos que a utilização de informações adicionais traz para a compreensão do texto (Watanabe et. al., 2010), foi decidido aplicar esta estratégia para elaborar os termos técnicos durante a simplificação léxica de manuais de instrução. Desta forma, estes receberiam uma definição adicional, com o uso da primeira oração da Wikipédia que relata o termo.

O primeiro passo na adaptação da simplificação léxica foi a geração de um dicionário a partir da lista de termos extraídos e seus respectivos C-Values pelo NorMan. Este dicionário foi então inserido como um novo dicionário de palavras simples no sistema de simplificação léxica. Dessa forma, o sistema passa a considerar os termos técnicos como palavras simples, evitando que os mesmos sejam marcados como palavras complexas, sendo estes linkados com definições da Wikipédia, sempre que houver uma, que podem ser usadas como explicações que acompanham os termos.

Tendo em vista que o método de extração de termos sensível ao gênero de manuais de instruções extrai unigramas, bigramas e trigramas, o sistema foi adaptado para percorrer o texto em três etapas e não apenas uma vez. Na primeira etapa, o sistema percorre o texto formando trigramas e verificando cada um deles no dicionário gerado pelo NorMan. Caso haja intersecção entre dois trigramas, aquele com o maior C-Value é escolhido para ser elaborado por uma definição da Wikipédia. Na segunda etapa, o sistema percorre o texto novamente formando bigramas e verificando cada um deles. Caso haja intersecção entre dois bigramas, vence aquele com maior $\mathrm{C}-\mathrm{Value}$, assim como ocorre com os trigramas, porém caso haja intersecção com trigramas, o trigrama tem preferência. Por ultimo, o texto é percorrido da forma tradicional, buscando cada palavra no dicionário e caso haja intersecção com bigramas ou trigramas, os bigramas e trigramas têm prioridade sobre unigramas.

Após identificar todos os termos técnicos do dicionário do NorMan no texto, tais termos são marcados para receber informações adicionais. Quando o usuário clica em um termo técnico marcado, uma consulta é feita na Wikipédia e é apresentado para o usuário um link como uma informação adicional (Figura 17), contendo as duas primeiras orações da Wikipédia para aquele termo técnico. 


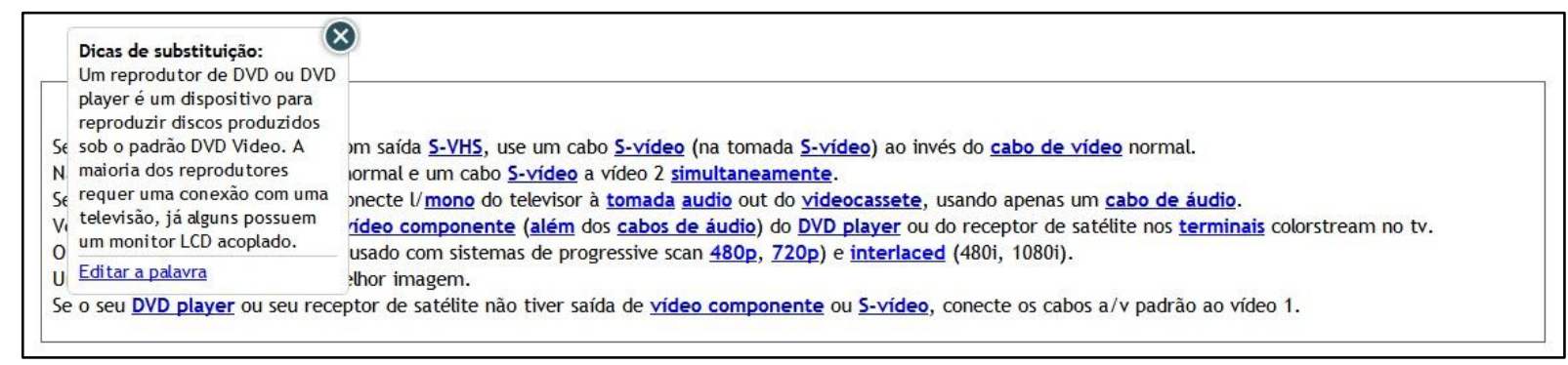

Figura 17 - Trecho de manual com termos técnicos marcados para receber informações adicionais ad Wikipédia

\subsection{O Portal do Projeto Norman e o sistema Norman Extractor}

Durante o desenvolvimento deste trabalho, foi criado o portal do projeto NorMan com o objetivo de armazenar todas as informações e recursos sobre o projeto, como por exemplo, o córpus, as ferramentas desenvolvidas, os resultados dos experimentos e as publicações (veja Apêndice A).

A principal ferramenta desenvolvida foi o NorMan Extractor, que é a implementação do método de extração de termos proposto neste trabalho.

O NorMan Extractor foi implementado com a linguagem de programação Java e foi projetado para ser simples de ser usado.

Para executar uma extração de termos usando o NorMan Extractor, o usuário precisa apenas que o córpus de estudo esteja compilado em um arquivo único no formato de texto puro. O único pré-requisito para usar a ferramenta é que o córpus já esteja processado pelo parser PALAVRAS. O usuário deve então usar o arquivo de saída gerado pelo PALAVRAS como entrada no NorMan Extractor. Este mesmo arquivo também deve ser usado como entrada na função de cálculo do C-Value, caso o usuário queira fazer um ranquemaneto dos candidatos a termos. O usuário precisa apenas pressionar um botão para dar início ao processo de extração, que após finalizado, apresenta três listas com candidatos a termos. Estas listas podem ser exportadas no formato de texto puro ou então no formato CSV (texto tabelado em formato texto, separado por vírgulas), para que possam ser usadas conforme a necessidade do usuário. A utilização da ferramenta está ilustrada no Apêndice C.

O portal do projeto NorMan fica localizado no seguinte endereço web: http://nilc.icmc.usp.br/norman/ 


\section{Avaliação do Método de Extração de Termos para Manuais}

As duas formas de avaliação de métodos de extração automática de termos, ou de outras tarefas de PLN, são a extrínseca e a intrínseca. A primeira é projetada para verificar a eficiência do método de extração de termos, sendo usadas, principalmente, as seguintes métricas para avaliar os resultados da extração automática: precisão (precision) $(\mathrm{P})$, cobertura (recall) $(\mathrm{R})$ e f-measure $(\mathrm{F})$. Estas métricas utilizam um conjunto de termos de referência (gold standard) criado ou revisado por humanos especialistas no domínio em questão e são assim definidas:

$\mathrm{P}=$ (Termos de Referência $\cap$ Termos Extraídos) / Termos Extraídos) e indica a capacidade do método em identificar os termos corretos, considerando a lista de referência.

$\mathrm{R}=($ Termos de Referência $\cap$ Termos Extraídos $) /$ Termos de Referência) e avalia a quantidade de termos corretos extraídos pelo método.

f-measure $(\mathrm{F}=(2 * \mathrm{P} * \mathrm{~A}) /(\mathrm{P}+\mathrm{A}))$ é a medida harmônica entre a precisão e cobertura.

A avaliação extrínseca visa avaliar um sistema em uso, para a realização de alguma tarefa específica, por exemplo, para as tarefas de categorização de textos, recuperação de informação, ou, como é o caso desta pesquisa, para a tarefa de adaptação léxica de textos.

Neste projeto de mestrado, avaliamos o método de extração de termos proposto Norman Extractor - tanto extrínseca como intrinsecamente. Entretanto, para a avaliação intrínseca não há listas de referências prontas para os vários manuais técnicos de produtos tecnológicos de interesse nesta pesquisa ou mesmo para outros produtos. Desta forma, propomos aqui avaliar via estatística kappa e via comparação com outros métodos da literatura para o gênero de textos científicos (Seção 5.1). Na avaliação extrínseca, avaliamos a integração do extrator proposto com o Sistema de Autoria de Textos Simplificados SIMPLIFICA, desenvolvido no projeto PorSimples (Seção 5.2).

\subsection{Avaliação Intrínseca}

As seções de "Instruções" e "Instalação" dos manuais de instruções do córpus de trabalho foram escolhidas para participar da avaliação do sistema (extrínseca e intrínseca). A escolha 
por estas seções se deu pelo fato de que ambas são as maiores seções do córpus, isto é, contêm o maior número de palavras. A seção de "Instalação" corresponde a 17,15\% do tamanho total do córpus, contendo 31236 palavras. A seção de "Instruções" corresponde a 43,89\% do tamanho total do córpus, contendo 79928 palavras.

Apesar de o método de extração de termos implementado não ser dependente de domínio, foi necessário especificar os manuais usados para um único tipo de produto tecnológico para que a avaliação do método fosse mais factível. A escolha dos manuais de "Televisores" se deu pelo fato de o produto ser extremamente popular e assim poderia ser avaliado por pessoas comuns, pois gostaríamos de avaliar, via medida kappa, a concordância de um grupo de alunos de mestrado e doutorado no NILC quanto à qualidade da lista de termos extraídos pelo método proposto. Esta avaliação é detalhada na Seção 5.1.2. Na Seção 5.1.1 apresenta-se uma comparação usando quatro outros métodos de extração da literatura (Teline, 2004) para verificar se o novo método proposto traz novidades (termos diferentes) ou se a lista de candidatos traz muitas semelhantes com métodos projetados para textos científicos.

\subsubsection{Comparação do Norman Extractor com métodos de Extração para Artigos Científicos}

As seções de "Instalação" dos manuais de instruções possuem um total de 31236 palavras e a seção de "Instruções" possui 79928. Este subcórpus das seções de "Instalação" e "Instruções" dos manuais foi submetido ao sistema de extração que implementa o método Norman Extractor.

Com o resultado do método implementado, três listas de candidatos a termos foram geradas: unigramas, bigramas e trigramas. Estas listas foram utilizadas na avaliação do sistema, que foi feita em duas etapas, sendo a primeira a avaliação intrínseca (avaliação comparativa e medida Kappa) e a segunda a avaliação extrínseca (no sistema SIMPLIFICA).

A falta de uma lista de referência para calcular a precisão e revocação do sistema obrigou o uso de métodos alternativos para avaliação da eficiência do sistema.

O mesmo subcórpus utilizado no sistema de extração deste projeto foi então submetido a outros quatro métodos de extração, implementados por Teline (2004), e descritos na Seção 3.4: 
- Linguístico;

- Estatístico;

- Hibrido-A (usando indicadores estruturais);

- Hibrido-B (sem indicadores estruturais).

O objetivo desta comparação foi verificar se o novo método trazia termos novos ou se havia muita intersecção entre os métodos já conhecidos.

Também foi calculada a similaridade entre os métodos através do cálculo do coeficiente Jaccard, que é uma estatística usada para comparar a similaridade e diversidade de conjuntos de amostra. O coeficiente de Jaccard entre dois grupos de amostras (A e B) é obtido através da seguinte fórmula:

$$
\mathrm{J}(\mathrm{A}, \mathrm{B})=|\mathrm{A} \cap \mathrm{B}| /|\mathrm{A} \mathrm{U} \mathrm{B}|
$$

A Tabela 4 apresenta os números totais de unigramas encontrados em cada método, bem como a união e a intersecção entre os termos de cada comparação. A intersecção entre o método Linguístico e o NorMan foi de 2113 termos, representando 71,6\% dos termos recuperados pelo método NorMan e 53,7\% do Linguístico. O Coeficiente de similaridade Jaccard para estes conjuntos é de 0,44. Entre o método Estatístico e o NorMan, a intersecção foi de 2284 termos, que representa 77,3\% dos termos recuperados pelo NorMan e 61,6\% do Estatístico. Neste caso, o coeficiente Jaccard foi de 0,52. A intersecção entre o método Híbrido-A e o NorMan foi de 1252 termos, que representa 42,4\% dos termos recuperados pelo NorMan e 61,6\% do Híbrido-A, obtendo o coeficiente de Jaccard de 0,37. Entre o método Híbrido-B e o NorMan, a intersecção foi de 1530 termos, que representa $51,8 \%$ dos termos recuperados pelo NorMan e 75,8\% do Híbrido-B. Neste caso, o coeficiente Jaccard foi de 0,44 .

Desta forma, o maior índice de similaridade foi entre o método Estatístico e o NorMan, contrariando as expectativas, já que o NorMan se baseia em informações linguísticas para achar o nicho dos termos.

$\mathrm{Na}$ Tabela 5 estão apresentados os resultados da comparação para os bigramas. A intersecção entre o método Linguístico e o NorMan foi de 334 termos, representando 42,5\% dos termos recuperados pelo método NorMan e $20 \%$ do Linguístico. O coeficiente de similaridade Jaccard foi 0,15. Entre o método Estatístico e o NorMan, a intersecção foi de 285 termos, que representa 36,3\% dos termos recuperados pelo NorMan e 4,2\% do 
Estatístico. Neste caso, o coeficiente Jaccard foi 0,03. A intersecção entre o método HíbridoA e o NorMan foi de 85 termos, que representa 10,8\% dos termos recuperados pelo NorMan e 39,3\% do Híbrido-A. O coeficiente Jaccard foi 0,09. Entre o método Híbrido-B e o NorMan, a intersecção foi de 99 termos, que representa 12,6\% dos termos recuperados pelo NorMan e 44,5\% do Híbrido-B. O coeficiente Jaccard foi de 0,10.

Neste caso, o maior índice de similaridade foi entre o método Linguístico e o NorMan, o que era esperado, pois os dois métodos são baseados em informações linguísticas para encontrar os candidatos a termos.

Tabela 4 - Resultados da lista de unigramas para os métodos de Teline (2004) e o Norman Extractor

\begin{tabular}{|c|c|c|c|c|c|}
\hline Método & Unigramas Recuperados & União & \multicolumn{2}{|c|}{ Intersecção } & Jaccard \\
\hline NorMan & 2951 & \multirow{2}{*}{4766} & \multirow{2}{*}{2113} & $71,6 \%$ & \multirow{2}{*}{0,44} \\
\hline Linguístico & 3928 & & & $53,7 \%$ & \\
\hline NorMan & 2951 & \multirow{2}{*}{4373} & \multirow{2}{*}{2284} & $77,3 \%$ & \multirow{2}{*}{0,52} \\
\hline Estatístico & 3706 & & & $61,6 \%$ & \\
\hline NorMan & 2951 & \multirow{2}{*}{3367} & \multirow{2}{*}{1252} & $42,4 \%$ & \multirow{2}{*}{0,37} \\
\hline Híbrido-A & 1668 & & & $75 \%$ & \\
\hline NorMan & 2951 & \multirow{2}{*}{3439} & \multirow{2}{*}{1530} & 51,8 & \multirow{2}{*}{0,44} \\
\hline Híbrido-B & 2018 & & & 75,8 & \\
\hline
\end{tabular}

A Tabela 6 apresenta os resultados da comparação para os trigramas. A intersecção entre o método Linguístico e o NorMan foi de 354 termos, representando 46,9\% dos termos recuperados pelo método NorMan e $22,2 \%$ do Linguístico. O coeficiente de similaridade Jaccard para este caso foi de 0,17. Entre o método Estatístico e o NorMan, a intersecção foi de 168 termos, que representa 22,2\% dos termos recuperados pelo NorMan e 4,1\% do Estatístico. Neste caso, o coeficiente Jaccard foi 0,03. A intersecção entre o método HíbridoA e o NorMan foi de 80 termos, que representa 10,6\% dos termos recuperados pelo NorMan e 45,1\% do Híbrido-A. O coeficiente Jaccard foi 0,09. Entre o método Híbrido-B e o NorMan, a intersecção foi de 114 termos, que representa $15,1 \%$ dos termos recuperados pelo NorMan e $52,7 \%$ do Híbrido-B, obtendo o coeficiente Jaccard de 0,13. 
Também neste caso o índice de similaridade foi entre o método Linguístico e o NorMan, o que era esperado, pois os dois métodos são baseados em informações linguísticas para encontrar os candidatos a termos.

Tabela 5 - Resultados da lista de bigramas para os métodos de Teline (2004) e o Norman Extractor

\begin{tabular}{|c|c|c|c|c|c|}
\hline Método & Bigramas Recuperados & União & \multicolumn{2}{|c|}{ Interseção } & Jaccard \\
\hline NorMan & 785 & \multirow{2}{*}{2120} & \multirow{2}{*}{334} & $42,5 \%$ & \multirow{2}{*}{0,15} \\
\hline Linguístico & 1669 & & & $20 \%$ & \\
\hline NorMan & 785 & \multirow{2}{*}{7153} & \multirow{2}{*}{285} & $36,3 \%$ & \multirow{2}{*}{0,03} \\
\hline Estatístico & 6653 & & & $4,2 \%$ & \\
\hline NorMan & 785 & \multirow{2}{*}{916} & \multirow{2}{*}{85} & $10,8 \%$ & \multirow{2}{*}{0,09} \\
\hline Híbrido-A & 216 & & & $39,3 \%$ & \\
\hline NorMan & 785 & \multirow{2}{*}{908} & \multirow{2}{*}{99} & $12,6 \%$ & \multirow{2}{*}{0,10} \\
\hline Híbrido-B & 222 & & & $44,5 \%$ & \\
\hline
\end{tabular}

Tabela 6 - Resultados da lista de trigramas para os métodos de Teline (2004) e o Norman Extractor

\begin{tabular}{|c|c|c|c|c|c|}
\hline Método & Trigramas Recuperados & União & \multicolumn{2}{|c|}{ Intersecção } & Jaccard \\
\hline NorMan & 754 & \multirow{2}{*}{1992} & \multirow{2}{*}{354} & $46,9 \%$ & \multirow{2}{*}{0,17} \\
\hline Linguístico & 1592 & & & $22,2 \%$ & \\
\hline NorMan & 754 & \multirow{2}{*}{4646} & \multirow{2}{*}{168} & $22,2 \%$ & \multirow{2}{*}{0,03} \\
\hline Estatístico & 4060 & & & $4,1 \%$ & \\
\hline NorMan & 754 & \multirow{2}{*}{851} & \multirow{2}{*}{80} & $10,6 \%$ & \multirow{2}{*}{0,09} \\
\hline Híbrido-A & 177 & & & $45,1 \%$ & \\
\hline NorMan & 754 & \multirow{2}{*}{856} & \multirow{2}{*}{114} & $15,1 \%$ & \multirow{2}{*}{0,13} \\
\hline Híbrido-B & 216 & & & $52,7 \%$ & \\
\hline
\end{tabular}

A análise dos resultados da intersecção entre o método NorMan e os diferentes métodos de extração mostrou que não houve nenhuma intersecção próxima de 100\%, embora 
para unigramas ela seja bem alta, menos nos cenários dos métodos híbridos em que a porcentagem da intersecção é menor para o método NorMan, isto é, é neste cenário que o método trouxe mais novidades. Para bigramas e trigramas a interseção é bem menor, mostrando que o método NorMan trouxe termos diferentes.

\subsubsection{Avaliação do método Norman Extractor via estatística Kappa}

A estatística Kappa (Carletta, 1996) é uma medida muito utilizada para medir a concordância entre diferentes anotadores, nas várias tarefas do PLN. Portanto, adotamos essa medida para calcularmos a concordância entre os avaliadores no julgamento dos 150 primeiro termos da lista de candidatos a termos uni, bi e trigramas do método proposto. Esta avaliação é detalhada a seguir.

Em cada uma das listas de termos que foram geradas pelo método proposto, foram selecionados os 150 primeiros candidatos a termos e cada uma delas foi enviada a três avaliadores diferentes para avaliarem os unigramas e dois avaliadores diferentes para avaliarem os bigramas e mais dois diferentes para os trigramas. Nenhum dos avaliadores era especialista no assunto, e a tarefa de cada um consistia simplesmente em decidir se cada um dos candidatos a termo apresentados na lista se insere no contexto do domínio de "televisão" ou não, isto é, é um forte candidato a termo ou não.

$\mathrm{Na}$ análise da lista de unigramas, o avaliador 1 identificou 104 (69,33\%) termos entre os 150 candidatos da lista de unigramas. O avaliador 2 identificou 126 (84\%) e o avaliador 3 identificou 105 (70\%) (Tabela 7). O valor da medida Kappa resultante dessa avaliação foi de 0.507. Este valor representa que houve um índice moderado de concordância entre os avaliadores como podemos ver na Tabela 8 .

Tabela 7 - Valor da estatística Kappa para unigramas, usando 3 juízes e 150 termos candidatos

\begin{tabular}{l|c|c}
\hline \multirow{2}{*}{} & \multicolumn{2}{c}{ Unigramas } \\
\cline { 2 - 3 } & É termo & Não é \\
\hline Avaliador 1 & $104-69,33 \%$ & $46-30,66 \%$ \\
\hline Avaliador 2 & $126-84 \%$ & $24-16 \%$ \\
\hline Avaliador 3 & $105-70 \%$ & $45-30 \%$ \\
\hline Medida Kappa & \multicolumn{2}{|}{$\mathbf{0 . 5 0 7}$} \\
\hline
\end{tabular}


Tabela 8 - Classificação de valores Kappa

\begin{tabular}{|c|c|}
\hline Intervalo Kappa & Classificação de concordância \\
\hline$<0.20$ & Pequena \\
\hline$[0.20 ; 0.40)^{30}$ & Razoável \\
\hline$[0.40 ; 0.60)$ & Moderada \\
\hline$[0.60 ; 0.80)$ & Boa \\
\hline$[0.80 ; 1.00]$ & Muito Boa \\
\hline
\end{tabular}

$\mathrm{Na}$ lista de bigramas, o Avaliador 4 identificou $91(60,66 \%)$ termos entre 150 candidatos da lista. O avaliador 5 identificou 75 (50\%) termos (Tabela 9). O valor da medida Kappa resultante dessa avaliação foi de 0.069. Este valor representa um índice de concordância pequeno/fraco.

Tabela 9 - Valor da estatística Kappa para bigramas, usando 2 juízes e 150 termos candidatos

\begin{tabular}{l|c|c}
\hline \multirow{2}{*}{} & \multicolumn{2}{c}{ Bigramas } \\
\cline { 2 - 3 } & É termo & Não é \\
\hline Avaliador 4 & $91-60,66 \%$ & $59-39,33 \%$ \\
\hline Avaliador 5 & $75-50 \%$ & $75-50 \%$ \\
\hline Medida Kappa & \multicolumn{2}{c}{$\mathbf{0 . 0 6 9}$} \\
\hline
\end{tabular}

Na lista de trigramas, o Avaliador 6 identificou 99 (66\%) termos entre 150 candidatos da lista. O avaliador 7 identificou $116(77,3 \%)$ termos (Tabela 10). O valor da medida Kappa resultante dessa avaliação foi de 0.061. Este valor representa um índice de concordância pequeno/fraco.

Tabela 10 - Valor da estatística Kappa para trigramas, usando 2 juízes e 150 termos candidatos

\begin{tabular}{l|c|c}
\hline \multirow{2}{*}{} & \multicolumn{2}{c}{ Trigramas } \\
\cline { 2 - 3 } & É termo & Não é \\
\hline Avaliador 6 & $99-66 \%$ & $51-34 \%$ \\
\hline Avaliador 7 & $116-77,33 \%$ & $34-22,66 \%$ \\
\hline Medida Kappa & \multicolumn{2}{|c|}{$\mathbf{0 6 1}$} \\
\hline
\end{tabular}

\footnotetext{
${ }^{30}$ Nesses intervalos foi usado o símbolo matemático parênteses para denotar intervalo aberto e colchetes para intervalo fechado.
} 
Os valores de concordância encontrados nesta etapa da avaliação podem ser um reflexo de que os avaliadores não são especialistas e, além disso, evidencia a dificuldade da avaliação manual da tarefa de extração automática de termos neste gênero de textos.

\subsection{Avaliação Extrínseca}

A avaliação extrínseca tem como objetivo analisar o sistema propriamente dito em uso. Para esta tarefa, um trecho do texto da seção de instalação de um manual de instruções de televisão foi submetido ao sistema SIMPLIFICA já adaptado para a simplificação léxica de manuais técnicos, como descrito na Seção 4.2.1.2. O trecho escolhido para avaliação continha 16 termos distintos marcados como termos para elaboração léxica. Dentre estes 16 termos, 12 foram reconhecidos pelo sistema como termos técnicos, pois pertencia às listas de candidatos a termo geradas pelo sistema Norman Extractor e os quatro restantes, como palavras complexas. Este trecho foi então adaptado como uma página web (html) para ser usado como um protótipo para a execução da avaliação. A Figura 18 mostra o trecho escolhido, com as palavras selecionadas que são tanto uni, bi como trigramas.

Conexões.

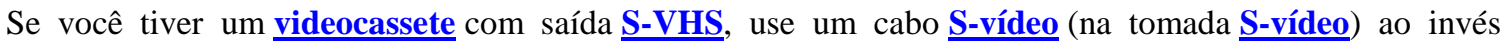
do cabo de vídeo normal.

Não conecte um cabo de vídeo normal e um cabo $\underline{\text { S-vídeo a vídeo } 2 \text { simultaneamente. }}$ Se tiver um videocassete mono, conecte $1 / \underline{\text { mono }}$ do televisor à tomada audio out do videocassete, usando apenas um cabo de áudio.

Você pode conectar os cabos de vídeo componente (além dos cabos de áudio $)$ do DVD player ou do receptor de satélite nos terminais colorstream no tv.

O terminal colorstream pode ser usado com sistemas de progressive scan $\underline{480 \mathrm{p}}, \underline{720 \mathrm{p}}$ ) e interlaced (480i, 1080i).

Um sinal 1080i oferecerá uma melhor imagem.

Se o seu DVD player ou seu receptor de satélite não tiver saída de vídeo componente ou $\underline{\mathbf{S} \text {-vídeo }}$, conecte os cabos a/v padrão ao vídeo 1 .

Figura 18 - Trecho do manual de instruções usado na avaliação, com as palavras marcadas 
A avaliação foi dividida em três etapas. Na primeira etapa, o avaliador voluntário recebeu uma explicação básica sobre este projeto e como seria a avaliação, recebendo instruções sobre como deveria proceder durante a leitura do trecho do manual e sobre o funcionamento dos links com informações extras sobre determinados termos.

A segunda etapa compreendeu a leitura do trecho de manual propriamente dita pelo voluntário e sua respectiva interação com o protótipo, através de clicks nos termos marcados.

Após a leitura completa do trecho do manual, dava-se início à terceira etapa, que era a aplicação de um questionário contendo 16 questões de múltipla escolha (Veja Apêndice B), com três opções de resposta cada. Além das questões de múltipla escolha, para cada palavra foi questionado se o avaliador já conhecia a palavra e se a informação da Wikipédia foi útil ou não para o entendimento do trecho do manual.

A Figura 19 mostra uma das questões sobre um termo técnico e uma questão sobre uma palavra complexa, com as três opções de resposta e a opção correta indicada em negrito.

Exemplo de uma questão sobre um termo técnico:

O que é um videocassete?

a) É um aparelho eletrônico capaz de gravar e reproduzir imagens que são registradas em fitas magnéticas. (resposta correta)

b) É um aparelho eletrônico capaz de reproduzir músicas.

c) É uma fita de vídeo.

Exemplo de uma questão sobre uma palavra complexa:

O que é uma Tomada?

a) Tomada significa: Um tipo de cabo.

b) Tomada significa: Interruptor elétrico.

c) Tomada significa: Conector elétrico. (resposta correta).

Figura 19 - Exemplos de questões utilizadas na avaliação 
Participaram da avaliação 15 voluntários, que são funcionários da Prefeitura do Campus da USP em São Carlos, trabalhando na Seção de Obras e Infraestrutura. A avaliação foi aplicada individualmente em um único dia, tendo início as 7:00 h e finalizando as 16:30 h, com um intervalo de duas horas entre 11:00 e 13:00. A média de duração da avaliação foi de 19 minutos e 51 segundos, sendo que a avaliação mais rápida durou 15 minutos e a mais longa, 30 minutos.

\subsubsection{Distribuição das Frequências}

O perfil dos voluntários avaliados e os resultados da avaliação são mostrados na Tabela 11 . Dentre os avaliados, três voluntários tinham ensino fundamental (20\%), onze tinham ensino médio $(73,3 \%)$ e um tinha curso superior $(6,6 \%)$.

Tabela 11 - Perfis e resultados da avaliação dos 15 funcionários da Prefeitura do Campus da USP em São Carlos

\begin{tabular}{|c|c|c|c|c|c|c|c|}
\hline & Escolaridade & Função & $\begin{array}{l}\text { Idade } \\
\text { (anos) }\end{array}$ & $\begin{array}{c}\text { Duração } \\
\text { (h) }\end{array}$ & $\begin{array}{c}\text { Conh. } \\
\text { Prévio } \\
(\%)\end{array}$ & $\begin{array}{c}\text { Utilidade } \\
\text { (\%) }\end{array}$ & $\begin{array}{c}\text { Acertos } \\
(\%)\end{array}$ \\
\hline 1 & Ensino Médio & Eletricista & 37 & $0: 15$ & 93,75 & 43,75 & 100 \\
\hline 2 & $\begin{array}{l}\text { Fund. Incomp. } \\
\text { (4⿳亠口了 série) }\end{array}$ & Eletricista & 68 & $0: 19$ & 75 & 68,75 & 87,5 \\
\hline 3 & $\begin{array}{l}\text { Fund. } \\
\text { Incompleto } \\
\text { (3ª série) }\end{array}$ & Aux. Manut. Obras & 62 & $0: 22$ & 62,5 & 87,5 & 37,5 \\
\hline 4 & Ensino Médio & Pedreiro & 45 & $0: 30$ & 68,75 & 31,25 & 87,5 \\
\hline 5 & $\begin{array}{l}\text { Ensino Médio } \\
\text { Técnico }\end{array}$ & Eletricista & 33 & $0: 16$ & 87,5 & 56,25 & 93,75 \\
\hline 6 & Ensino Médio & Aux. Manut. Obras & 51 & $0: 16$ & 75 & 56,25 & 93,75 \\
\hline 7 & Ensino Médio & Aux. Serv. Gerais & 54 & $0: 20$ & 81,25 & 68,75 & 93,75 \\
\hline 8 & $\begin{array}{l}\text { Pós } \\
\text { Graduação }\end{array}$ & Encanador & 37 & $0: 19$ & 68,75 & 37,5 & 93,75 \\
\hline 9 & $\begin{array}{l}\text { Fund. Incomp. } \\
\text { (Ginásio) }\end{array}$ & Op. de Máquina & 49 & $0: 17$ & 62,5 & 12,5 & 68,75 \\
\hline 10 & Ensino Médio & Eletrotécnico & 51 & $0: 22$ & 75 & 18,75 & 93,75 \\
\hline 11 & Ensino Médio & Pedreiro & 56 & $0: 20$ & 81,25 & 50 & 81,25 \\
\hline 12 & Ensino Médio & Aux. Manut. Obras & 42 & $0: 22$ & 62,5 & 56,25 & 81,25 \\
\hline 13 & Ensino Médio & Pedreiro & 43 & $0: 23$ & 62,5 & 43,75 & 100 \\
\hline 14 & Ensino Médio & Aux. Serv. Gerais & 43 & $0: 17$ & 93,75 & 43,75 & 93,75 \\
\hline 15 & Ensino Médio & Aux. Manut. Obras & 42 & $0: 20$ & 87,5 & 50 & 93,75 \\
\hline
\end{tabular}


Dentre todas as palavras marcadas, os voluntários responderam que conheciam em média $80 \%$ delas. Ao separar termos técnicos de palavras complexas, os voluntários responderam que conheciam em média, $67,74 \%$ dos termos técnicos e conheciam $100 \%$ das palavras complexas (Figura 20).

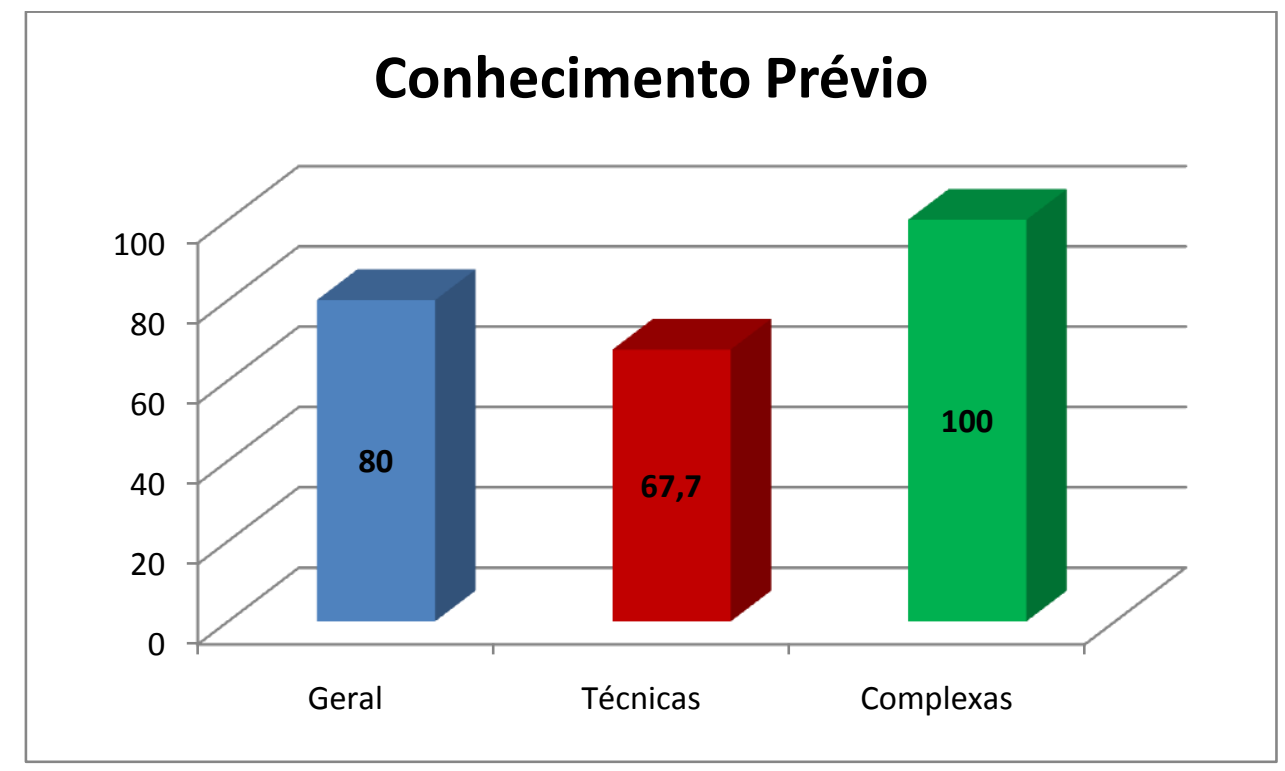

Figura 20 - Média de conhecimento prévio dos termos da avaliação

Sobre a utilidade da informação extra que foi disponibilizada para os voluntários ao clicar em um termo marcado (definições da Wikipédia, como descrito no Capítulo 4.2.1.2), os voluntários responderam em média que $51,52 \%$ das informações extras foram úteis em geral. A média de utilidade sobe para $62,19 \%$ ao serem considerados somente os termos técnicos e cai para $6,64 \%$ se consideradas apenas as palavras complexas (Figura 21). 


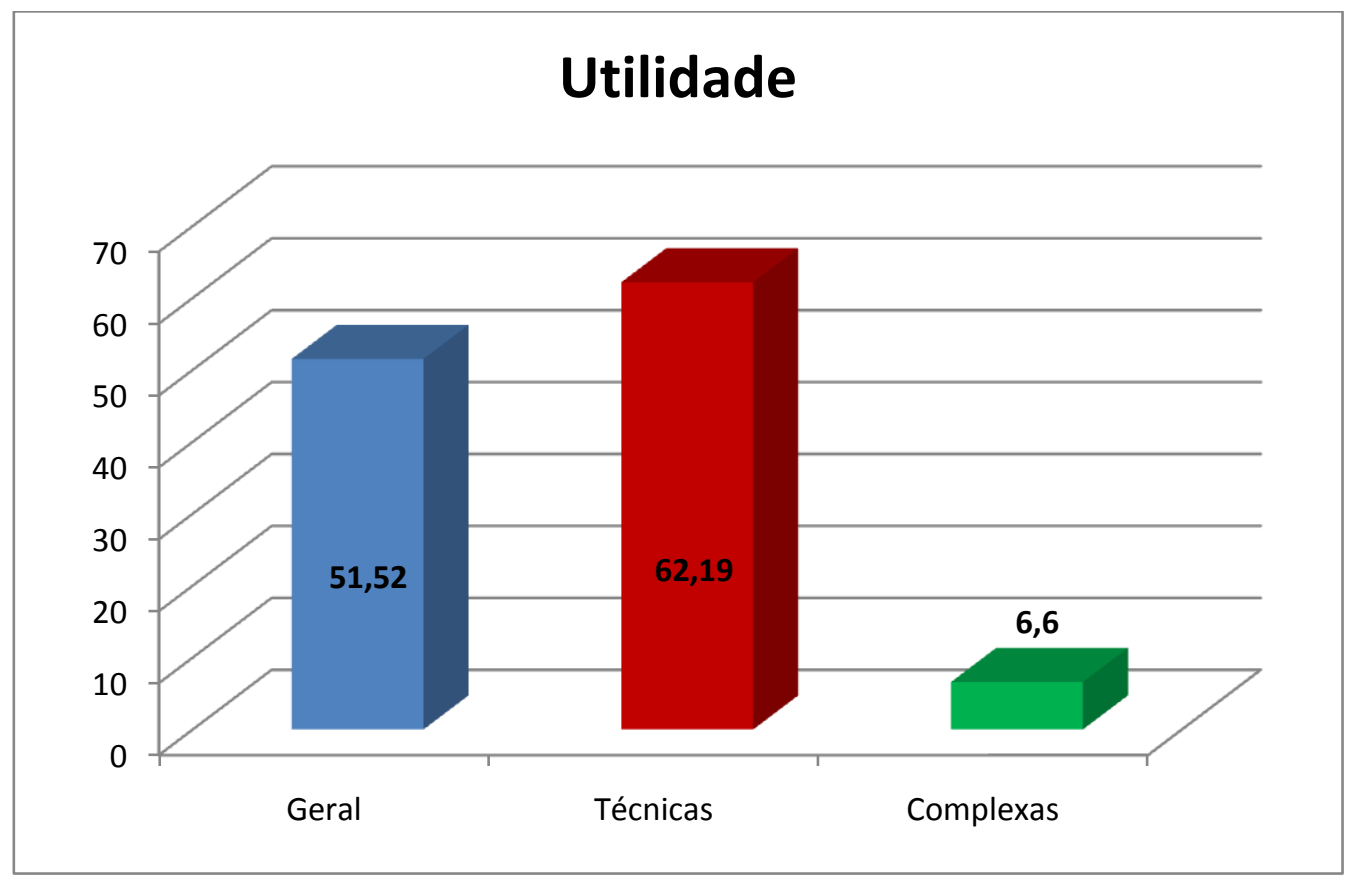

Figura 21 - Média da utilidade da informação extra fornecida para cada termo

Após a contabilização das respostas do questionário aplicado aos voluntários, foi verificado que a média de acerto da definição das palavras de todas as palavras foi de 86,65\%. Ao calcular a média de acerto entre as palavras complexas e termos técnicos, foi verificada que ambas tiveram também uma média de $86,6 \%$ (Figura 22).

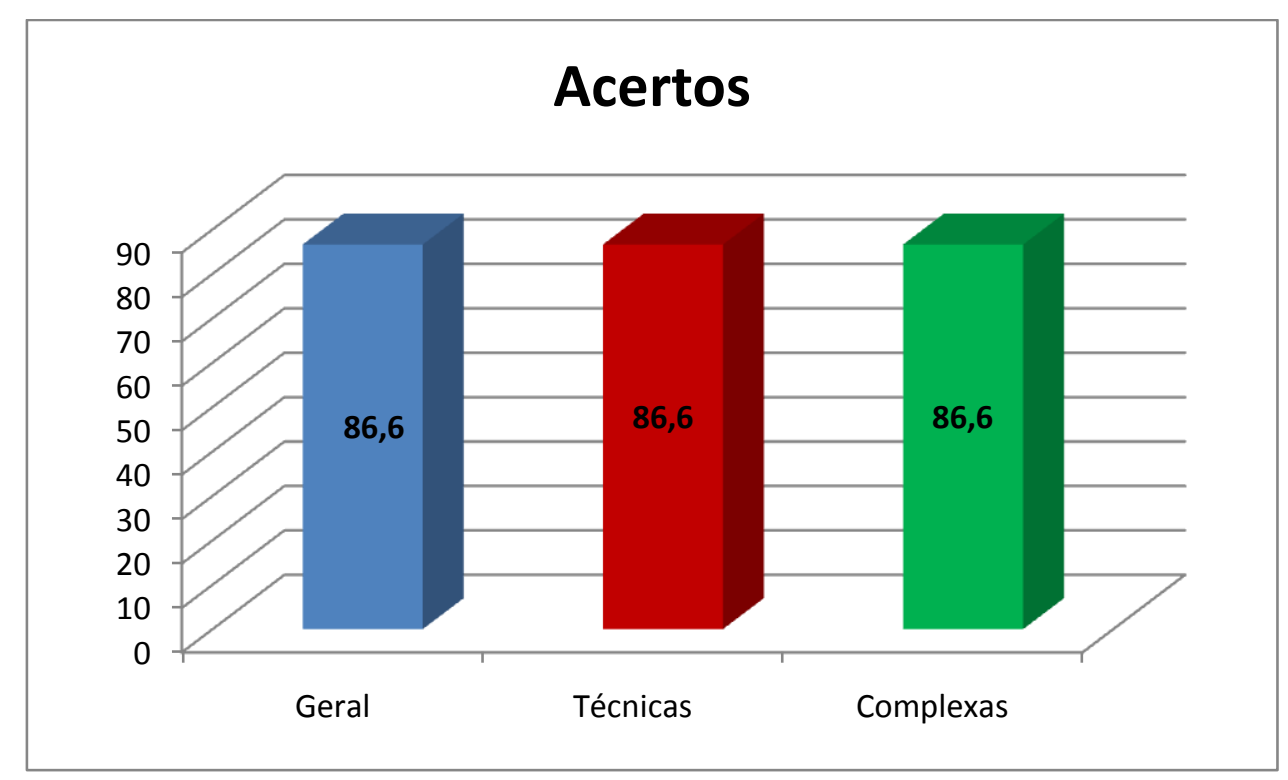

Figura 22 - Média de acerto das questões 
Ao se comparar os termos técnicos encontrados no texto com as palavras complexas, nota-se que a média das respostas dos voluntários sobre conhecimento prévio das palavras complexas foi de $100 \%$ e a média de utilidade da informação apresentada para estas palavras foi de apenas 6,6\%. Além disso, vimos que mesmo declarando total conhecimento prévio sobre as palavras complexas, a média de acerto foi de $86,6 \%$. Quanto às palavras técnicas, observou-se que os voluntários a média de conhecimento prévio foi de $67,7 \%$ dos termos. No entanto, a média de utilidade das informações complementares fornecidas para os termos técnicos foi de $62,19 \%$, bem acima da média de 6,6\% das palavras complexas (Figura 23).

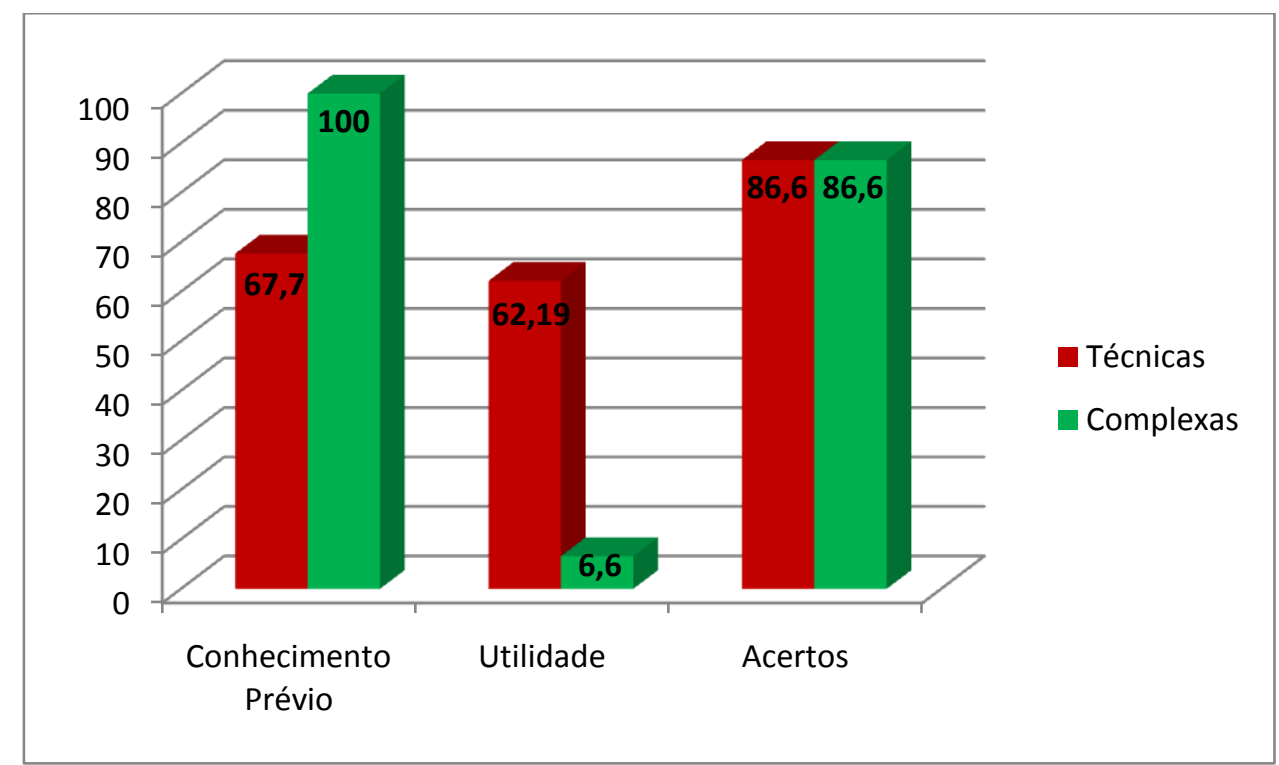

Figura 23 - Comparação de conhecimento prévio, utilidade e acertos entre as palavras complexas e os termos técnicos

Dentre todos os termos presentes no texto, podemos destacar o termo técnico "interlaced", o qual apenas 13,3\% dos voluntários declararam ter conhecimento prévio sobre o termo, porém, 66,6\% dos voluntários declaram como útil a informação fornecida no link disponível com definição da Wikipédia e o índice de acerto na questão referente a este termo foi de 93,3\%, mostrando que a informação extra fornecida via elaboração léxica foi comprovadamente útil. O termo "video componente" também era pouco conhecido pelos voluntários $(26,6 \%)$ e $80 \%$ considerou a informação fornecida como sendo útil, mas neste caso o índice de acerto da questão referente ao termo foi de $66,6 \%$, abaixo da média geral de $86,6 \%$, demonstrando que neste caso a informação fornecida não foi boa o suficiente para ajudar os voluntários a entender melhor o termo e responder a questão. É importante observar aqui, que ficamos reféns da qualidade da informação fornecida na Wikipédia, o que nem 
sempre é adequada para definir um termo/conceito. A Tabela 12 apresenta as porcentagens para cada resposta de cada um das 16 palavras analisadas.

Tabela 12 - Porcentagens de respostas

\begin{tabular}{|l|c|c|c|}
\hline & $\begin{array}{c}\text { Conhecimento } \\
\text { Prévio }\end{array}$ & Utilidade & Acertos \\
\hline Videocassete & $100 \%$ & $26,6 \%$ & $86,6 \%$ \\
\hline S-VHS & $73,3 \%$ & $86,6 \%$ & $86,6 \%$ \\
\hline s-video & $33,3 \%$ & $86,6 \%$ & $86,6 \%$ \\
\hline cabo de vídeo & $93,3 \%$ & $40 \%$ & $93,3 \%$ \\
\hline mono & $100 \%$ & $53,3 \%$ & $86,6 \%$ \\
\hline audio & $93,3 \%$ & $60 \%$ & $86,6 \%$ \\
\hline cabo de audio & $93,3 \%$ & $26,6 \%$ & $93,3 \%$ \\
\hline vídeo componente & $26,6 \%$ & $80 \%$ & $66,6 \%$ \\
\hline dvd player & $93,3 \%$ & $60 \%$ & $86,6 \%$ \\
\hline 480p & $46,6 \%$ & $80 \%$ & $93,3 \%$ \\
\hline 720p & $46,6 \%$ & $80 \%$ & $80 \%$ \\
\hline interlaced & $13,3 \%$ & $66,6 \%$ & $93,3 \%$ \\
\hline simultaneamente & $100 \%$ & $6,66 \%$ & $93,3 \%$ \\
\hline terminal & $100 \%$ & $13,3 \%$ & $93,3 \%$ \\
\hline tomada & $100 \%$ & $0 \%$ & $80 \%$ \\
\hline além & $100 \%$ & $6,6 \%$ & $80 \%$ \\
\hline
\end{tabular}

\subsubsection{Análise de Correlações}

A análise de correlações é utilizada para verificar a existência de relações entre duas ou mais variáveis. Esta técnica determina a significância estatística presente entre as variáveis e através dela é possível determinar a força da associação.

A estatística qui-quadrado é usada para se comparar a contagem de respostas categóricas (ou nominais) entre dois ou mais grupos independentes. No caso mais simples do qui-quadrado, é usado uma tabela de contingência $2 \times 2$ na notação apresentada na Tabela 13.

Tabela 13 - Tabela de contingência

\begin{tabular}{|l|c|c|c|}
\hline & Tipo de dado 1 & Tipo de dado 2 & Totais \\
\hline Categoria 1 & $\mathrm{a}$ & $\mathrm{b}$ & $\mathrm{a}+\mathrm{b}$ \\
\hline Categoria 2 & $\mathrm{c}$ & $\mathrm{d}$ & $\mathrm{c}+\mathrm{d}$ \\
\hline Totais & $\mathrm{a}+\mathrm{c}$ & $\mathrm{b}+\mathrm{d}$ & $\mathrm{a}+\mathrm{b}+\mathrm{c}+\mathrm{d}=\mathrm{N}$ \\
\hline
\end{tabular}

A fórmula para o qui-quadrado para a Tabela 13 é:

$$
X^{2}=(a d-b c)^{2}(a+b+c+d) /(a+b)(c+d)(c+d)(a+c) .
$$


Além disso, é necessário saber qual o grau de liberdade (G.L.) a ser usado. Para uma comparação entre um conjunto e outro, a regra básica é que o grau de liberdade é dado por: $\left(\mathrm{N}^{\mathrm{o}}\right.$ colunas da tabela de contingência - 1$) \times\left(\mathrm{N}^{\mathrm{o}}\right.$ linhas da tabela de contingência -1$)$

Para este exemplo, o grau de liberdade é: $(2-1) \times(2-1)=1$.

O grau de liberdade é utilizado para acharmos o nível de probabilidade correspondente na tabela de distribuição do qui-quadrado (Tabela 14). Na literatura estatística, o valor do nível de significância mais comum é menor que 0.05 .

Tabela 14 - Tabela de distribuição do qui-quadrado

\begin{tabular}{|c|l|l|l|l|l|l|}
\hline $\begin{array}{c}\text { G.L./Nível de } \\
\text { Significância }\end{array}$ & $\mathbf{0 . 5}$ & $\mathbf{0 . 1 0}$ & $\mathbf{0 . 0 5}$ & $\mathbf{0 . 0 2}$ & $\mathbf{0 . 0 1}$ & $\mathbf{0 . 0 0 1}$ \\
\hline $\mathbf{1}$ & 0.455 & 2.706 & 3.841 & 5.412 & 6.635 & 10.827 \\
\hline $\mathbf{2}$ & 1.386 & 4.605 & 5.991 & 7.824 & 9.210 & 13.815 \\
\hline $\mathbf{3}$ & 2.366 & 6.251 & 7.815 & 9.837 & 11.345 & 16.268 \\
\hline $\mathbf{4}$ & 3.357 & 7.779 & 9.488 & 11.668 & 13.277 & 18.465 \\
\hline $\mathbf{5}$ & 4.351 & 9.236 & 11.070 & 13.388 & 15.086 & 20.517 \\
\hline
\end{tabular}

Após a avaliação, a contabilização dos resultados e a análise do perfil dos voluntários, surgiram hipóteses sobre quais fatores que poderiam influenciar os resultados da avaliação.

A primeira hipótese levantada foi de que a função exercida pelo voluntário tinha influência sobre o índice de utilidade das informações trazidas da Wikipédia e dicionário de sinônimos. Outra hipótese que surgiu foi de que o conhecimento prévio informado pelos voluntários estava correlacionado com o nível de acerto referente aos termos técnicos. Ainda, havia as hipóteses de que a idade e o nível de escolaridade influenciariam o nível de acerto. Por último, também foi levantada a hipótese de que a idade do voluntário influenciava na utilidade.

Ao se dividir o grupo de voluntários entre técnicos e auxiliares, verificamos que o grupo de voluntários técnicos considerou apenas 40,27\% das informações extras fornecidas como sendo útil, contra $60,41 \%$ do grupo de voluntários com funções de auxiliares. Ao executar o teste qui-quadrado nas respostas dos 2 grupos, obtivemos o valor de 9.3548, que fica entre 0.01 e 0.001 no nível de probabilidade, ou seja, podemos concluir que o desvio entre os dois grupos é significativo (Tabela 15). 
Tabela 15 - Grupos versus utilidade

\begin{tabular}{c|c|c|c}
\hline \multicolumn{4}{c}{ Grupos (Auxiliares/técnicos) $\mathbf{X}$ Utilidade (S/N ou 0/1) } \\
& Sim & Não & Totais \\
\hline Auxiliares & $58-60,41 \%$ & $38-39,58 \%$ & 96 \\
\hline Técnicos & $58-40,27 \%$ & $86-59,72 \%$ & 144 \\
\hline Totais & $116-48,33 \%$ & $124-51,66 \%$ & 240 \\
\hline
\end{tabular}

Excluindo as palavras complexas e analisando somente os termos técnicos, foi verificado que houve uma taxa de acerto de 90,16\% quando o voluntário respondeu que já conhecia o termo previamente. Quando o voluntário não tinha conhecimento prévio do termo, a taxa de acerto foi de 79,31\%. Para esta relação, foi obtido o valor de 4.0074 no quiquadrado, que fica entre 0.05 e 0.02 no nível de probabilidade, concluindo que este desvio é significativo (Tabela 16).

Tabela 16 - Conhecimento prévio versus acertos

\begin{tabular}{|c|c|c|c|}
\hline \multicolumn{4}{|c|}{12 Termos Técnicos -Conhecimento prévio x N. acertos } \\
\hline & Acertos Sim & Acertos Não & Totais \\
\hline Com Conhecimento Prévio & $110-90,16 \%$ & $12-9,83 \%$ & 122 \\
\hline Sem Conhecimento Prévio & $46-79,31 \%$ & $12-20,68 \%$ & 58 \\
\hline Totais & 156 & 24 & 180 \\
\hline
\end{tabular}

Ao se dividir o grupo de voluntários pelo nível de escolaridade (Fundamental / Ensino Médio e Superior) e analisar o índice de acerto em todas as palavras, foi verificado que o grupo com ensino fundamental teve um índice de acerto de $64,58 \%$, e o grupo com ensino médio ou superior teve um índice de acerto de 90,16\%. Nesta relação, foi obtido o valor de 25.3215 no cálculo do qui-quadrado, que fica abaixo de 0.001 no nível de probabilidade. Portanto, neste caso o nível de significância do desvio foi bem alto (Tabela 17).

Tabela 17 - Nível de escolaridade versus acertos

\begin{tabular}{c|c|c|c}
\hline \multicolumn{2}{|c}{ (Nível Escolaridade) X Acertos (S/N ou 0/1) } \\
& Acertos Sim & Acertos Não & Totais \\
\hline Ensino Fundamental & $31-64,58 \%$ & $17-35,41 \%$ & 48 \\
\hline Ensino Médio e Superior & $177-92,18 \%$ & $15-7,81 \%$ & 192 \\
\hline Totais & 208 & 32 & 240 \\
\hline
\end{tabular}


A utilidade das informações apresentadas aos usuários também foi avaliada em relação à idade dos voluntários, que foram divididos em dois grupos (30-49 anos / 50-68 anos). Neste caso, o grupo com idade entre 30-49 anos considerou 41,66\% das informações como sendo úteis. O grupo com idade entre 50-68 anos considerou 58,33\% das informações como úteis. Foi obtido o valor de 6.4071 no cálculo do qui-quadrado para esta relação. Este valor está situado entre 0.02 e 0.01 no nível de probabilidade, portanto o nível de significância deste desvio é alto (Tabela 18).

Tabela 18 - Idade versus utilidade

\begin{tabular}{c|c|c|c}
\hline \multicolumn{4}{c}{ Idade(30-49 $\times$ 50-68) $\times$ Utilidade (S/N) } \\
& Sim & Não & Totais \\
\hline Idade entre 30-49 & $60-41,66 \%$ & $84-58,33 \%$ & 144 \\
\hline Idade entre 50-68 & $56-58,33 \%$ & $40-41,66 \%$ & 96 \\
\hline Totais & 116 & 124 & 240 \\
\hline
\end{tabular}

Ainda utilizando a divisão dos voluntários em dois grupos em função da idade, foi avaliado o índice de acerto do questionário levando em consideração todos os termos. O grupo com idade entre 30-49 anos acertou 90,27\% das questões, enquanto o grupo com idade entre 50-68 anos acertou 81,25\%. No cálculo do qui-quadrado, foi obtido o valor de 4.0625, que fica entre 0.05 e 0.02 no nível de probabilidade e, portanto, este desvio entre os dois grupos é significativo (Tabela 19).

Tabela 19 - Idade versus acertos

\begin{tabular}{c|c|c|c}
\hline \multicolumn{4}{c}{ Idade(30-49 x 50-68) $\times$ Acertos(S/N) } \\
& Sim & Não & Totais \\
\hline Idade entre 30-49 & $130-90,27 \%$ & $14-9,72 \%$ & 144 \\
\hline Idade entre 50-68 & $78-81,25 \%$ & $18-18,75 \%$ & 96 \\
\hline Totais & 208 & 32 & 240 \\
\hline
\end{tabular}




\section{Conclusão}

O objetivo principal do projeto Norman - o desenvolvimento de um método de extração de termos de manuais de instruções de produtos tecnológicos e sua utilização em sistemas de adaptação textual - foi alcançado com sucesso. O método encontra-se disponível no Portal Norman para ser utilizado em outras pesquisas de extração de termos de manuais.

O trabalho envolveu o estudo de Linguagens Controladas, métodos de extração de termos para textos científicos e principalmente a estrutura dos manuais de instruções e suas relações gera e habilita. Estes estudos apresentaram os principais conceitos e técnicas utilizadas na tarefa, resultando na proposta de um novo método.

O método é baseado em informações linguísticas e estatísticas, e deve ser aplicado para a geração de candidatos quando não houver muitos manuais sobre um determinado produto tecnológico, que é uma das diferenças do que ocorre com a extração de termos de artigos científicos de um dado domínio. O método proposto concentra a busca de termos no habitat natural destes, parafraseando Moura (2008), que é nas sentenças que apresentam as relações procedimentais gera e habilita, e ranqueia os termos usando a medida $\underline{C \text {-value }}$, utilizada para extração de termos compostos. Esta medida evita que subcadeias de cadeias já extraídas sejam consideradas candidatas a termos.

Durante o desenvolvimento do trabalho, foi criado um córpus de manuais de instruções. Este córpus serviu como base para os estudos sobre a estrutura de manuais e a partir dele foi gerado um subcórpus das seções de "instalação" e "instrução" de manuais de instrução de aparelhos televisores. Este subcórpus foi então utilizado como entrada no sistema de extração de termos proposto, implementado e avaliado.

O primeiro experimento realizado foi a extração de termos do subcórpus de televisão, porém a avaliação do desempenho do método foi prejudicada devido a falta de uma lista de referência.

Foi feito uma comparação dos resultados desta extração com os resultados dos métodos de extração de Teline (2004) e também foi calculado o coeficiente de similaridade Jaccard (J). Para unigramas, o método NorMan teve uma intersecção de 71,6\% com o método Linguístico $(\mathrm{J}=0,44), 77,3 \%$ com o método Estatístico $(\mathrm{J}=0,52), 42,4 \%$ com o método Hibrido-A $(\mathrm{J}=0,37)$ e $51,8 \%$ com o Híbrido-B $(\mathrm{J}=0,44)$. A comparação dos bigramas mostrou que os termos recuperados pelo método NorMan tiveram uma intersecção de 42,5\% 
com o método Linguístico $(\mathrm{J}=0,15), 36,3 \%$ com o método Estatístico $(\mathrm{J}=0,03), 10,8 \%$ com o método Híbrido-A $(\mathrm{J}=0,09)$ e 12,6\% com o método Híbrido-B $(0,10)$. Em trigramas, a intersecção dos termos recuperados pelo método NorMan com o método Linguístico foi de $46,9 \%$ ( $\mathrm{J}=0,17), 22,2 \%$ com o método Estatístico $(0,03), 10,6 \%$ com o método Híbrido-A $(0,09)$ e $15,1 \%$ com o método Híbrido-B $(0,13)$.

A análise da intersecção e coeficiente de similaridade dos termos recuperados entre o método NorMan e os diferentes métodos utilizados nesta avaliação mostrou que o método NorMan trouxe mais novidades para bi e trigramas, sendo que a interseção e similaridade com outros métodos de extração para unigramas foi mais alta.

O próximo experimento realizado foi o cálculo da medida estatística Kappa, para a verificação do nível de concordância dos avaliadores para os 150 primeiros termos ranqueados pelo $\mathrm{C}$-value. $\mathrm{O}$ valor da medida Kappa calculado com os dados fornecidos pelos avaliadores da lista de unigramas foi de 0,507 , representando um índice de concordância moderado, segundo a tabela de classificação de valores Kappa. Para a lista de bigramas, o valor da medida Kappa foi de apenas 0,069, que representa uma concordância pequena entre os avaliadores. Por fim, o valor da medida Kappa para a lista de trigramas foi de 0,061, que também representa um índice pequeno de concordância entre os avaliadores. O fato de que não houve a participação de especialistas do domínio de televisores pode ter influenciado o baixo índice de concordância.

O outro experimento realizado foi a avaliação extrínseca do método via adaptação do método de simplificação léxica do sistema SIMPLIFICA para o uso com manuais de instrução. Essa adaptação foi feita através do uso dos termos extraídos pelo sistema NorMan como um dicionário e também através da elaboração dos termos através do uso de informações da Wikipédia. A avaliação da adaptação foi conduzida com 15 funcionários do departamento de obras do campus da USP de São Carlos, com idades entre 30 e 68 anos, nível escolaridade entre nível fundamental e superior e com funções auxiliares e técnicas. Os voluntários leram um trecho de manual de instrução de televisores e então avaliaram o sistema que fornecia informações adicionais provenientes da Wikipédia sobre os termos técnicos ou então sugestões de substituição para palavras complexas. Após a leitura, os voluntários foram questionados sobre o conhecimento prévio sobre os termos técnicos ou palavras complexas, a utilidade da elaboração destes termos ou palavras e, por fim, foi feito um questionário para checar o conhecimento efetivo dos termos técnicos e palavras do texto. 
Este experimento avaliou várias hipóteses sobre a elaboração dos termos técnicos com o uso de informações da Wikipédia e com a indicação de lista de sinônimos e sua utilidade para o entendimento do manual de instruções.

Neste experimento foi avaliado o conhecimento prévio dos termos técnicos entre os voluntários, a utilidade da elaboração dos termos usando a Wikipédia para a compreensão e a checagem, via teste de múltipla escolha, do conhecimento dos termos pelos voluntários.

Os resultados mostraram que apesar de os voluntários afirmarem conhecer uma média de $67,7 \%$ dos termos técnicos, uma média de 62,19\% das informações da Wikipédia foram colocadas como úteis, resultando em um índice de acerto no questionário de 86,6\%, mostrando que o uso da elaboração foi realmente útil.

Para palavras complexas, os voluntários afirmaram ter um conhecimento prévio de $100 \%$ sobre elas e apenas uma média de 6,6\% das sugestões de substituição das palavras complexas foram consideradas úteis, resultando numa média de acerto de 86,6\%, o que implica que os usuários não conheciam bem a definição delas.

Uma análise estatística mostrou que a função exercida pelo funcionário tem influência significativa no nível do índice de utilidade averiguado pelo voluntário. Neste caso, o índice de utilidade foi de $60,4 \%$ para os voluntários com funções auxiliares contra 40,2\% dos voluntários com funções técnicas.

Outra análise realizada mostrou que o conhecimento prévio dos termos técnicos também influencia o nível de acerto das questões referentes a estes termos. O índice de acertos foi de $90,1 \%$ para os voluntários que afirmaram ter conhecimento prévio do termo, contra $79,3 \%$ dos voluntários que afirmaram não conhecer os termos previamente.

A próxima análise estatística mostrou que o nível de escolaridade também influencia o nível de acerto das questões. Neste caso, os voluntários que possuíam apenas ensino fundamental tiveram um índice de $64,5 \%$ de acerto das questões, contra um índice de 92,1\% dos voluntários com nível médio ou superior.

Além do nível de escolaridade, também foi verificado estatisticamente que a idade influencia o nível de acerto das questões. Os voluntários com idade entre 30 e 49 anos obtiveram um índice de acerto de 90,2\%, contra 81,2\% dos voluntários com idade entre 50 e 68 anos. 
Por último, foi verificado estatisticamente que a idade também influenciava o nível de utilidade percebido pelos voluntários. Neste caso, os voluntários com idade entre 30 e 49 tiveram um índice de utilidade de $41,6 \%$ contra 58,3\% dos voluntários com idade entre 50 e 68 anos.

\subsection{Contribuições do Trabalho}

Ao final deste trabalho podemos destacar as contribuições deste projeto, entre elas a proposta e a implementação de um novo método de extração de termos voltado para o gênero de manuais de instrução, além da revisão atualizada dos métodos de extração. Além disso, houve um amplo estudo sobre os manuais de instruções e sua estrutura.

Também devemos destacar a importância da aplicação dos resultados do método de extração em aplicações de caráter social, como é o caso do editor de simplificação SIMPLIFICA.

Por fim, a criação do Portal do Projeto NorMan, que traz informações, recursos e ferramentas criados durante este trabalho.

\subsection{Limitações do Trabalho}

Uma das principais limitações deste trabalho foi dificuldade enfrentada para efetuar as avaliações intrínsecas do método de extração de termos sem uma lista de referência ou sem especialistas do gênero que pudessem colaborar nesta tarefa.

\subsection{Trabalhos Futuros}

A partir deste trabalho, podemos identificar algumas tarefas para possíveis trabalhos futuros:

- A criação de listas de referência do gênero de manuais de instrução, para vários produtos tecnológicos, para que o método desenvolvido nesta pesquisa e outros para este gênero possam ser avaliados.

- Estudar os fenômenos sintáticos complexos em manuais para a adaptação da simplificação sintática do Editor de Simplificação SIMPLIFICA para o gênero de manuais de instrução, via criação de regras ou escolha do conjunto de regras dedicado a eles. 
- Aprofundamento do estudo do uso de recursos linguísticos (como a Wikipédia que foi escolhida) disponíveis livremente para a criação de outros métodos de elaboração textual.

- Estudar e aplicar novos padrões morfossintáticos na extração automática de termos.

- Analisar os novos formatos de manuais de instrução que estão surgindo, por exemplo, devido ao uso da leitura eletrônica.

- Analisar outras seções dos manuais, além das seções de instalação e instruções, contabilizando as frequências dos padrões escolhidos para as relações gera e habilita.

- Estender o estudo e avaliação em manuais de software livre, pois estes são escritos por várias pessoas carecendo, por exemplo, de uniformização e simplificação das instruções. 


\section{Referências}

ALTWARG, R. (2006). Controlled Languages, an Introduction. Centre for Language Technology website on Controlled Natural Languages, Macquarie University. Available at http://www.shlrc.mq.edu.au/masters/students/raltwarg/clindex.htm

ALUÍSIO, S.M.; GASPERIN, C. (2010a). Fostering Digital Inclusion and Accessibility: The PorSimples project for Simplification of Portuguese Texts. Proceedings of the NAACL HLT 2010 Young Investigators Workshop on Computational Approaches to Languages of the Americas. New York : ACL, 2010. v. 1. p. 46-53.

ALUÍSIO, S. M.; SPECIA, L.; GASPERIN, C.; SCARTON, C. E. (2010b). Readability Assessment for Text Simplification. In: NAACL 5th Workshop on Innovative Use of NLP for Building Educational Applications (BEA-2010), 2010, Los Angeles. Proceedings of the NAACL HLT 2010 Fifth Workshop on Innovative Use of NLP for Building Educational Applications. New York: ACL, 2010. v. 1. p. 1-9.

ALUÍSIO, S. M.; SPECIA, L.; PARDO, T.; MAZIERO, E.; CASELI, H. M.; FORTES, R. (2008a). "A Corpus Analysis of Simple Account Texts and the Proposal of Simplification Strategies: First Steps towards Text Simplification Systems " In proceedings of The 26th ACM Symposium on Design of Communication (SIGDOC 2008), pp. 15-22.

ALUÍSIO, S. M.; SPECIA, L.; PARDO, T.; MAZIERO, E.; FORTES, R. (2008b). "Towards Brazilian Portuguese Automatic Text Simplification Systems." In proceedings of The Eight ACM Symposium on Document Engineering (DocEng 2008), pp. 240-248.

AOULADOMAR, F. (2005a). Towards Answering Procedural Questions, Workshop KRAQ05, IJCAI05, Edinburgh, 2005.

AOULADOMAR, F. (2005b). A Preliminary Analysis of the Discursive and Rhetorical Structure of Procedural Texts, Symposium on the Exploration and Modelling of Meaning, SEM-05, Biarritz (Basque Country, France), 2005. 
AOULADOMAR, F.; SAINT-DIZIER, P. (2005). An Exploration of the Diversity of Natural Argumentation in Instructional Texts, Workshop CMNA, IJCAI05, Edinburgh, July 2005.

BICK, E. (2000). The Parsing System "Palavras". Automatic Grammatical Analysis of Portuguese in a Constraint Grammar Framework. Tese (Doutorado) - Arhus University, 2000 .

BIDERMAN, M. T. C. (2005). DICIONÁRIO Ilustrado de Português. São Paulo, Editora Ática.. 1ª ed. São Paulo: Ática, 2005.

BURG, J. F. M. (1996). Linguistic Instruments in Requirements Engineering, IOS Press, Amsterdam, The Netherlands, 1996.

BURSTEIN, J. (2009). Opportuni ties for Natural Language sing Research in Education. In Proceedings of CICLing '2009, 6-27.

CANDIDO JR. A, OLIVEIRA M., ALUISIO S. M. (2009). Simplifica: um Sistema Web de Autoria de Textos Simplificados. In the Proceedings of WEBMEDIA 2009 - Simpósio Brasileiro de Sistemas Multimídia e Web, 2009, Fortaleza - CE. v. 2. p. 55 - 58.

CARDOSO， N. M.; CRISTINA; SANTOS; DIANA; SEGUNDO， O. (eds) (2008). REMBRANDT - Reconhecimento de Entidades Mencionadas Baseado em Relações e Análise Detalhada do Texto. Desafios na avaliação conjunta do reconhecimento de entidades mencionadas pp. 195-211. HAREM , Linguateca.

CARLETTA, J. (1996). Assessing agreement on classification tasks: The kappa statistic. Computational Linguistics, 22(2), pp. 249-254.

CARVALHO NETTO, J. R. (2003). Ao Encontro da Lei: O Novo Código Civil ao alcance de todos. São Paulo: Imprensa Oficial, 2003.

CASELI, H.M.; PEREIRA, T.F., SPECIA, L.; PARDO, T.A.S.; GASPERIN, C.; ALUÍSIO, S.M.; (2009). Building a Brazilian Portuguese parallel corpus of original and simplified texts. In Alexander Gelbukh (ed), Advances in Computational Linguistics, Research in 
Computer Science, vol 41, pp. 59-70. 10th Conference on Intelligent Text Processing and Computational Linguistics (CICLing-2009), March 01-07, Mexico City.

COLE, R. (1997). Survey of the state of the art in human language technology, Cambridge University Press, New York, NY, 1997

DAILLE, B. (1996). Study and Implementation of Combined Techniques for Automatic Extraction of Technology. In: Klavans, J., Resnik, P. The Balancing ACT- Combining Symbolic and Statistical Approaches to Language, The MIT Press, p. 49-66.

DELIN, J.; HARTLEY, A.; PARIS, C., SCOTT, D.; VANDER LINDEN, K. (1994). Expressing Procedural Relationships in Multilingual Instructions, Proceedings of the Seventh International Workshop on Natural Language Generation, pp. 61-70, Maine, USA. 1994.

Di EUGENIO, B. (1992). Understanding Natural Language Instructions: the Case of Purpose Clauses, Proceedings 30th Annual Meeting of the Association for Computational Linguistics, ACL92, Newark, Delaware, 120-127, 1992. Disponível em http://www.aclweb.org/anthology-new/P/P92/P92-1016.pdf

EDWARDS, J. A.; A. G. KINGSCOTT. (1997). eds. Language Industries Atlas. Second edn. (Amsterdam: IOS Press, 1997).

EIJK, P. (1997). Controlled languages in technical documentation (1997) Computational Linguistics in the Netherlands, 1997 - pag 187

ESTOPÀ BAGOT, R. (1999). Extracció de terminologia: elements per a la construcció d'um SEACUSE (Sistema d'Extracció Automàtica de Candidats a Unitats de Signficació Especialitzada). Tese de Doutorado. Universidade Pompeu Fabra, 1999.

FELLBAUM, C. (1998). WordNet An Electronic Lexical Database, The MIT Press, 1998.

FONTAN, L.; SAINT-DIZIER, P. (2008). Analyzing the explanation structure of procedural texts: dealing with Advices and Warnings. Dans / In : International Symposium on Text 
Semantics (STEP 2008), Venise, 22/09/2008-24/09/2008, Johan Bos (Eds.), Association for Computational Linguistics (ACL), p. 84-93, septembre / september 2008.

FRANTZY, K. T.; ANANIADOU, S. (1997). Automatic Term Recognition using Contextual Cues. Manchester Metropolitan University. THIRD DELOS WORKSHOP CrossLanguage Information Retrieval Zurich, 5-7 March 1997 ISBN 2-912335-02-7.

GASPERIN, C.; MAZIERO, E.; ALUÍSIO, S.M. (2010). Challenging Choices for Text Simplification, In: Proceedings of PROPOR 2010, p. 40-50, António Branco, Aldebaro Klautau, Renata Vieira, Vera Lúcia Strube de Lima (Eds.): Computational Processing of the Portuguese Language, 9th International Conference, PROPOR 2010, Porto Alegre, RS, Brazil, April 27-30, 2010. Proceedings. Springer 2010, v. 6001. p. 40-50. ISBN 978-3-642$12319-1$

GRISHMAN, R. (2001). Adaptive Information Extraction and Sublanguage Analysis. Proceedings of IJCAI, 2001. Disponível em: http://nlp.cs.nyu.edu/publication/papers/grishman-ijcai01.pdf

HARTLEY, A. F., SCOTT, D. R., BATEMAN, J., \& DOCHEV, D. (2001). AGILE - A System for Multilingual Generation of Technical Instructions. In Proceedings of 8th Machine Translation Summit (MT Summit VIII), pp. 145-150

HEID, U.; JAUß, S.; KRÜGER, K.; HOHMANN, A. (1996). Term extraction with standard tools for corpus exploration. IN: 4th International Congress on Terminology and Knowledge Engineering. Wien. August.

INAF (2009). Instituto P. Montenegro and Ação Educativa. INAF Brasil - Indicador de Alfabetismo Funcional - 2009. Available online at http://www. ibope. com.br/ipm/relatorios/relatorio_inaf_2009.pdf

JANCZURA, G. A.; CASTILHO, G. M.; ROCHA, N. O. (2007). Normas de concretude para 909 palavras da língua portuguesa. Psic.: Teor. e Pesq., v. 23, p. 195-204, 2007.

KAJI, H. (1999). Controlled languages for machine translation: State of the art, Proceedings of Machine Translation Summit VII, pp.37-39, 1999. 
KLAVANS, J. L.; MURESAN, S. (2000). DEFINDER: Rule-Based Methods for the Extraction of Medical Terminology and their Associated Definitions from Online Text. In: Proceedings of the Annual Fall Symposium of the American Medical Informatics Association, AMIA. 2000. pp. 1906.

KLAVANS, J. L.; MURESAN, S. (2001a). Evaluation of DEFINDER: A System to Mine Definitions from Consumer-oriented Medical Text. In: Proceedings of JCDL 2001.pp.201202.

KLAVANS, J. L.; MURESAN, S. (2001b). Evaluation of the DEFINDER System for Fully Automatic Glossary Construction. In Proceedings of AMIA Symposium. 2001.pp.324-328.

LEFFA, V.J. (1996). Fatores da compreensão na leitura. Cadernos no IL, Porto Alegre, v.15, p.143159, 1996. <http:// www.leffa.pro.br/fatores.htm>. Acesso em jan. 2008.

LOPES, L.; VIEIRA, R.; FINATTO, M. J.; MARTINS, D. (2010). Extracting compound terms from domain corpora. Journal of the Brazilian Computer Society (Impresso), p. 01$13,2010$.

MANNING, C.; SCHÜTZE, H. (1999). Collocations. In: Foundations of Statistical Natural Language Processing, p. 141-77. MIT Press. Cambrige.

MAPLESON, D.L. (2006). Post-Grammatical Processing for Discourse Segmentation. PhD Thesis. School of Computing Sciences, University of East Anglia, Norwich.

MAX, A. (2006). Writing for Language-impaired Readers. In Proceedings of Seventh International Conference on Intelligent Text Processing and Computational Linguistics (Mexico City, Mexico, February 19-25, 2006). CICLing 2006. Springer-Verlag, Berlin Heidelberg New York, 567-570.

MITKOV, R. (2003). The Oxford Handbook of Computational Linguistics (Oxford Handbooks in Linguistics S.), Oxford University Press, 2003 
MOURA, A. B. N. (2008). Tipologia Textual e Ativação de Terminologia: um Estudo em Manuais Técnicos de Produtos Tecnológicos. Tese de Doutorado em Letras - Universidade Federal do Rio Grande do Sul, p. 287.

MUNIZ, F.; ALUÍSIO, S. M. (2010). NorMan Extractor: Automatic term extraction from technical manuals. In Proceedings of PROPOR 2010, 9th International Conference on Computational Processing of the Portuguese Language, Extended Activities Proceedings, 1 CD-ROM v1. ISSN: 21773580.

OGDEN, C.K. (1932). Basic English, A General Introduction with Rules and Grammar. London: Paul Treber \& Co.

PANTEL, P.; LIN, D. (2001). A statistical corpus-based term extractor. In: E. Stroulia \& S. Matwin (Ed.), AI 2001, Lecture Notes in Artificial Intelligence, Springer-Verlag, p. 36-46.

PARIS, C.; SCOTT, D. (1994). Stylistic variation in multilingual instructions. In Proceedings of the Seventh International Workshop on Natural Language Generation, Kennebunkport, MN, 21--24 June 1994, pages 45--52.

PARIS, C.; VANDER LINDEN, K., FISCHER, M.; HARTLEY, A.; PEMBERTON, L.; POWER, R.; SCOTT, D. (1995). A support tool for writing multilingual instructions. In Proceedings of the 14th International Joint Conference on Artificial Intelligence, pages 1398--1404, Montreal, Canada, 1995.

PETERSEN, S. E.; OSTENDORF, M. (2007). Text Simplification for Language Learners: A Corpus Analysis. 2007. In Proceedings of the Speech and Language Technology for Education Workshop (Pennsylvania, USA, October 1-3, 2007). SLaTE-2007. Carnegie Mellon University and ISCA Archive, http://www.isca-speech.org/archive/slate_2007. 6972.

RAMOS, W. M. (2006). A compreensão leitora e a ação docente na produção do texto para o ensino a distância. Linguagem e Ensino, 9(1):215-242. 
RATNAPARKHI, A. (1996). A maximum entropy model for part-of-speech tagging. In Brill, E. \& Church, K., editors, Proceedings of the Conference on Empirical Methods in Natural Language Processing, pag. 133-142. Nova Jérsei, EUA.

RIBEIRO JR., L. C. (2008). OntoLP: Construção Semi-Automática de Ontologias a partir de Textos da Língua Portuguesa. Dissertação (Mestrado) - Programa de Pós-Graduação em Computação Aplicada, Universidade do Vale do Rio dos Sinos, 2008.

SAINT-DIZIER, P. (1998). Verb Semantic Classes Based on 'Alternations' and WordNet-like criteria, in : Predicative Forms in Natural language and lexical Knowledge Bases, Reds: Saint-Dizier,P., Eds: Kluwer Academic, Cambridge, USA, 1998.

SCARTON, C. E. ; GASPERIN, C. ; ALUÍSIO, S. M. (2010). Revisiting the Readability Assessment of Texts in Portuguese. In: IBERAMIA 2010, 2010, Bahia Blanca. Lecture Notes in Computer Science. Heidelberg : Springer, 2010. v. 6433. p. 306-315.

SIDDHARTHAN, A. (2002). An Architecture for a Text Simplification System. In Proceedings of the Language Engineering Conference (LEC), pp. 64-71. (2002)

SPECIA, L.; ALUÍSIO, S. M.; PARDO, T. A. S. (2008). Manual de Simplificação Sintática para o Português. Série de Relatórios do Núcleo Interinstitucional de Lingüística Computacional (NILC-TR-08-06), 27 p., Junho 2008, São Carlos-SP. Disponível em: http://caravelas.icmc.usp.br/wiki/index.php/Publications.

TELINE, M. F. (2004). Avaliação de métodos para extração automática de terminologia de textos em português. ICMC-USP, São Carlos, 2004. Dissertação de Mestrado.

URANO, K. (2000). Lexical simplification and elaboration: Sentence comprehension and incidental vocabulary acquisition. Unpublished master's thesis, University of Hawai'i at Manoa, Honolulu, 2000. Available at http://www.urano-ken.com/research/thesis.pdf

WATANABE, W. M. ; CÂNDIDO, A. ; AMANCIO, M.A. ; OLIVEIRA, M. ; PARDO, T. A. S. ; FORTES, R. P. M. ; ALUÍSIO, S. M. (2010). Adapting Web content for low-literacy 
readers by using lexical elaboration and named entities labeling. New Review of Hypermedia and Multimedia , v. 16, p. 303-327, 2010.

YOUNG, D. N (1999). Linguistic Simplification of SL Reading Materials: Effective Instructional Practice? The Modern Language Journal, 83(3):350-366, 1999.

ZAVAGLIA, C., OLIVEIRA, L.H.M., NUNES, M.G.V., ALUÍSIO, S.M. (2007). Estrutura Ontológica e Unidades Lexicais: Uma Aplicação Computacional no Domínio da Ecologia, In: Anais do $5^{\circ}$ Workshop em Tecnologia da Informação e da Linguagem Humana TIL'2007, pp. 1575-1584 


\section{Anexo A}

Lista de 850 palavras do vocabulário do Inglês Básico. Elas denotam conceitos simples e são usadas para situações do dia a dia.

\section{Operações - 100 palavras}

come, get, give, go, keep, let, make, put, seem, take, be, do, have, say, see, send, may, will, about, across, after, against, among, at, before, between, by, down, from, in, off, on, over, through, to, under, up, with, as, for, of, till, than, a, the, all, any, every, no, other, some, such, that, this, I, he, you, who, and, because, but, or, if, though, while, how, when, where, why, again, ever, far, forward, here, near, now, out, still, then, there, together, well, almost, enough, even, little, much, not, only, quite, so, very, tomorrow, yesterday, north, south, east, west, please, yes.

\section{Coisas - 400 palavras gerais}

A-F

account, act, addition, adjustment, advertisement, agreement, air, amount, amusement, animal, answer, apparatus, approval, argument, art, attack, attempt, attention, attraction, authority, back, balance, base, behaviour, belief, birth, bit, bite, blood, blow, body, brass, bread, breath, brother, building, burn, burst, business, butter, canvas, care, cause, chalk, chance, change, cloth, coal, colour, comfort, committee, company, comparison, competition, condition, connection, control, cook, copper, copy, cork, cotton, cough, country, cover, crack, credit, crime, crush, cry, current, curve, damage, danger, daughter, day, death, debt, decision, degree, design, desire, destruction, detail, development, digestion, direction, discovery, discussion, disease, disgust, distance, distribution, division, doubt, drink, driving, dust, earth, edge, education, effect, end, error, event, example, exchange, existence, expansion, experience, expert, fact, fall, family, father, fear, feeling, fiction, field, fight, fire, flame, flight, flower, fold, food, force, form, friend, front, fruit

G-O

glass, gold, government, grain, grass, grip, group, growth, guide, harbour, harmony, hate, hearing, heat, help, history, hole, hope, hour, humour, ice, idea, impulse, increase, industry, ink, insect, instrument, insurance, interest, invention, iron, jelly, join, journey, judge, jump, kick, kiss, knowledge, land, language, laugh, law, lead, learning, leather, letter, level, lift, light, limit, linen, liquid, list, look, loss, love, machine, man, manager, mark, market, mass, 
meal, measure, meat, meeting, memory, metal, middle, milk, mind, mine, minute, mist, money, month, morning, mother, motion, mountain, move, music, name, nation, need, news, night, noise, note, number, observation, offer, oil, operation, opinion, order, organization, ornament, owner

\section{$\mathrm{P}-\mathrm{Z}$}

page, pain, paint, paper, part, paste, payment, peace, person, place, plant, play, pleasure, point, poison, polish, porter, position, powder, power, price, print, process, produce, profit, property, prose, protest, pull, punishment, purpose, push, quality, question, rain, range, rate, ray, reaction, reading, reason, record, regret, relation, religion, representative, request, respect, rest, reward, rhythm, rice, river, road, roll, room, rub, rule, run, salt, sand, scale, science, sea, seat, secretary, selection, self, sense, servant, sex, shade, shake, shame, shock, side, sign, silk, silver, sister, size, sky, sleep, slip, slope, smash, smell, smile, smoke, sneeze, snow, soap, society, son, song, sort, sound, soup, space, stage, start, statement, steam, steel, step, stitch, stone, stop, story, stretch, structure, substance, sugar, suggestion, summer, support, surprise, swim, system, talk, taste, tax, teaching, tendency, test, theory, thing, thought, thunder, time, tin, top, touch, trade, transport, trick, trouble, turn, twist, unit, use, value, verse, vessel, view, voice, walk, war, wash, waste, water, wave, wax, way, weather, week, weight, wind, wine, winter, woman, wood, wool, word, work, wound, writing, year.

\section{Coisas - 200 palavras concretas}

angle, ant, apple, arch, arm, baby, bag, ball, band, basin, basket, bath, bed, bee, bell, berry, bird, blade, board, boat, bone, book, boot, bottle, box, boy, brain, brake, branch, brick, bridge, brush, bucket, bulb, button, cake, camera, card, cart, carriage, cat, chain, cheese, chest, chin, church, circle, clock, cloud, coat, collar, comb, cord, cow, cup, curtain, cushion, dog, door, drain, drawer, dress, drop, ear, egg, engine, eye, face, farm, feather, finger, fish, flag, floor, fly, foot, fork, fowl, frame, garden, girl, glove, goat, gun, hair, hammer, hand, hat, head, heart, hook, horn, horse, hospital, house, island, jewel, kettle, key, knee, knife, knot, leaf, leg, library, line, lip, lock, map, match, monkey, moon, mouth, muscle, nail, neck, needle, nerve, net, nose, nut, office, orange, oven, parcel, pen, pencil, picture, pig, pin, pipe, plane, plate, plough, pocket, pot, potato, prison, pump, rail, rat, receipt, ring, rod, roof, root, sail, school, scissors, screw, seed, sheep, shelf, ship, shirt, shoe, skin, skirt, snake, sock, spade, sponge, spoon, spring, square, stamp, star, station, stem, stick, stocking, stomach, store, street, sun, 
table, tail, thread, throat, thumb, ticket, toe, tongue, tooth, town, train, tray, tree, trousers, umbrella, wall, watch, wheel, whip, whistle, window, wing, wire, worm.

\section{Qualidades - 100 palavras descritivas}

able, acid, angry, automatic, beautiful, black, boiling, bright, broken, brown, cheap, chemical, chief, clean, clear, common, complex, conscious, cut, deep, dependent, early, elastic, electric, equal, fat, fertile, first, fixed, flat, free, frequent, full, general, good, great, grey, hanging, happy, hard, healthy, high, hollow, important, kind, like, living, long, male, married, material, medical, military, natural, necessary, new, normal, open, parallel, past, physical, political, poor, possible, present, private, probable, quick, quiet, ready, red, regular, responsible, right, round, same, second, separate, serious, sharp, smooth, sticky, stiff, straight, strong, sudden, sweet, tall, thick, tight, tired, true, violent, waiting, warm, wet, wide, wise, yellow, young.

\section{Qualidades - 50 opostos}

awake, bad, bent, bitter, blue, certain, cold, complete, cruel, dark, dead, dear, delicate, different, dirty, dry, false, feeble, female, foolish, future, green, ill, last, late, left, loose, loud, low, mixed, narrow, old, opposite, public, rough, sad, safe, secret, short, shut, simple, slow, small, soft, solid, special, strange, thin, white, wrong. 


\section{Anexo B}

STOPLIST usada no sistema NorMan Extractor

\begin{tabular}{|c|c|c|c|c|}
\hline $\mathrm{A}$ & lá & exemplo & Pela & Caracterizados \\
\hline B & dois & exemplos & Pelas & Caracterizada \\
\hline $\mathrm{C}$ & duas & ter & Que & Caracterizadas \\
\hline $\mathrm{D}$ & segundo & tendo & Quem & Classe \\
\hline $\mathrm{E}$ & segundos & tido & Qual & Classes \\
\hline $\mathrm{F}$ & segunda & tenho & Quais & Compreendend \\
\hline $\mathrm{G}$ & segundas & tens & Anteriormente & \\
\hline $\mathrm{H}$ & três & tem & Entre & Compreendido \\
\hline I & quatro & temos & Entretanto & Compreendida \\
\hline $\mathrm{J}$ & cinco & tendes & Mas & Compreendidos \\
\hline $\mathrm{K}$ & seis & têm & Mais & Compreendidas \\
\hline $\mathrm{L}$ & sete & tinha & Exceto & Conhecido \\
\hline M & oito & tinhas & Outro & Conhecida \\
\hline $\mathrm{N}$ & nove & tinha & Outros & Conhecidos \\
\hline $\mathrm{O}$ & dez & tínhamos & Outra & Conhecidas \\
\hline $\mathrm{P}$ & era & tínheis & Outras & Consiste \\
\hline Q & eram & tinham & Onde & Contém \\
\hline $\mathrm{R}$ & for & tive & Aonde & Contêm \\
\hline $\mathrm{S}$ & quando & tiveste & Logo & Em \\
\hline $\mathrm{T}$ & quanto & teve & Resumo & Outras \\
\hline $\mathrm{U}$ & quantos & tivemos & Introdução & Palavras \\
\hline V & quanta & tivestes & Palavra-Chave & Implica \\
\hline $\mathrm{W}$ & quantas & tiveram & Palavras-Chave & Implicam \\
\hline$X$ & cujo & tivera & Palavras-Chaves & Isto \\
\hline $\mathrm{Y}$ & cujos & tiveras & Conclusão & $\mathrm{Ou}$ \\
\hline $\mathrm{Z}$ & cuja & tivera & Respectivamente & Seja \\
\hline $\mathrm{a}$ & cujas & tivéramos & Tal & Por \\
\hline b & enquanto & tivéreis & Tais & Exemplo \\
\hline $\mathrm{c}$ & ano & tiveram & Tanto & Tal \\
\hline d & ambos & teria & Tantos & Utilizado \\
\hline $\mathrm{e}$ & ambas & terias & Tanta & Utilizada \\
\hline $\mathrm{f}$ & cada & teria & Tantas & Utilizados \\
\hline g & totalmente & teríamos & Etc & Utilizadas \\
\hline $\mathrm{h}$ & além & teríeis & Etc. & Característica \\
\hline $\mathrm{i}$ & aceitável & teriam & Conforme & Características \\
\hline $\mathrm{j}$ & aceitáveis & terei & Geralmente & Composto \\
\hline $\mathrm{k}$ & aconselhável & terás & Inicialmente & Compostos \\
\hline 1 & atacável & terá & Adiante & Estado \\
\hline $\mathrm{m}$ & adequadamente & teremos & Diante & Matéria-Prima \\
\hline $\mathrm{n}$ & adicionalmente & tereis & Bem & Matérias-Prima \\
\hline o & aleatoriamente & terão & Bom & Método \\
\hline $\mathrm{p}$ & altamente & tem & Boa & Métodos \\
\hline $\mathrm{q}$ & amplamente & tenha & Bons & Parte \\
\hline$r$ & aparentemente & tenhamos & Bens & Partes \\
\hline $\mathrm{s}$ & apreciavelmente & tende & Boas & Processo \\
\hline $\mathrm{t}$ & aproximadamente & ser & Bastante & Processos \\
\hline
\end{tabular}




\begin{tabular}{|c|c|c|c|c|}
\hline $\mathrm{u}$ & atualmente & sendo & Bastantes & Propriedade \\
\hline $\mathrm{v}$ & basicamente & sido & Portanto & Propriedades \\
\hline $\mathrm{W}$ & brevemente & sou & Consequentemente & Tipo \\
\hline $\mathrm{x}$ & bruscamente & és & Conseqüentemente & Tipos \\
\hline $\mathrm{y}$ & certamente & é & Através & Adição \\
\hline $\mathrm{Z}$ & claramente & somos & Finalmente & Chamamos \\
\hline I & comparativamente & sois & Pois & Constitui \\
\hline i & completamente & são & Juntamente & Constituem \\
\hline 1 & comumente & era & Já & Constituído \\
\hline II & concomitantement & eras & Mesmo & Constiídos \\
\hline ii & e & era & Mesmos & Depende \\
\hline 2 & conjuntamente & éramos & Mesma & Dependem \\
\hline III & consideravelmente & éreis & Mesmas & Desenvolvido \\
\hline iii & continuamente & eram & Primeiramente & Desenvolvida \\
\hline 3 & convenientemente & fui & Preferencialmente & Desenvolvidos \\
\hline IV & corretamente & foste & Sua & Desenvolvidas \\
\hline iv & cuidadosamente & foi & Suas & Determinado \\
\hline 4 & definitivamente & fomos & Seu & Determinada \\
\hline V & demasiadamente & fostes & Seus & Determinados \\
\hline $\mathrm{V}$ & detalhadamente & foram & Tua & Determinadas \\
\hline 5 & devidamente & fora & Tuas & Empregado \\
\hline VI & diariamente & foras & Teu & Empregada \\
\hline vi & diferentemente & fora & Teus & Empregados \\
\hline 6 & dificilmente & fôramos & Simplesmente & Empregadas \\
\hline VII & diretamente & fôreis & Dela & Expresso \\
\hline vii & drasticamente & foram & Delas & Expressos \\
\hline 7 & economicamente & seria & Dele & Formado \\
\hline VIII & efetivamente & serias & Deles & Formada \\
\hline viii & especialmente & seria & Dentro & Formados \\
\hline 8 & especificamente & seríamos & Dentre & Formadas \\
\hline IX & esquematicamente & seríeis & Apenas & Obtido \\
\hline ix & essencialmente & seriam & Apesar & Obtidos \\
\hline 9 & esteticamente & serei & Muito & Palavra \\
\hline $\mathrm{X}$ & eventualmente & serás & Muitos & Palavras \\
\hline $\mathrm{x}$ & evidentemente & será & Muita & Relacionado \\
\hline 10 & exatamente & seremos & Muitas & Relacionada \\
\hline et & excessivamente & sereis & Não & Relacionados \\
\hline al & exclusivamente & serão & Sim & Relacionadas \\
\hline $\mathrm{Et}$ & experimentalmente & haver & Necessariamente & Chamado \\
\hline $\mathrm{Al}$ & extremamente & havendo & $\mathrm{Se}$ & Chamada \\
\hline $\mathrm{mg}$ & facilmente & havido & $\mathrm{Si}$ & Chamados \\
\hline $\mathrm{Mg}$ & finamente & hei & Agora & Chamadas \\
\hline $\mathrm{kg}$ & fortemente & hás & Até & Definido \\
\hline $\mathrm{Kg}$ & frequentemente & há & Após & Definida \\
\hline $\mathrm{dl}$ & frequentemente & havemos & Ainda & Definidos \\
\hline Dl & fundamentalmente & haveis & Assim & Definidas \\
\hline ng & geograficamente & hão & Somente & Como \\
\hline $\mathrm{Ng}$ & globalmente & havia & $\mathrm{Ou}$ & Expressão \\
\hline $\mathrm{ml}$ & gradualmente & havias & Nosso & Expressões \\
\hline Ml & gradativamente & havia & Nossos & $\mathrm{Se}$ \\
\hline
\end{tabular}




\begin{tabular}{|c|c|c|c|c|}
\hline $\mathrm{cm}$ & graficamente & havíamos & Nossa & Entende \\
\hline $\mathrm{Cm}$ & habitualmente & havíeis & Nossas & Significa \\
\hline $\mathrm{m}$ & historicamente & haviam & Fora & Significam \\
\hline 1 & igualmente & houve & Cima & Termo \\
\hline $\mathrm{pg}$ & imediatamente & houveste & Embaixo & Termos \\
\hline nmol & indiretamente & houve & Abaixo & ( \\
\hline mol & individualmente & houvemos & Baixo & ) \\
\hline kcal & inevitavelmente & houvestes & Exemplo & - \\
\hline $\mathrm{mmHg}$ & infelizmente & houveram & Exemplos & \\
\hline $\mathrm{g}$ & inteiramente & houvera & Apropriadamente & Conceito \\
\hline http & intimamente & houveras & Pessoalmente & Conceitos \\
\hline HTTP & isoladamente & houvera & Pessoa & Corresponde \\
\hline WWW & justamente & houvéramo & Pessoas & Correspondem \\
\hline WWW & largamente & & Pouco & Define \\
\hline $\mathrm{e}$ & lentamente & houvéreis & Poucos & Definem \\
\hline é & levemente & houveram & Pouca & Denominado \\
\hline à & ligeiramente & haveria & Poucas & Denominada \\
\hline às & linearmente & haverias & Próximo & Denominados \\
\hline $\mathrm{a}$ & localmente & haveria & Próximos & Denominadas \\
\hline ao & logicamente & haveríamos & Próximas & Feito \\
\hline $\mathrm{o}$ & majoritariamente & haveríeis & Próxima & Feitos \\
\hline aos & manualmente & haveriam & Então & Usado \\
\hline os & matematicamente & haverei & Algo & Usados \\
\hline as & meramente & haverás & Algum & Figura \\
\hline na & mundialmente & haverá & Alguns & Figuras \\
\hline nas & naturalmente & haveremos & Alguma & Tabela \\
\hline no & negativamente & havereis & Algumas & Tabelas \\
\hline nos & nomeadamente & haverão & Alguém & Quadro \\
\hline nessa & normalmente & estar & Lhe & Quadros \\
\hline nessas & notavelmente & estando & Lhes & Fig \\
\hline nesse & novamente & estado & $\mathrm{La}$ & Figs \\
\hline nesses & obviamente & estou & Las & Metodologia \\
\hline nisso & paralelamente & estás & Lo & Metodologias \\
\hline nesta & parcialmente & está & Los & Resultados \\
\hline nestas & particularmente & estamos & Lá & Resultado \\
\hline neste & paulatinamente & estais & Dois & Discussão \\
\hline nestes & perfeitamente & estão & Duas & Exemplo \\
\hline nisto & periodicamente & estava & Segundo & Exemplos \\
\hline dessa & plenamente & estavas & Segundos & Ter \\
\hline dessas & possivelmente & estava & Segunda & Tendo \\
\hline desse & posteriormente & estávamos & Segundas & Tido \\
\hline desses & praticamente & estáveis & Três & Tenho \\
\hline disso & precisamente & estavam & Quatro & Tens \\
\hline disto & predominantement & estive & Cinco & Tem \\
\hline desta & & estiveste & Seis & Temos \\
\hline destas & previamente & esteve & Sete & Tendes \\
\hline deste & principalmente & estivemos & Oito & Têm \\
\hline destes & prioritariamente & estivestes & Nove & Tinha \\
\hline da & profundamente & estiveram & Dez & Tinhas \\
\hline das & progressivamente & estivera & Era & Tinha \\
\hline
\end{tabular}




\begin{tabular}{|c|c|c|c|c|}
\hline do & proporcionalmente & estiveras & Eram & Tínhamos \\
\hline dos & propriamente & estivera & For & Tínheis \\
\hline de & provavelmente & estivéramos & Quando & Tinham \\
\hline essa & qualitativamente & estivéreis & Quanto & Tive \\
\hline essas & quantitativamente & estiveram & Quantos & Tiveste \\
\hline esse & quimicamente & estaria & Quanta & Teve \\
\hline esses & rapidamente & estarias & Quantas & Tivemos \\
\hline esta & raramente & estaria & Cujo & Tivestes \\
\hline estas & realmente & estaríamos & Cujos & Tiveram \\
\hline este & recentemente & estaríeis & Cuja & Tivera \\
\hline estes & regularmente & estariam & Cujas & Tiveras \\
\hline isso & relativamente & estarei & Enquanto & Tivera \\
\hline isto & resumidamente & estarás & Ano & Tivéramos \\
\hline nele & rigorosamente & estará & Anos & Tivéreis \\
\hline neles & sensivelmente & estaremos & Ambos & Tiveram \\
\hline nela & separadamente & estareis & Ambas & Teria \\
\hline nelas & significativamente & estarão & Cada & Terias \\
\hline naquele & simultaneamente & existir & Totalmente & Teria \\
\hline naqueles & sistematicamente & existindo & Além & Teríamos \\
\hline naquela & substancialmente & existido & Aceitável & Teríeis \\
\hline naquelas & sucessivamente & existo & Aceitáveis & Teriam \\
\hline naquilo & suficientemente & existes & Aconselhável & Terei \\
\hline daquele & tecnologicamente & existe & Atacável & Terás \\
\hline daqueles & teoricamente & existimos & Adequadamente & Terá \\
\hline daquela & termicamente & existis & Adicionalmente & Teremos \\
\hline daquelas & tipicamente & existem & Aleatoriamente & Tereis \\
\hline daquilo & tradicionalmente & existia & Altamente & Terão \\
\hline aquele & unicamente & existias & Amplamente & Tem \\
\hline aqueles & uniformemente & existia & Aparentemente & Tenha \\
\hline aquela & usualmente & existíamos & Apreciavelmente & Tenhamos \\
\hline aquelas & visualmente & existíeis & Aproximadamente & Tende \\
\hline aquilo & agradecimentos & existiam & Atualmente & Ser \\
\hline um & bibliografia & existi & Basicamente & Sendo \\
\hline uma & bibliografias & exististe & Brevemente & Sido \\
\hline uns & conclusão & existiu & Bruscamente & Sou \\
\hline umas & conclusões & existimos & Certamente & És \\
\hline nós & considerações & exististes & Claramente & É \\
\hline eu & finais & existiram & Comparativamente & Somos \\
\hline tu & afim & existira & Completamente & Sois \\
\hline ela & aí & existiras & Comumente & São \\
\hline ele & ali & existira & Concomitantement & Era \\
\hline elas & aliás & existíramos & $\mathrm{e}$ & Eras \\
\hline eles & aqui & existíreis & Conjuntamente & Era \\
\hline você & contudo & existiram & Consideravelmente & Éramos \\
\hline vocês & convém & existiria & Continuamente & Éreis \\
\hline sob & desde & existirias & Convenientemente & Eram \\
\hline sobre & hoje & existiria & Corretamente & Fui \\
\hline sobretudo & nem & existiríamo & Cuidadosamente & Foste \\
\hline depois & num & $\mathrm{s}$ & Definitivamente & Foi \\
\hline durante & numa & existiríeis & Demasiadamente & Fomos \\
\hline
\end{tabular}




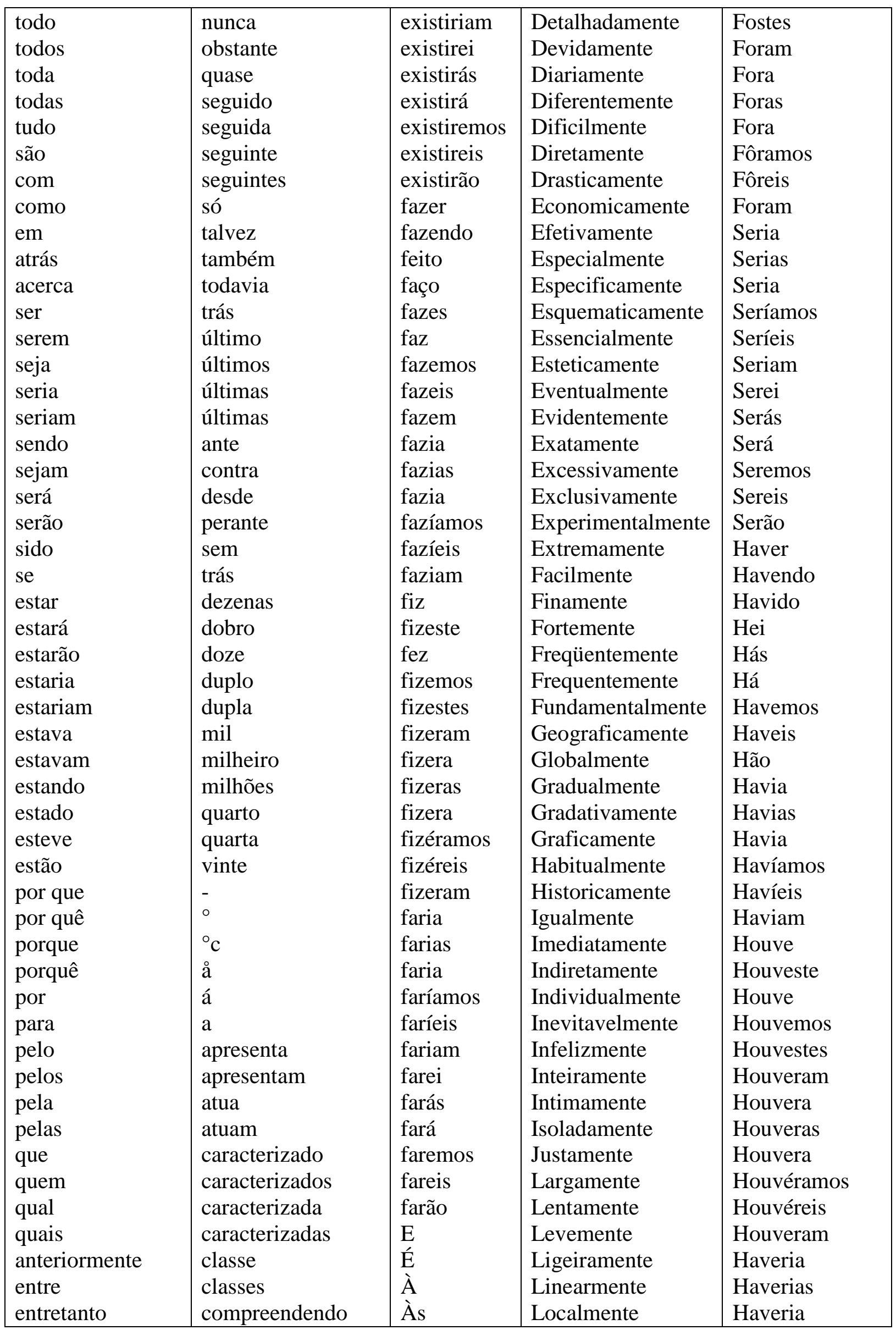




\begin{tabular}{|c|c|c|c|c|}
\hline mas & compreendido & $\mathrm{A}$ & Logicamente & Haveríamos \\
\hline mais & compreendida & Ao & Majoritariamente & Haveríeis \\
\hline exceto & compreendidos & $\mathrm{O}$ & Manualmente & Haveriam \\
\hline outro & compreendidas & Aos & Matematicamente & Haverei \\
\hline outros & conhecido & Os & Meramente & Haverás \\
\hline outra & conhecida & As & Mundialmente & Haverá \\
\hline outras & conhecidos & $\mathrm{Na}$ & Naturalmente & Haveremos \\
\hline onde & conhecidas & Nas & Negativamente & Havereis \\
\hline aonde & consiste & No & Nomeadamente & Haverão \\
\hline $\log 0$ & contém & Nos & Normalmente & Estar \\
\hline resumo & contêm & Nessa & Notavelmente & Estando \\
\hline introdução & em & Nessas & Novamente & Estado \\
\hline palavra-chave & outras & Nesse & Obviamente & Estou \\
\hline palavras-chave & palavras & Nesses & Paralelamente & Estás \\
\hline palavras-chaves & implica & Nisso & Parcialmente & Está \\
\hline conclusão & implicam & Nesta & Particularmente & Estamos \\
\hline respectivamente & isto & Nestas & Paulatinamente & Estais \\
\hline tal & ou & Neste & Perfeitamente & Estão \\
\hline tais & seja & Nestes & Periodicamente & Estava \\
\hline tanto & por & Nisto & Plenamente & Estavas \\
\hline tantos & exemplo & Dessa & Possivelmente & Estava \\
\hline tanta & & Dessas & Posteriormente & Estávamos \\
\hline tantas & utilizado & Desse & Praticamente & Estáveis \\
\hline etc & utilizada & Desses & Precisamente & Estavam \\
\hline etc. & utilizados & Disso & Predominantement & Estive \\
\hline conforme & utilizadas & Disto & & Estiveste \\
\hline geralmente & característica & Desta & Previamente & Esteve \\
\hline inicialmente & características & Destas & Principalmente & Estivemos \\
\hline adiante & composto & Deste & Prioritariamente & Estivestes \\
\hline diante & compostos & Destes & Profundamente & Estiveram \\
\hline bem & estado & $\mathrm{Da}$ & Progressivamente & Estivera \\
\hline bom & matéria-prima & Das & Proporcionalmente & Estiveras \\
\hline boa & matérias-prima & Do & Propriamente & Estivera \\
\hline bons & método & Dos & Provavelmente & Estivéramos \\
\hline bens & métodos & De & Qualitativamente & Estivéreis \\
\hline boas & parte & Essa & Quantitativamente & Estiveram \\
\hline bastante & partes & Essas & Quimicamente & Estaria \\
\hline bastantes & processo & Esse & Rapidamente & Estarias \\
\hline portanto & processos & Esses & Raramente & Estaria \\
\hline consequentement & propriedade & Esta & Realmente & Estaríamos \\
\hline e & propriedades & Estas & Recentemente & Estaríeis \\
\hline conseqüentement & tipo & Este & Regularmente & Estariam \\
\hline $\mathrm{e}$ & tipos & Estes & Relativamente & Estarei \\
\hline através & adição & Isso & Resumidamente & Estarás \\
\hline finalmente & chamamos & Isto & Rigorosamente & Estará \\
\hline pois & constitui & Nele & Sensivelmente & Estaremos \\
\hline juntamente & constituem & Neles & Separadamente & Estareis \\
\hline & constituído & Nela & Significativamente & Estarão \\
\hline mesmo & constiídos & Nelas & Simultaneamente & Existir \\
\hline mesmos & depende & Naquele & Sistematicamente & Existindo \\
\hline
\end{tabular}




\begin{tabular}{|c|c|c|c|c|}
\hline mesma & dependem & Naqueles & Substancialmente & Existido \\
\hline mesmas & desenvolvido & Naquela & Sucessivamente & Existo \\
\hline primeiramente & desenvolvida & Naquelas & Suficientemente & Existes \\
\hline preferencialmente & desenvolvidos & Naquilo & Tecnologicamente & Existe \\
\hline sua & desenvolvidas & Daquele & Teoricamente & Existimos \\
\hline suas & determinado & Daqueles & Termicamente & Existis \\
\hline seu & determinada & Daquela & Tipicamente & Existem \\
\hline seus & determinados & Daquelas & Tradicionalmente & Existia \\
\hline tua & determinadas & Daquilo & Unicamente & Existias \\
\hline tuas & empregado & Aquele & Uniformemente & Existia \\
\hline teu & empregada & Aqueles & Usualmente & Existíamos \\
\hline teus & empregados & Aquela & Visualmente & Existíeis \\
\hline simplesmente & empregadas & Aquelas & Agradecimentos & Existiam \\
\hline dela & expresso & Aquilo & Bibliografia & Existi \\
\hline delas & expressos & Um & Bibliografias & Exististe \\
\hline dele & formado & Uma & Conclusão & Existiu \\
\hline deles & formada & Uns & Conclusões & Existimos \\
\hline dentro & formados & Umas & Considerações & Exististes \\
\hline dentre & formadas & Nós & Finais & Existiram \\
\hline apenas & obtido & $\mathrm{Eu}$ & Afim & Existira \\
\hline apesar & obtidos & $\mathrm{Tu}$ & Aí & Existiras \\
\hline muito & palavra & Ela & Ali & Existira \\
\hline muitos & palavras & Ele & Aliás & Existíramos \\
\hline muita & relacionado & Elas & Aqui & Existíreis \\
\hline muitas & relacionada & Eles & Contudo & Existiram \\
\hline não & relacionados & Você & Convém & Existiria \\
\hline $\operatorname{sim}$ & relacionadas & Vocês & Desde & Existirias \\
\hline necessariamente & chamado & Sob & Hoje & Existiria \\
\hline se & chamada & Sobre & Nem & Existiríamos \\
\hline si & chamados & Sobretudo & Num & Existiríeis \\
\hline agora & chamadas & Depois & Numa & Existiriam \\
\hline até & definido & Durante & Nunca & Existirei \\
\hline após & definida & Todo & Obstante & Existirás \\
\hline ainda & definidos & Todos & Quase & Existirá \\
\hline assim & definidas & Toda & Seguido & Existiremos \\
\hline somente & como & Todas & Seguida & Existireis \\
\hline ou & expressão & Tudo & Seguinte & Existirão \\
\hline nosso & expressões & São & Seguintes & Fazer \\
\hline nossos & se & Com & Só & Fazendo \\
\hline nossa & entende & Como & Talvez & Feito \\
\hline nossas & significa & Em & Também & Faço \\
\hline fora & significam & Atrás & Todavia & Fazes \\
\hline cima & termo & Acerca & Trás & Faz \\
\hline embaixo & termos & Ser & Último & Fazemos \\
\hline abaixo & ( & Serem & Últimos & Fazeis \\
\hline baixo & ) & Seja & Últimas & Fazem \\
\hline exemplo & - & Seria & Últimas & Fazia \\
\hline exemplos & : & Seriam & Ante & Fazias \\
\hline apropriadamente & conceito & Sendo & Contra & Fazia \\
\hline pessoalmente & conceitos & Sejam & Desde & Fazíamos \\
\hline
\end{tabular}




\begin{tabular}{|l|l|l|l|l|}
\hline pessoa & corresponde & Será & Perante & Fazíis \\
pessoas & correspondem & Serão & Sem & Faziam \\
pouco & define & Sido & Trás & Fiz \\
poucos & definem & Se & Dezenas & Fizeste \\
pouca & denominado & Estar & Dobro & Fez \\
poucas & denominada & Estará & Doze & Fizemos \\
próximo & denominados & Estarão & Duplo & Fizestes \\
próximos & denominadas & Estaria & Dupla & Fizeram \\
próximas & feito & Estariam & Mil & Fizera \\
próxima & feitos & Estava & Milheiro & Fizeras \\
então & usado & Estavam & Milhões & Fizera \\
algo & usados & Estando & Quarto & Fizéramos \\
algum & figura & Estado & Quarta & Fizéreis \\
alguns & figuras & Esteve & Vinte & Fizeram \\
alguma & tabela & Estão & - & Faria \\
algumas & tabelas & Por Que & o & Farias \\
alguém & quadro & Por Quê & oc & Faria \\
lhe & quadros & Porque & Á & Faríamos \\
lhes & fig & Porquê & Á & Faríeis \\
la & figs & Por & A & Fariam \\
las & metodologia & Para & Apresenta & Farei \\
lo & metodologias & Pelo & Apresentam & Farás \\
los & resultados & Pelos & Atua & Fará \\
& resultado & discussão & & Faremos \\
& & & Caracterizado & Fareis \\
& & & Farão \\
& & & \\
\hline
\end{tabular}




\section{Apêndice A}

\section{O portal do Projeto NorMan}

\section{NorMan}

Início o Córpus Recursos

Norman Extractor

Córpus Generator

Experimentos - Extração

Publicações Contato
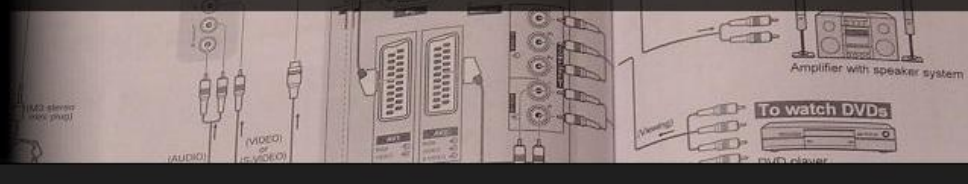

O Projeto Norman

\section{Resumo}

No Brasil, cerca de $68 \%$ da população são classificadas como leitores com baixos niveis de alfabetização, isto é, possuem o nivel de alfabetizaçăo rudimentar $(21 \%)$ ou basico $(47 \%$ ) segundo dados do INAF (2009). O projeto PorSimples utilizou as duas abordagens de Adaptação Textual, a Simplificação e a Elaboração, para ajudar leitores com baixo nivel de alfabetização a compreender documentos disponiveis na Web em portugues do Brasil, principaimente textos jornalisticos. Esta pesquisa de mestrado também se dedicou às duas abordagens acina, mas o foco foi o genero de textos instrucionais. Em tarefas que exigem o uso de docu mentação téchica, a qualidade da do generation - (quando uma aç̃o ? gera automaticamente umac̃o ?) a relacão habilita - Enablement - (quando a realizaçẫo de uma ação? permite a realização da açå ? mas o agente precisa fazer algo a mais para garantir que ? ira ocorrer). 0 projeto a estudou como as relações procedimentais entre ações chamadas de gera e habilita são realizadas em manuais de instruções, dando base para a criação de um metodo de extração de termos dedicado ao genero de textos instrucionais, especificamente aos manuais técnicos. Também proposs uma adaptação do sistema de autoria de textos simplificados criado no projeto porsimples - o SIMPLIFICA proposto, com duas funç̧ões: (a) para auxiliar na identificação de palavras que não devem ser simplificadas pelo método de simplificação léxica baseado em sinônimos, e (b) para gerar uma elaboração lexical para facilitar o entendimento do texto.

\section{Projeto Norman}




\section{Apêndice B}

Formulário utilizado na avaliação da simplificação léxica

Voluntário:

Escolaridade:

Função:

Idade:

Início:

Fim:

Você conhece estas palavras?

videocassete: $\operatorname{Sim}($ ) Não( ) - Útil( ) Inútil( )

S-VHS Sim( ) Não( ) - Útil( ) Inútil( )

s-video: $\operatorname{Sim}($ ) Não( ) - Útil( ) Inútil( )

cabo de video: $\operatorname{Sim}($ ) Não( ) - Útil( ) Inútil( )

simultaneamente: Sim( ) Não( ) - Útil( ) Inútil( )

Terminal: Sim( ) Não( ) - Útil( ) Inútil( )

Tomada: $\operatorname{Sim}($ ) Não( ) - Útil( ) Inútil( )

Além: $\operatorname{Sim}($ ) Não( ) - Útil( ) Inútil( )

mono: $\operatorname{Sim}($ ) Não( ) - Útil( ) Inútil( )

audio: $\operatorname{Sim}($ ) Não( ) - Útil( ) Inútil( )

cabo de audio: $\operatorname{Sim}($ ) Não( ) - Útil( ) Inútil( )

video componente: $\operatorname{Sim}($ ) Não( ) - Útil( ) Inútil( )

dvd player: $\operatorname{Sim}($ ) Não( ) - Útil( ) Inútil( )

480p: $\operatorname{Sim}($ ) Não( ) - Útil( ) Inútil( )

720p: $\operatorname{Sim}($ ) Não( ) - Útil( ) Inútil( )

interlaced: $\operatorname{Sim}($ ) Não( ) - Útil( ) Inútil( ) 


\section{Questionário}

1. O que é um videocassete?

$x$ a) É um aparelho eletrônico capaz de gravar e reproduzir imagens que são registradas em fitas magnéticas.

b) É um aparelho eletrônico capaz de reproduzir músicas.

c) É uma fita de vídeo.

\section{O que é S-VHS?}

a) É um aparelho que reproduz DVD.

b) É um aparelho de Blu Ray.

x c) É uma versão 'melhorada' do VHS (videocassete) convencional.

\section{O que é S-video?}

a) É um tipo de videocassete.

$x$ b) É um sinal de vídeo analógico que carrega dados de vídeo com dois sinais separados

c) É uma fita de vídeo.

\section{O que é um cabo de vídeo?}

$x$ a) É um cabo conector comumente utilizados em equipamentos eletrônicos.

b) É um cabo de ligação elétrica.

c) É um cabo de aterramento.

5. O que significa Simultaneamente?

a) Simultaneamente significa: antes.

x b) Simultaneamente significa: ao mesmo tempo.

c) Simultaneamente significa: depois. 


\section{O que significa Terminal?}

$x$ a) Terminal significa: Que termina ou que marca o fim.

b) Terminal significa: Que se inicia.

c) Terminal significa: Interruptor elétrico.

7. O que é uma Tomada?

a) Tomada significa: Um tipo de cabo.

b) Tomada significa: Interruptor elétrico.

x c) Tomada significa: Conector elétrico.

8. O que significa Além?

a) Além significa: Para menos.

$x$ b) Além significa: Para mais.

c) Além significa: Ninguém.

9. O que significa Mono:

$x$ a) Mono é o som que é transmitido por meio de um único canal.

b) Mono é o som que é transmitido por meio de vários canais.

c) Mono é a função que tira o volume da televisão.

10. O que é Áudio?

a) É um tipo de rádio.

b) Áudio é a função que coloca o volume máximo da televisão.

x c) Áudio é o nome técnico da palavra "som ".

\section{O que é um cabo de áudio?}

$x$ a) É um cabo conector comumente utilizado em equipamentos eletrônicos.

b) É um cabo de ligação elétrica.

c) É um cabo de aterramento. 


\section{O que é um Vídeo componente?}

a) É um sinal de áudio de vários canais.

$x$ b) É um sinal de vídeo dividido em dois ou mais componentes.

c) É um sinal de áudio e vídeo juntos.

\section{O que é um DVD player?}

$x$ a) É um dispositivo para reproduzir discos produzidos sob o padrão DVD Vídeo.

b) É um aparelho que reproduz fitas cassete.

c) É um aparelho que reproduz discos produzidos sob o padrão Blu Ray.

\section{O que é 480p?}

a) 480p é o número que identifica um tipo de fita cassete.

x b) 480p é um formato de vídeo que contém 480 linhas de resolução.

c) 480p é o tempo de duração do vídeo.

\section{O que é $720 p$ ?}

x a) 720p é um formato de vídeo HDTV que contém 720 linhas de resolução.

b) 720p é o número que identifica um tipo de fita cassete.

c) 720p é o tempo de duração do vídeo.

16. O que é interlaced?

a) É um tipo de cabo entrelaçado.

b) É um formato de som.

x c) Interlaced é quando a imagem é intercalada com uma linha preta para aparentar ter uma resolução maior. 


\section{Apêndice C}

Etapas para utilização da ferramenta NorMan Extractor
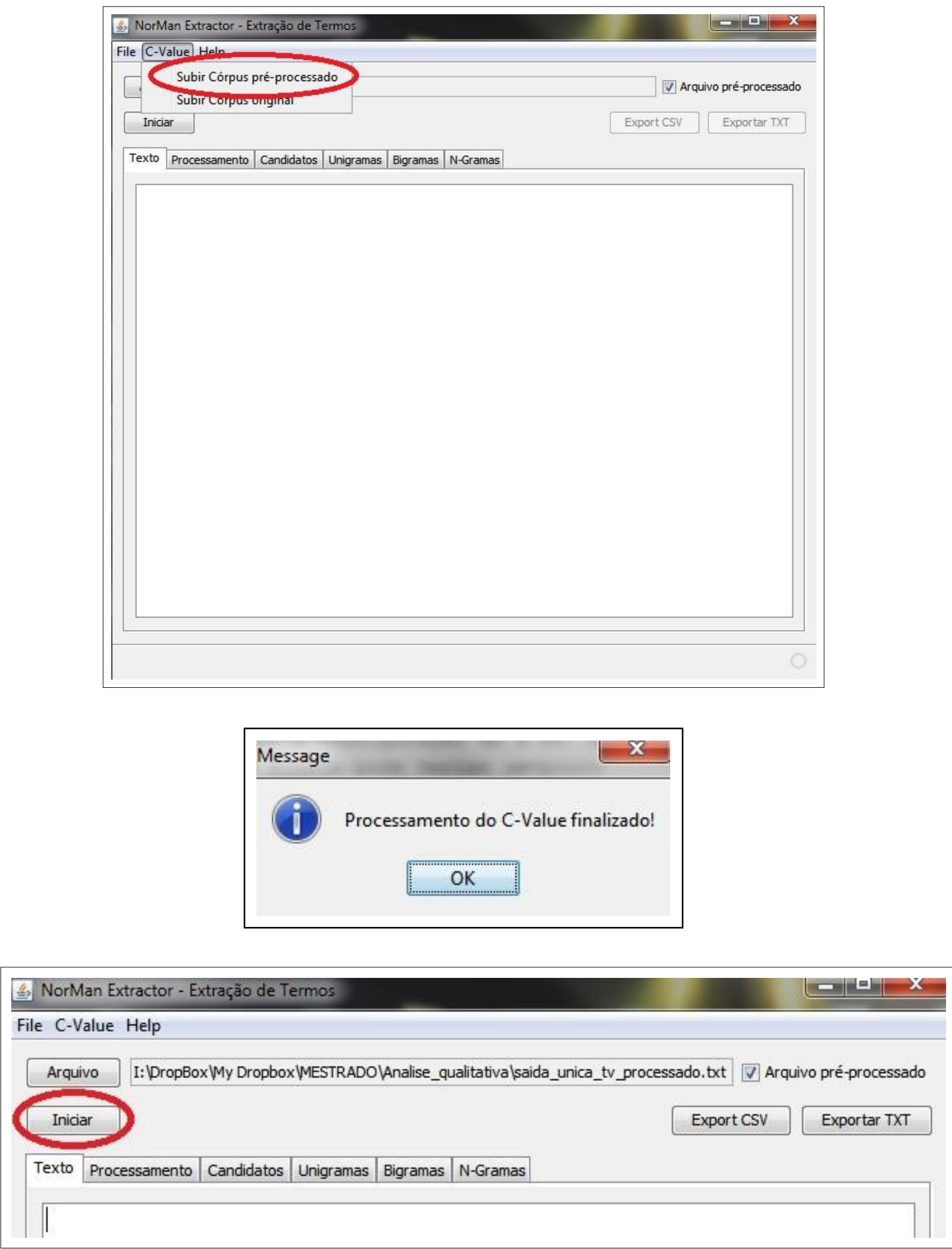


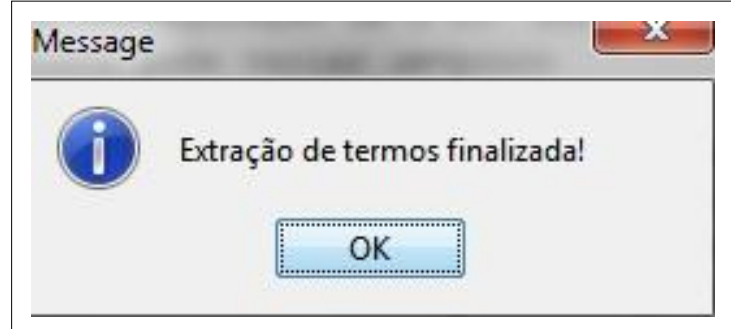

\begin{tabular}{|c|c|c|c|c|c|}
\hline \multicolumn{5}{|c|}{ @) NorMan Extractor - Extração de Termos } & 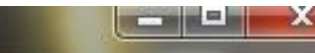 \\
\hline \multicolumn{6}{|c|}{ File C-Value Help } \\
\hline Arquivo & \multicolumn{4}{|c|}{ I:DropBox My Dropbox MESTRADOWAnalise_qualitativalsaida_unica_tv_processado.txt } & $\nabla$ Arquivo pré-processado \\
\hline Iniciar & & & & Export & Exportar TXT \\
\hline Texto & Processamento & Candidatos & Unigramas Bigramas & N-Gramas & \\
\hline \multicolumn{2}{|c|}{ Candidato } & & & C-Value & \\
\hline \multicolumn{2}{|c|}{ pressione } & & & 788.9962347034829 & 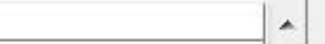 \\
\hline \multicolumn{2}{|l|}{ tv } & & & 640.9888609978036 & $\square$ \\
\hline \multicolumn{2}{|l|}{ teda } & & & 452.99372450580483 & \\
\hline \multicolumn{2}{|l|}{ menu } & & & 435.98823344838405 & \\
\hline \multicolumn{2}{|c|}{ selecionar } & & & 383.9993724505805 & \\
\hline \multicolumn{2}{|c|}{ imagem } & & & 372.9883903357389 & \\
\hline \multicolumn{2}{|l|}{ canal } & & & 357.99199874490114 & \\
\hline \multicolumn{2}{|l|}{ tela } & & & 353.992155632256 & \\
\hline \multicolumn{2}{|c|}{ entrada } & & & 330.9879196736743 & \\
\hline \multicolumn{2}{|c|}{ canais } & & & 291.9894885472231 & \\
\hline \multicolumn{2}{|c|}{ função } & & & 270.99372450580483 & \\
\hline \multicolumn{2}{|c|}{ selecione } & & & 264.9902729839975 & \\
\hline \multicolumn{2}{|c|}{ cabo } & & & 252.99215563225604 & \\
\hline \multicolumn{2}{|l|}{ pode } & & & 249.0 & \\
\hline \multicolumn{2}{|l|}{ modo } & & & 217.98650768748038 & \\
\hline \multicolumn{2}{|l|}{ áudio } & & & 215.9894885472231 & \\
\hline \multicolumn{2}{|c|}{ ajuste } & & & 205.98321305302792 & \\
\hline \multicolumn{2}{|c|}{ televisor } & & & 195.99796046438658 & \\
\hline \multicolumn{2}{|l|}{ vídeo } & & & 187.9915280828365 & \\
\hline \multicolumn{2}{|l|}{ som } & & & 176.99294006903042 & \\
\hline sinal & & & & 170.99262629432067 & \\
\hline tedas & & & & 158.9976466896768 & \\
\hline item & & & & 149.99827423909633 & \\
\hline $\mathrm{pc}$ & & & & 139.99733291496705 & - \\
\hline
\end{tabular}

